\title{
Creative Synergy in Interdisciplinary Design Collaboration: Using Speedstorming to Generate Ideas
}

\section{Tim Haats}

A thesis submitted to the Faculty of Graduate and Postdoctoral Affairs in partial fulfillment of the requirements for the degree of

\section{Master of Design}

in

Industrial Design

Carleton University Ottawa, Ontario

(C) 2012, Tim Haats 
Library and Archives

Canada

Published Heritage

Branch

395 Wellington Street

Ottawa ON K1A ON4

Canada
Bibliothèque et

Archives Canada

Direction du

Patrimoine de l'édition

395 , rue Wellington

Ottawa ON K1A ON4

Canada
Your file Votre référence

ISBN: 978-0-494-93500-2

Our file Notre référence

ISBN: $978-0-494-93500-2$
NOTICE:

The author has granted a nonexclusive license allowing Library and Archives Canada to reproduce, publish, archive, preserve, conserve, communicate to the public by telecommunication or on the Internet, loan, distrbute and sell theses worldwide, for commercial or noncommercial purposes, in microform, paper, electronic and/or any other formats.

The author retains copyright ownership and moral rights in this thesis. Neither the thesis nor substantial extracts from it may be printed or otherwise reproduced without the author's permission.
AVIS:

L'auteur a accordé une licence non exclusive permettant à la Bibliothèque et Archives Canada de reproduire, publier, archiver, sauvegarder, conserver, transmettre au public par télécommunication ou par l'Internet, prêter, distribuer et vendre des thèses partout dans le monde, à des fins commerciales ou autres, sur support microforme, papier, électronique et/ou autres formats.

L'auteur conserve la propriété du droit d'auteur et des droits moraux qui protege cette thèse. $\mathrm{Ni}$ la thèse ni des extraits substantiels de celle-ci ne doivent être imprimés ou autrement reproduits sans son autorisation.
In compliance with the Canadian Privacy Act some supporting forms may have been removed from this thesis.

While these forms may be included in the document page count, their removal does not represent any loss of content from the thesis.
Conformément à la loi canadienne sur la protection de la vie privée, quelques formulaires secondaires ont été enlevés de cette thèse.

Bien que ces formulaires aient inclus dans la pagination, il n'y aura aucun contenu manquant. 


\begin{abstract}
Creative synergy is referred to as a performance gain due to group interaction when collaborating on idea-generation tasks. Central to this is the notion that a diversity of perspectives can stimulate more cognitive processing, allowing for cross-fertilization of ideas. Various techniques have been developed specifically to achieve this synergy; but, there are several inhibiting mechanisms that prevent teams from taking full advantage of their synergistic potential. This study has shown that speedstorming - a new idea-generation technique for interdisciplinary collaboration - can facilitate creative synergy; but, it can also inhibit it. The importance of sharing ideas and the forced interactions that occur during speedstorming have been found as potentially supportive factors for the facilitation of creative synergy whereas the existence of evaluation apprehension and the effects of personality as well as the limited interactions derived from the speedstorming protocol have been found as potentially supportive factors for its inhibition. Furthermore, the dependency of the topic or problem and the dependency of time constraints have been found as both facilitative and inhibitive in ideational performance. This comes down to the pros and cons of the speedstorming structure, the suitability of speedstorming for certain topics, and the difficulties that arise in interdisciplinary design collaboration.
\end{abstract}

Keywords: Creative Synergy, Interdisciplinarity, Collaboration, Speedstorming, Idea-Generation 


\section{ACKNOWLEDGMENTS}

There are many people who have contributed, in some capacity, to the development of this thesis and have supported me throughout the process, and I could not thank them enough. Amongst these people are my friends and family, the faculty and staff at the School of Industrial Design, my fellow MDes colleagues, and the many researchers and practitioners that I have met at various conferences and events.

In particular, I would like to thank my parents for always being there and supporting me right from day one. I would like to thank my close friends who were ready and willing to take me away from the thesis when I needed a well-deserved break. I would like to thank my friend Michael Grigoriev for helping me with some of the data analysis that was an essential part of my research. And I would also like to sincerely thank Professor Lois Frankel for her contributions to the data analysis process and for volunteering her valuable time to provide a wealth of knowledge and experience in conducting the necessary evaluations.

Most importantly, I must give great thanks to my thesis advisor, Dr. WonJoon Chung, and co-advisor, Dr. Greg Sears, for their outstanding commitment and dedication to guiding me through the development of this thesis. I very much appreciate the long, productive hours spent in Dr. Chung's office discussing the many issues and considerations with my research, and the long, fruitful phone calls with Dr. Sears going over my data and discussing the procedures for going about the statistical analyses. I appreciate the amount of time that they both have devoted to attending my frequent emails, reading my lengthy drafts, and providing me with useful feedback every step of the way. Without their advisory, this thesis would not have succeeded. 


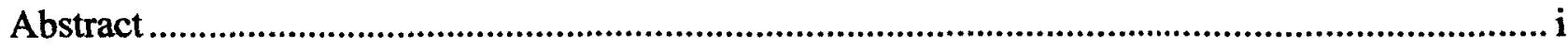

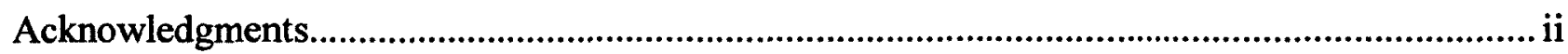

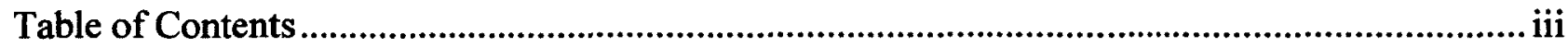

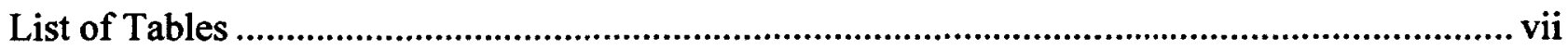

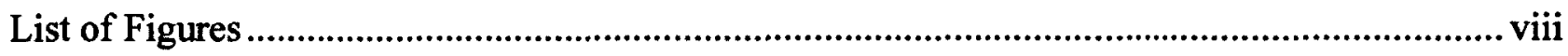

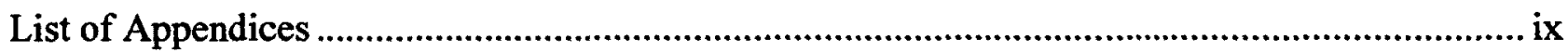

\section{CHAPTER}

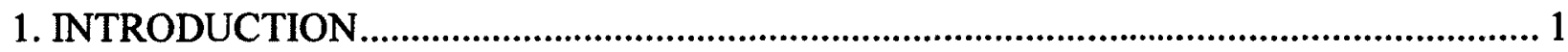

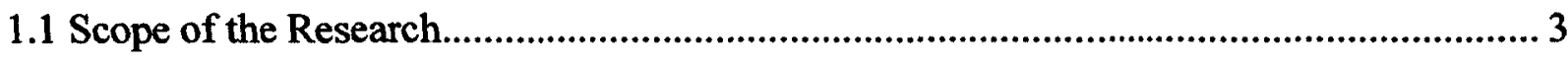

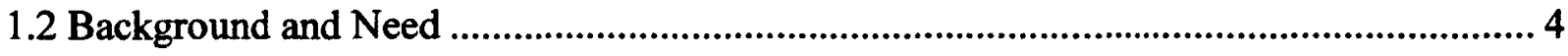

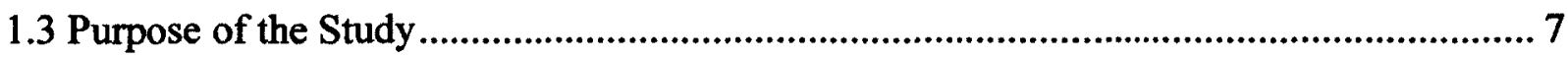

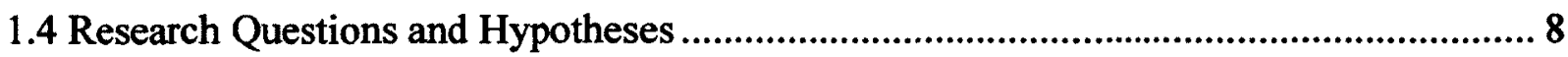

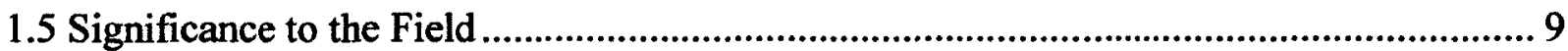

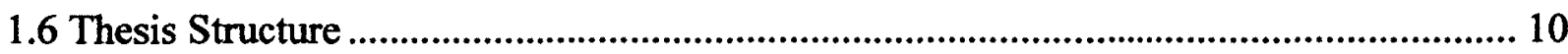

2. LITERATURE REVIEW

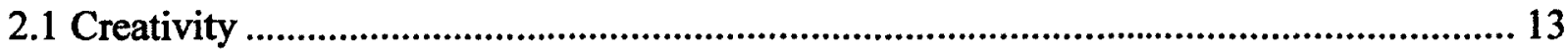

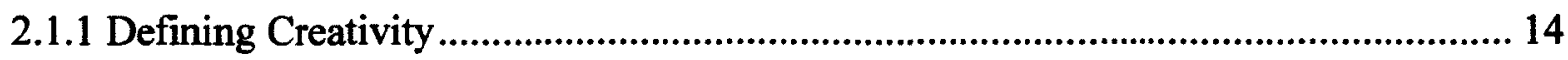

2.1.2 Idea-Generation and the Creative Idea ................................................................... 17

2.2 Synergy and Team Performance.................................................................................... 18

2.2.1 Defining Synergy....................................................................................................... 19

2.2.1.1 Weak Synergy and Strong Synergy .............................................................. 20 


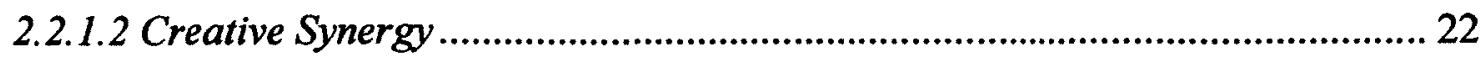

2.2.2 Creative Synergy and Idea-Generation .................................................................. 22

2.2.2.1 Production Blocking ....................................................................................... 29

2.2.2.2 Evaluation Apprehension ................................................................................ 30

2.2.2.3 Social Loafing and Free Riding ...................................................................... 32

2.2.2.4 Performance Matching ...................................................................................... 33

2.2.2.5 Electronic Brainstorming................................................................................ 34

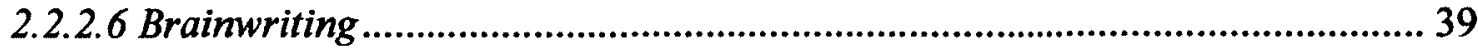

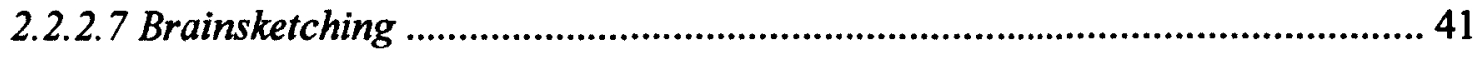

2.2.2.8 Speedstorming .................................................................................................... 43

2.2.2.8.1 Structure and Time Limits .................................................................... 44

2.2.2.8.2 One-on-One Interactions ...................................................................... 45

2.2.2.8.3 Empirical Research on Speedstorming ................................................. 47

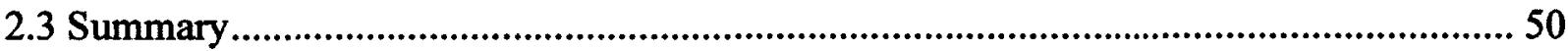

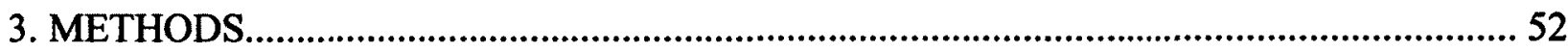

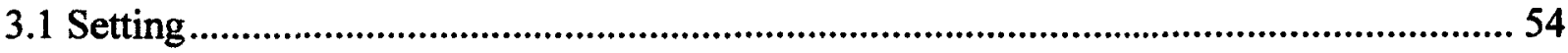

3.2 Sample

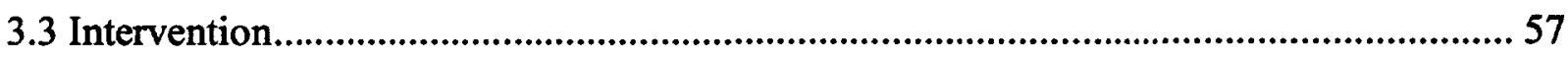

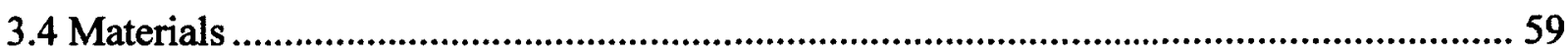

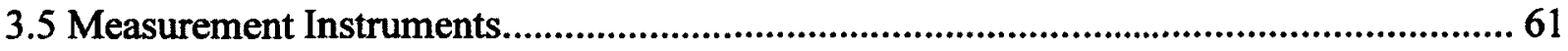

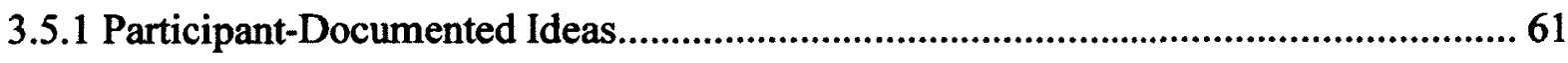

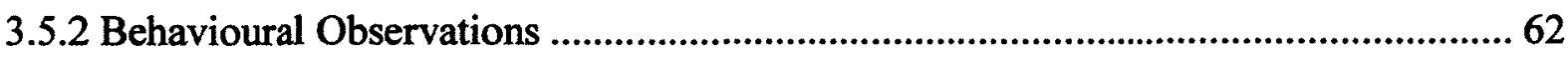

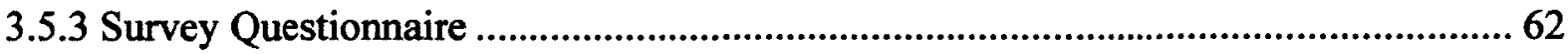

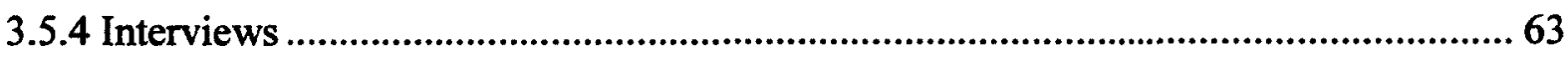

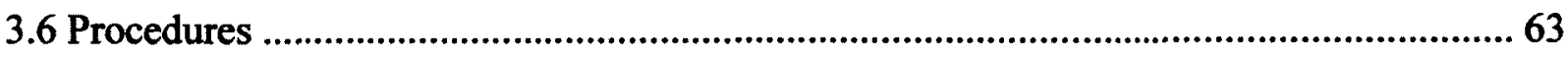

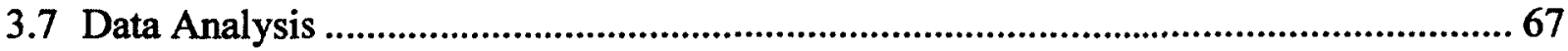

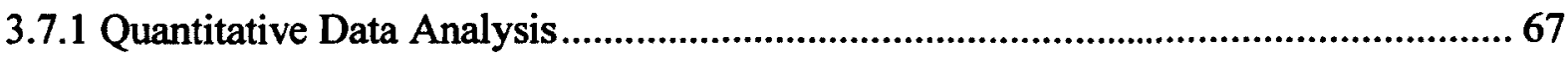

3.7.1.1 Hypothesis Tests..................................................................................................69

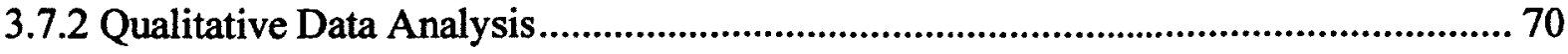


4.1 Quantitative Results........................................................................................ 72

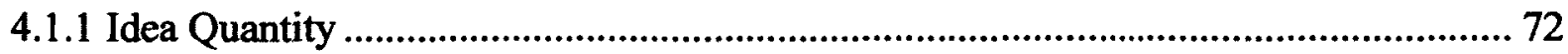

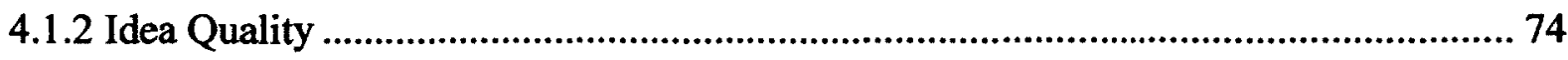

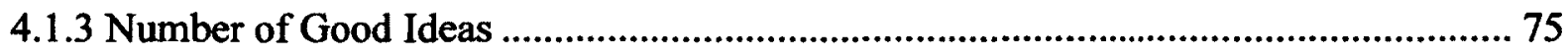

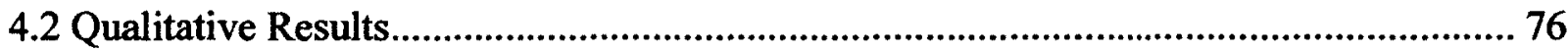

4.2.1 Speedstorming Facilitates Creative Synergy .................................................. 76

4.2.1.1 Importance of Idea-Sharing ............................................................... 77

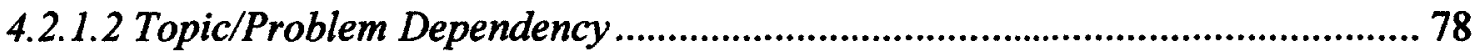

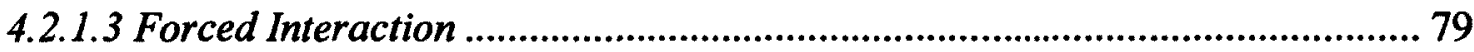

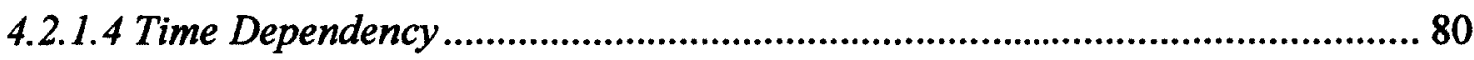

4.2.2 Speedstorming Inhibits Creative Synergy .......................................................... 80

4.2.2.1 Topic/Problem Dependency ................................................................. 81

4.2.2.2 Evaluation Apprehension and Personality Factors ................................... 82

4.2.2.3 Time Dependency ................................................................................. 84

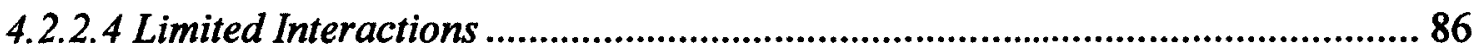

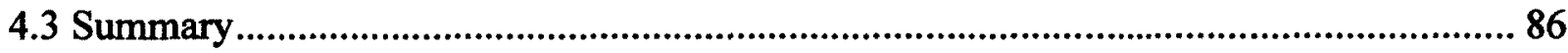

5. DISCUSSION

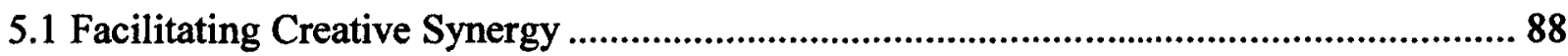

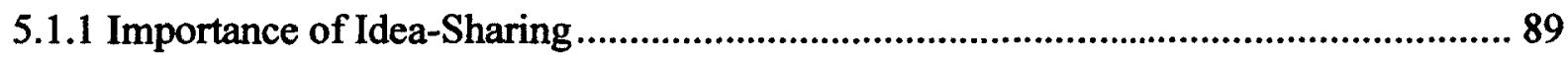

5.1.2 Topic/Problem Dependency .......................................................................... 90

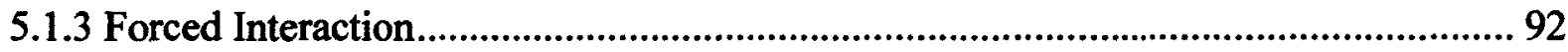

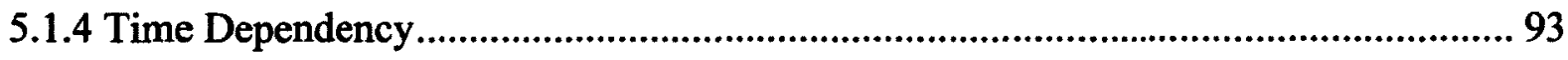

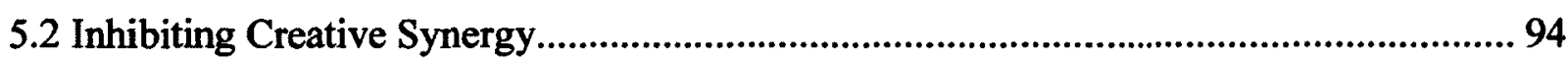

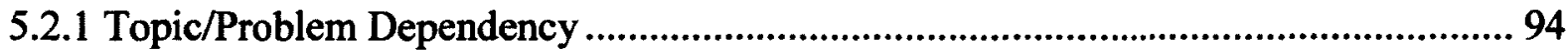

5.2.2 Evaluation Apprehension and Personality Factors ............................................96

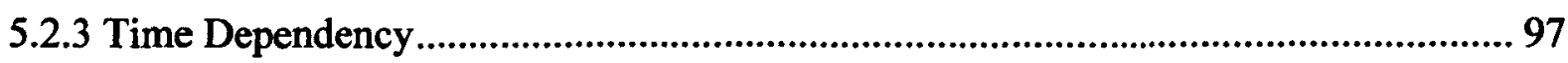

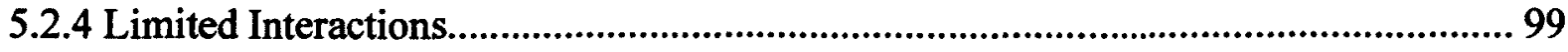




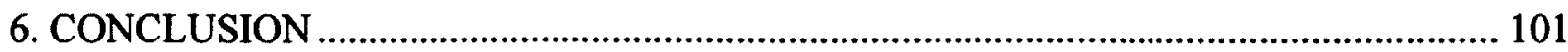

6.1 Contribution to the Field.................................................................................. 106

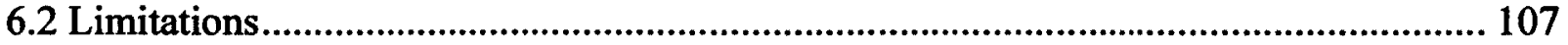

6.3 Recommendations for Future Research.................................................................. 110

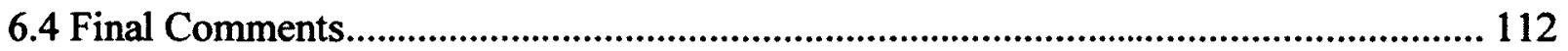

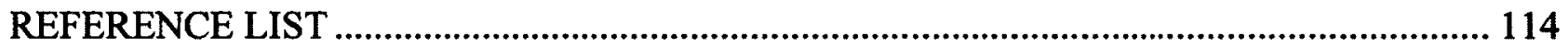

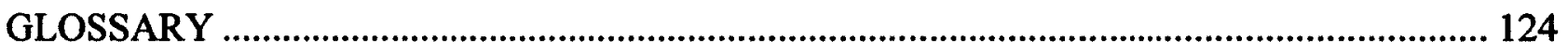

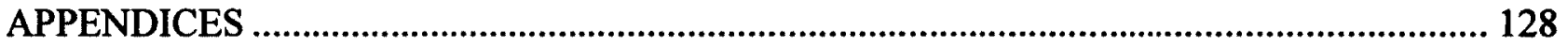




\section{LIST OF TABLES}

Table 1. Participant Demographics and Groupings ................................................................... 57

Table 2. Workshop Topics with Associated Titles, Problems, and Questions ..............................60

Table 3. ICC Indexes and Agreement Scores for Idea Quantity and Quality Measures .............. 68

Table 4. Mean Quantity of Ideas Produced .................................................................................... 73

Table 5. Mean Quantity of Ideas Produced Following the Best Member Criterion ...................... 74

Table 6. Mean Quality of Ideas Produced …………....................................................................... 75

Table 7. Mean Number of Good Ideas Produced ……................................................................. 76 


\section{LIST OF FIGURES}

Figure 1. Workshop Room Layout for the Individual (left) and Group (right) Activities............. 55 


\section{LIST OF APPENDICES}

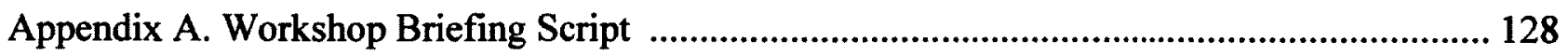

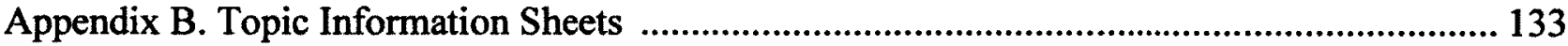

Appendix C. Survey Questionnaire ..................................................................................... 137

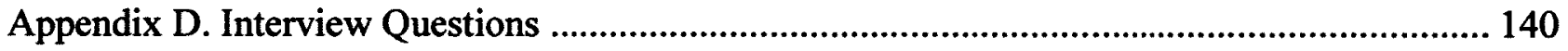

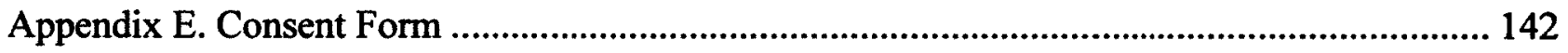

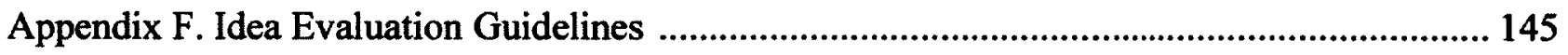

Appendix G. Speedstorming Protocol .................................................................................. 147 


\section{CHAPTER 1}

\section{INTRODUCTION}

Creativity is an essential component of human progression and it is with this that society is able to address the innumerable problems that the world faces each and every day (Hennessey and Amabile 2010). Without creativity, innovation would not exist and civilization would be stagnant. This is because creativity is the first step to innovation; it is essentially the development of ideas while innovation is the implementation and application of those ideas (Amabile et al. 1996; West 2002). As the marketplace becomes increasingly competitive and fast-paced, and advances in technology become more and more rampant, organizations are required to foster creativity to capitalize on their innovation potential and to ultimately develop innovative products, services, and processes (Holtzman and Anderberg 2011; Farh, Lee, and Farh 2010), which is crucial for organizational success (de Jong and den Hartog 2010; Miura and Hida 2004).

In most cases, organizations implement teams in an attempt to achieve this success. The frequency in which such teams are utilized clearly reflects the widespread expectation that teamwork provides specific advantages to an organization's process and output (Hertel 2011). It is argued that "a well performing team will create additional value to a company by combining individuals' strengths and take advantage of synergies that may exist, thereby making the whole greater than the sum of its parts" (Holtzman and Anderberg 2011, 75-76). This idea of synergy is the very essence of collaboration; it is what organizations strive for when assembling groups of individuals to work together (Larson 2010). It is the performance and process gains that result 
from successful collaboration that will lead to truly creative and innovative solutions (Hertel 2011).

One of the most eminent reasons for assembling teams and collaborating is to take advantage of the different strengths that the individual members possess. In many cases, this comes down to capitalizing on member diversity. It is believed that teams having members with diverse backgrounds, knowledge, and skills have the potential to perform at higher levels than teams that are more homogenous (Holtzman and Anderberg 2011). In terms of creativity and idea-generation, heterogeneous teams often have a divergence of viewpoints and perspectives which can stimulate creative thinking and the generation of creative ideas, leading to the development of innovative solutions (Barczak, Lassk, and Mulki 2010; Bassett-Jones 2005; Roberge and van Dick 2010). With this comes a push for interdisciplinarity ${ }^{1}$. Existing, domainspecific knowledge is considered inadequate in supporting innovative development (Leenders, van Engelen, and Kratzer 2003) which means that teams need to share and exchange knowledge to maximize their creative performance and improve the quality of the design process (BadkeSchaub, Goldschmidt, and Meijer 2010).

So, how can interdisciplinary design teams take advantage of their diversity to enhance their collective creativity and achieve the synergy that they were put together specifically for? How can these teams improve their collaborative performance and produce highly creative conceptual solutions that will lead to innovative outcomes? More specifically, how can these interdisciplinary teams generate good, creative ideas that no one person would be able to come up with on their own? These are the questions that have sparked interest amongst researchers

\footnotetext{
'As stated by Stein, "interdisciplinary is ill-defined" $(2007,93)$. In this regard, it is important to note that for the purpose of this thesis, the terms interdisciplinary and interdisciplinarity are used very loosely to generally mean the communication and collaboration of multiple disciplines, and the exchange and integration of knowledge towards achieving a common goal or objective (Jacobs and Frickel 2009).
} 
and practitioners and are essentially the driving forces for this thesis research. Providing answers to these questions will be of great value for organizations and, ultimately, for the future of design practice and research.

\subsection{SCOPE OF THE RESEARCH}

This research is about creative synergy in interdisciplinary design collaboration. Within this topic, there are a number of sub-topics or areas of inquiry that are distinct but have significant overlap with each other. The first of these is the study of creativity. Since creativity and design are inseparably connected (Taura and Nagai 2011) and creativity manifests in the generation of novel and useful products or ideas (Hennessey and Amabile 2010), understanding creativity is imperative for the development of this thesis. The second is the study of synergy. As defined by Larson (2010), synergy refers to performance gains that are due to group interaction $^{2}$. In this regard, the study of synergy focuses on measures of team performance and the gains or losses in output that result from the collaboration and interaction amongst group members. Furthermore, since this research is focusing on creative synergy, it is the performance gains or losses in idea-generation tasks that are of consideration. The third area revolves around interdisciplinarity and the effects of diversity on team performance. The key factor here is that diverse perspectives and the sharing of knowledge can stimulate greater cognitive processing, increasing the potential number of novel combinations that can be developed and allowing for cross-fertilization of ideas (Kurtzberg and Amabile 2001; Miura and Hida 2004; Paulus 2000). Finally, the fourth area involves the methods of collaboration and the techniques that are used to

\footnotetext{
${ }^{2}$ Although there is a difference between what constitutes a group versus a team (Katzenbach and Smith 1993), the literature revolving around teams and small group performance often use the terms interchangeably without any real distinction. For the purposes of this thesis, these terms are also used interchangeably to mean a collection of individuals who work together on a common task and are interdependent with a shared goal or objective (Larson 2010).
} 
facilitate group interaction. These are important because they provide a means of coordinating communication and the interaction process. From a holistic view, these four areas converge to inform an understanding of how collaborative interdisciplinary design teams can facilitate synergy in their creative performance, and what techniques or methods they can use to achieve such creative synergy through the sharing and integration of diverse knowledge.

It must be noted here that the scope of this research is set within the design activity of ideageneration. Other activities which are essential to the design process - earlier procedures such as problem-definition and opportunity-finding, and later procedures such as idea-evaluation and conceptual development - are not addressed in this thesis. Future research may be able to tackle these other activities and test the effectiveness of speedstorming in such phases of the design process.

\subsection{BACKGROUND AND NEED}

The research focusing on team performance for idea-generation tasks generally examines the use of brainstorming techniques to facilitate creative synergy. Although Osborn (1963) claimed that group brainstorming was an effective technique for generating many good ideas, the empirical evidence has indicated that the collective efforts of a group result in consistent performance loss (see Diehl and Stroebe 1987; Lamm and Trommsdorff 1973; Mullen, Johnson, and Salas 1991). That is, individuals who generate ideas alone and pool their outputs (i.e. nominal groups) have consistently been shown to outperform groups of equal size who interact with one another and generate ideas together. This has been found to be attributable to particular inhibiting mechanisms such as production blocking, evaluation apprehension, social loafing, free riding, and performance matching (see Larson 2010; Mullen, Johnson, and Salas 1991). 
In response to these inhibitory mechanisms, researchers have developed and tested other forms of brainstorming that attempt to minimize these effects or eliminate them all together. One such technique is that of electronic brainstorming where individuals collaborate remotely via computers to generate and share ideas by typing them out in text format. Studies on electronic brainstorming have shown that ideational productivity is greater when a team of four or more collaborate through computers as compared to face-to-face brainstorming (Gallupe, Bastianutti, and Cooper 1991; Gallupe et al. 1992) and, as the size of the team increases, their performance drastically improves (Dennis and Williams 2005; Gallupe et al. 1992). However, when compared to individuals that pool their ideational outputs, electronic brainstorming groups need to be much larger in size (eight or more members) to show any real synergistic benefits in their collaborative efforts (Dennis and Valacich 1993; Dennis and Williams 2005).

As the research shows, there is clear evidence that electronic brainstorming has the potential to facilitate creative synergy if groups consist of many members. But, as Pinsonneault et al. (1999) point out, there are a number of additional inhibitory mechanisms that arise specifically from this method of collaboration, and these can have drastic effects on a group's ideational performance when membership is large. Therefore, another technique called brainwriting has been developed which attempts to build on some of the benefits of electronic brainstorming while avoiding some of these detrimental factors.

Brainwriting is actually a family of collaborative idea-generation techniques which prevent group members from talking aloud with each other and constrains them to communicating and sharing their ideas by writing them down on paper and presenting them to each other visually or graphically (VanGundy 1988). Of the limited research assessing the brainwriting technique, findings have evidenced traces of synergy in collaborative ideation. A study by Paulus and Yang 
(2000) has shown that interacting groups using brainwriting can produce almost twice as many ideas as the same number of individuals working alone. Furthermore, Coskun (2005) was able to find similar synergistic effects even in collaborative dyads. Other research addressing the effectiveness of brainwriting techniques in a design context more specifically have shown that creative synergy can exist when designers use a combination of sketches and words to communicate and share their ideas (Linsey and Becker 2011). This form of brainwriting has been more appropriately termed as brainsketching (van der Lugt 2002).

Although these recent studies have demonstrated the potential synergies that can exist in collaborative ideation, the majority of them were conducted with homogeneous teams consisting of members who were very similar to each other in their knowledge and ways of thinking. It has been argued that heterogeneous teams can be more creative and innovative by taking advantage of the diversity in knowledge, skills, abilities, and perspectives that each member brings to the collective effort (Bassett-Jones 2005; Holtzman and Anderberg 2011; Kurtzberg and Amabile 2001; Roberge and van Dick 2010), and this has been somewhat supported empirically (e.g., Diehl 1992, as cited in Stroebe and Diehl 1994; Kurtzberg 2005; Miura and Hida 2004).

Very recently, a new technique called speedstorming has been developed specifically for facilitating interdisciplinary interaction and capitalizing on team diversity and the resulting creative potential (Hey et al. 2009; Joyce et al. 2010). Even though speedstorming was developed in the field of nanoscience as a way of improving the process of finding interdisciplinary research collaborations, preliminary investigation has shown great prospects for the successful sharing and integration of diverse knowledge, and the synergistic generation of creative ideas (Joyce et al. 2010). This has led to a great opportunity to further investigate the benefits of speedstorming for idea-generation. 
It is clear from the research on brainstorming that there is a need for a new technique that can eliminate or at least minimize the inhibitory mechanisms acting on ideation in collaborative teams. Electronic brainstorming, brainwriting, and brainsketching have all shown some benefits towards achieving creative synergy, but there are still evident problems that are preventing the synergistic potential to be fully exploited. With the recent introduction of speedstorming, a new path has been drawn whereby the collaborative efforts of a team may lead to enhanced creativity while taking advantage of the diversity of knowledge and perspectives inherent in an interdisciplinary group. But, does this technique provide such benefits in a design context? Is creative synergy achievable using speedstorming when generating ideas for design problems? These questions have never been addressed and, thus, there is a clear need for empirically investigating the potential of speedstorming for facilitating creative synergy in interdisciplinary design collaboration.

\subsection{PURPOSE OF THE STUDY}

The purpose of this study was to compare the ideational performance of interdisciplinary interacting groups using speedstorming to that of equivalent nominal groups using individual brainstorming, to determine if speedstorming can facilitate creative synergy in interdisciplinary design collaboration. The purpose was also to explore how the effectiveness and the process of speedstorming was perceived by the interdisciplinary team members and why speedstorming may or may not be a valuable technique for enabling creative synergy in interdisciplinary design ideation. This study was developed as a pilot to test speedstorming as a potentially beneficial method of collaboration in design. It has never been tested before in this type of context; therefore, a pilot study has been selected as an appropriate investigative approach. 
In order to compare the ideational performance of the interacting groups to that of the nominal groups, two workshops were conducted whereby twenty-four participants from a variety of disciplines were purposely selected and then divided into four groups of six, each having a particular interdisciplinary makeup. Each group participated in both an individual brainstorming session and a collaborative speedstorming session to generate ideas for two different design problems respectively. The ideas produced during the workshops were evaluated by two independent evaluators on measures of quantity and quality. Quantity was scored by counting the number of non-redundant ideas produced and quality was scored by rating each of those ideas on a 7-point scale for three dimensions: novelty and originality, utility and effectiveness, and feasibility. A survey questionnaire was completed by each participant at the end of the workshops and interviews were conducted with eight select participants to gauge their perceptions of the effectiveness of speedstorming and its process. Observations were also conducted during the workshops to collect any behavioural information pertinent to understanding why speedstorming may or may not be effective for stimulating creative synergy.

\subsection{RESEARCH QUESTIONS AND HYPOTHESES}

In order to investigate the benefits of interdisciplinary collaboration for idea-generation in design, and to assess whether creative synergy exists for such tasks using speedstorming, the following research questions and hypotheses have been addressed in this study:

Question 1: How do interdisciplinary interacting groups using speedstorming compare to equivalent nominal groups using individual brainstorming, in terms of their creative performance with respect to the quantity and quality of ideas produced?

Hypothesis la: The interacting groups using speedstorming will generate more ideas than the nominal groups using individual brainstorming. 
Hypothesis 1b: The interacting groups using speedstorming will generate ideas of greater quality as compared to the nominal groups using individual brainstorming.

Hypothesis 1c: The interacting groups using speedstorming will generate more good ideas than the nominal groups using individual brainstorming.

Question 2: How does speedstorming facilitate or inhibit creative synergy in interdisciplinary design collaboration for idea-generation tasks?

\subsection{SIGNIFICANCE TO THE FIELD}

This research is important for advancing our understanding of how creativity can be enriched within design collaboration and ideation. Although there has been a lot of discussion about addressing creativity in a team context (e.g., Barczak, Lassk, and Mulki 2010; Kurtzberg and Amabile 2001; Paulus 2000), there has been little empirical investigation into how design teams in particular can facilitate creativity (Dahl 2011). Furthermore, this research contributes to the knowledge about interdisciplinary design and how interdisciplinary collaboration can be successful in enhancing the process and outcome of design practice. As Dykes, Rodgers, and Smyth (2009) point out, there are contemporary transformations happening in the field of design which include the emergence of work that integrates various disciplinary influences and the need for collaboration that spans disciplinary boundaries. It is with these transformations that such investigation into the effects of interdisciplinarity become so fruitful and necessary for the progression of the design field.

Quoting Dahl, "research directed towards a better understanding of what enables design team effectiveness is clearly needed" $(2011,425)$. By testing the potential value of speedstorming as an idea-generation technique for interdisciplinary design teams, this research may introduce new avenues for investigation and it may also initiate new opportunities for design practitioners to utilize a different method of collaboration in hopes of sparking greater 
creative thinking. Speedstorming has the potential of being the next best tool for early design collaboration and this research initiative is the starting point to revealing its synergistic potential.

\subsection{THESIS STRUCTURE}

This thesis consists of six main chapters, each containing a number of sections and subsections. In this first chapter, the research was introduced by discussing the general context that surrounds the topic of this thesis; describing the scope of the research and what areas are relevant to the topic; discussing some of the background research and pointing out the need for empirical investigation; explaining the purpose of the study followed by the research questions and hypotheses pertinent to this research; and finally, describing the significance of this research to the field of design, indicating the value that this thesis will have for design practice and research.

The second chapter is the literature review which presents an extensive examination of the extant literature that surrounds the topic of creative synergy in interdisciplinary design collaboration. This chapter is broken down into two main sections. The first section covers the topic of creativity whereby the creativity construct is thoroughly defined and an understanding is built-up around the creative act of generating ideas and what constitutes a good or creative idea. The second section is much more extensive covering the topic of synergy and team performance, beginning again with a thorough definition of the synergy construct, followed by a comprehensive review of the empirical research addressing team performance for ideageneration tasks. A particular focus is placed on the various techniques used in attempts to stimulate creative synergy, along with the various inhibiting mechanisms that are inherent in each method of collaboration. Furthermore, a new collaborative idea-generation technique called speedstorming is introduced, providing an overview of the process and its benefits as well 
as a review of the limited empirical research that has been conducted to date utilizing this technique for interdisciplinary collaboration.

The third chapter is dedicated to explaining the methods utilized to conduct the primary research for this thesis. It discusses the setting in which the study took place; the sample which participated in the study; the intervention that was implemented including the independent and dependent variables controlled and measured in the study; the materials and measurement instruments that were used to conduct the study; and the procedures followed for collecting and analyzing the data.

The fourth chapter consists of the study results which presents the quantitative and qualitative findings from the empirical investigation and the data analysis. Descriptive and inferential statistics are presented as well as the major themes and patterns that had emerged from the interviews, survey questionnaires, and behavioural observations.

These results are then interpreted and discussed in chapter five. This chapter is dedicated to understanding what the findings mean for interdisciplinary design collaboration and creative synergy, and connecting some of the results with past research on idea-generation and team performance. It is here that the research questions are reviewed and clearly answered.

Finally, conclusions of this research study are made in the last chapter. This is where the key findings from the research are clearly defined and the major contributions to the field of design are discussed. This chapter also includes a discussion revolving around the limitations of this study and suggestions for future research initiatives. These suggestions will allow researchers to improve on the methodology and to deepen our understanding of how speedstorming might facilitate creative synergy in interdisciplinary design collaboration. 


\section{CHAPTER 2}

\section{LITERATURE REVIEW}

In order to be innovative and to compete in a fast-paced marketplace, organizations need to foster creativity and take advantage of the potential synergies that occur through the collaboration and collective efforts of a team (Chen 2006; Holtzman and Anderberg 2011; Farh, Lee, and Farh 2010). These synergies represent performance gains that result from the interactions amongst team members by which the output is something that the members would not be able to achieve on their own (Larson 2010). It is with these synergies in collaborative action that organizations will be able to develop truly creative and innovative solutions (Hertel 2011).

However, as technologies continue to advance at a rapid rate and problems become more complex, existing knowledge becomes inadequate in supporting the development of innovative solutions (Leenders, van Engelen, and Kratzer 2003). This calls for a more interdisciplinary approach whereby members who have a diversity of backgrounds, skills, and expertise collaborate, share knowledge, and integrate various perspectives in order to generate new combinations that will lead to greater creative ends. In this regard, it is argued that teams need to promote diversity amongst their members in order to maximize their creative performance and improve the quality of the design process (Badke-Schaub, Goldschmidt, and Meijer 2010; Bassett-Jones 2005).

This literature review is broken down into two main sections. The first section covers the topic of creativity. This sets the stage for understanding what creativity means and how it is applied in the context of this thesis. The second section covers the topic of synergy and team 
performance. Within this section, a number of important things are discussed in regards to understanding what synergy is and how it manifests in a team's creative performance on ideageneration tasks. Empirical research on group brainstorming and other variations of the brainstorming technique is presented along with some of the pitfalls that are associated with each in preventing creative synergy to flourish. At the end, a new idea-generation technique called speedstorming is introduced and its potential for facilitating creative synergy in interdisciplinary team collaborations is discussed.

\subsection{CREATIVITY}

People have been interested in creativity for a long period of time, but it wasn't seriously accepted as a research field until 1950 with the contributions of Joy P. Guilford and his declaration that creativity needed to be studied and researched at a more serious level (Barron and Harrington 1981; Kaufman 2009; Rhodes 1961). Recently, the study of creativity has proliferated in many different disciplines, each having its own focal concerns and pursuits (Hennessey and Amabile 2010). This has introduced several challenges to the overall approach of creativity research and has led to some inconsistencies in how creativity is defined, how it is measured, and what it means for the various fields of inquiry.

Despite such challenges, this section of the literature review attempts to build-up a fair understanding of what creativity is and how it fits within the field of design. This is done by providing a holistic definition of the term and describing how each element of the construct relates and interacts with one another to influence its final embodiment. Following this definition, the specific process of idea-generation is addressed with a focus on defining the characteristics of an idea and what constitutes a good or creative idea. 


\subsubsection{Defining Creativity}

Due to the proliferation of literature in various research domains, the creativity construct has not been consistently defined and there is a lack of consensus as to its exact definition (Barron and Harrington 1981; Furnham and Bachtiar 2008; Hennessey and Amabile 2010). Plucker, Beghetto, and Dow have said that there is a "definition problem' surrounding the study of creativity" $(2004,90)$. In fact, creativity is rarely explicitly defined in the research literature (Kaufman 2009; Kaufman, Plucker, and Baer 2008; Plucker, Beghetto, and Dow 2004). This is an important consideration because, just like any other area of empirical research, researchers need to be measuring for the same construct in order to make any valid generalizations, which requires a consistent and accurate definition.

In response to this "definition problem", Plucker, Beghetto, and Dow (2004) conducted a content analysis of the literature revolving around creativity research to draw-out all of the explicit and implicit definitions of the construct. Although the results of their analysis supported the fact that creativity is poorly defined, it did allow them to identify several reoccurring, constituent elements that led them to creating a synthesized, holistic definition. Accordingly, they define creativity as "the interaction among aptitude, process, and environment by which an individual or group produces a perceptible product that is both novel and useful as defined within a social context" (Plucker, Beghetto, and Dow 2004, 90).

This definition includes several key aspects. Firstly, "creativity emerges from an interaction among certain aptitudes, specific cognitive processes, and influences from the environment [italics added] in which the individual or group exists" (Plucker, Beghetto, and Dow 2004, 91). In this sense, people's dispositions, abilities, attitudes, and motivations as well as their ways of thinking and approaching a problem or a situation can inspire creativity, given that 
the environment provides the right atmosphere to be creative. Secondly, creativity is materialized through the generation of a perceptible product that is both novel and useful. "Without observable and measureable evidence of some act, idea, or performance, it is difficult to determine whether creativity has occurred" (Plucker, Beghetto, and Dow 2004, 91). A person or team with creative abilities will only be recognized as creative through the act of doing or producing something (e.g., behavior, product, idea). Furthermore, this perceptible product must also have elements of novelty and usefulness; it must represent something new and different (novel) as well as something appropriate and relevant (useful). These two criteria are by far the most prevalent within the extant definitions of creativity (Hennessey and Amabile 2010; Kaufman 2009; Plucker, Beghetto, and Dow 2004). Lastly, creativity is dependent upon the social context within which the individual or team is acting. It is the society that judges and determines what is and is not creative. In this sense, a behavior, product, or idea may be creative in one context but not in another. As an example, Plucker, Beghetto, and Dow (2004) describe the differences between considering the creativity of fourth-grade science projects in comparison to that of Nobel Prize-winning discoveries. A particular fourth-grade science project may be very creative in the context of fourth-graders and student science fairs, but not so much in the context of the projects and discoveries of Nobel Prize-winning scientists.

Plucker, Beghetto, and Dow's (2004) definition of creativity is quite harmonious with the "Four P's" model of creativity which distinguishes the creative person, process, product, and press (i.e. environment) (Kaufman 2009; Kaufman, Plucker, and Baer 2008; Rhodes 1961). The creative person has to do with an individual's characteristics and dispositions including their personality, temperament, motivation, intellect, thinking styles, attitudes, values, emotional intelligence, knowledge, and behaviour. This reflects a person's aptitude for creativity. The 
creative process refers to the actual experience of being creative and the ways in which a person learns, thinks, and acts on a problem or situation. The creative product is a tangible or observable item, object, idea, response, or behavior. It is the perceptible result of some creative activity. Finally, Rhodes described the term press as referring to "the relationship between human beings and their environment" $(1961,308)$. In this sense, the creative press represents the environment in which creativity occurs. It encompasses the physical and social contexts which may or may not be conducive to creativity (Kaufman 2009; Kaufman, Plucker, and Baer 2008).

In addition to the Four P's, Simonton (1988) introduced a fifth P: persuasion. He refers to creativity as an interpersonal and social phenomenon whereby individuals must impress those around them for creativity to emerge. The people within the given social context must be convinced that what is being produced or displayed is creative. Therefore, it is only with the acceptance from the society that creativity is deemed upon something or someone. This has some overlap with the creative press from the Four P's model, but is more in-line with the characteristics of the social context component of Plucker, Beghetto, and Dow's (2004) definition.

So, although creativity seems to be the result of an interaction amongst an individual or team's aptitude, process, environment, and social context, it is the embodiment of creativity through a product or idea that is what organizations are most interested in. As long as each component plays its part and contributes to the generation of creative solutions, innovation will then be possible and organizations will be gratified. Therefore, it is the creative product that is of relevance for this thesis and, in particular, the creative ideas that result from the ideageneration process. 


\subsubsection{Idea-Generation and the Creative Idea}

Idea-generation or "ideation is the process of generating ideas useful for attaining some desired state or outcome" (Briggs and Reinig 2010, 123), often in an attempt to solve a particular problem. According to Kim, "an idea is a concept that may serve as a component of a solution" $(1990,13)$. The idea could be directly related to some aspect of a solution or it could be an indirect insight that aids in finding a solution. Kim (1990) contends that there are two levels or types of ideas: elementary ideas and compound ideas. Elementary ideas refer to the very basic conceptions that cannot be reasonably divided into smaller concepts whereas compound ideas are those which are made up of multiple ideas packaged into one aggregate concept that serves as a solution to a problem. In this sense, compound ideas cannot be produced without the generation of elementary ideas. "The solution to many a difficult problem lies not in a solitary idea, but in a collection of them" (Kim 1990, 15). Therefore, the ultimate goal is to generate compound ideas as the outcome or desired state.

Although it is important to produce these compound ideas, it is considered more important to produce good ideas and creative ideas that will lead to innovative solutions. In any design process, it is always good ideas that are of the desired state or outcome (Goldschmidt and Tatsa 2005). Goldschmidt and Tatsa (2005) argue that not all good ideas qualify as creative ideas, but all creative solutions are derived from good ideas. They define a good idea as one that is critical and influential. In other words, good ideas are those which create links with other ideas. In this sense, a regular idea may stand alone without being linked with, and having influence on, other generated ideas; but, a good idea would have many links and would be considered influential in the development of a creative solution. Even though Goldschmidt and Tatsa (2005) do not describe what a creative idea is and how it differs from a good idea, it is inferred, based on the 
definition of a creative product (Hennessey and Amabile 2010), that a good idea does not have to be novel or useful, but a creative idea does.

Despite this difference that Goldschmidt and Tatsa (2005) have introduced, it is often the case that a good idea is considered equivalent to a creative idea. According to Rietzschel, Nijstad, and Stroebe (2010), good ideas are usually defined as those which are both highly original or unusual and highly feasible or useful. This is consistent, again, with the definition given for a creative product (Hennessey and Amabile 2010). Briggs and Reinig (2010) also consider good ideas as those which are of high-quality, as defined by their instrumentality in achieving a goal and their feasibility in implementation. So, it seems that a good idea can be classified as a high-quality idea whereby quality is characterized by the attributes of a creative product; therefore, for the purposes of this thesis, a good idea is considered to be a creative idea.

\subsection{SYNERGY AND TEAM PERFORMANCE}

The term synergy stems from the Greek word "sunergos" which means "working together" (Larson 2010). It is often used as a way to describe the performance potential of a taskperforming group whereby the group members "work together" to complete some given task. This is the very root of why teams are believed to be better than individuals working alone. Teamwork has even been described as "a co-operative process that allows ordinary people to achieve extraordinary results" (Scarnati 2001, 5). It is these extraordinary results that resemble the concept of synergy in team performance.

This section of the literature review begins with establishing a clear definition of synergy in the context of this thesis. Then, the empirical literature revolving around synergy and team performance is discussed with an emphasis on idea-generation tasks using traditional face-to- 
face brainstorming. The various inhibiting mechanisms found with the use of brainstorming are introduced followed by a review of some of the more recent techniques that have been developed to address these issues. Finally, a new idea-generation technique specifically developed for interdisciplinary collaboration is presented and the limited empirical research that has been done using this technique are discussed.

\subsubsection{Defining Synergy}

The term synergy is broadly used in a variety of contexts and disciplines. For example, fields in medicine such as physiology (Marieb 2004), endocrinology (Fox 1996), and pharmacology (Katzung 1998) use the term to describe the additive, complementary, and multiplicative effects of two or more components (muscles, hormones, and drugs, respectively) working together. In contrast, fields such as psychology and business management employ the concept to describe the increases in performance of a small group working together (Collins and Guetzkow 1964; Overstreet 1925), different business units working together (Vizjak 1994), and different organizations working together (Lasker, Weiss, and Miller 2001). A common metaphor that is often used to describe synergy is $1+1=4$ (Diamond 1987; Larson 2010; Scarnati 2001). In other words, the combining of two or more components produces a whole that is greater than the sum of the parts.

The term synergy is also sometimes used as a way of describing the excitement, motivation, or high levels of cohesiveness that individuals feel when working together with others. For example, Cattell referred to the concept as the "energy going into the group life as a result of satisfaction with fellow members" $(1957,791)$. Accordingly, it is about the experience of working together and the motivation gains as a result. However, consistent with the previously stated conceptions of synergy, it has been more consistently defined from a performance 
perspective by gauging the actual output of two or more constituents working together. It is the end result that is of importance and not the experience one has when collaborating with others. So, despite the wide use of the term, it is best defined from a performance perspective; and since this thesis is about collaboration in design teams, the focus is at the level of small group performance.

Larson, who can be considered a leader in research on synergy in small group performance, states that "synergy is simply a performance gain that is due to group interaction" $(2010,5)$. More specifically, he affirms that synergy is a gain in performance that results from the collective interaction of a group by which the output is greater than the simple combination of individual members' efforts alone. The key components of this definition include group performance gains and group interactions. The group must have some measureable output that is greater than the combination of individual inputs and this results from an interaction amongst the members by which the verbal and nonverbal behaviours exhibited by each member has some direct influence on the others. With this being said, it is clear that synergy does not exist at an individual level but only at the collaborative, team level.

\subsubsection{Weak Synergy and Strong Synergy}

There are two levels or degrees of synergy: weak synergy and strong synergy. Weak synergy is defined as "group performance that exceeds the performance of the typical group member when working alone" (Larson 2010, 6) whereas strong synergy is defined as "group performance that exceeds the solo performance of even the best group member" (Larson 2010, 7). In this regard, weak synergy is demonstrated when the group's performance gain is within a range that at least some members of the group could reasonably have achieved working alone and strong synergy is demonstrated when the gain is beyond that range. 
There is substantial empirical evidence for the existence of weak synergy; however, this is not the case when it comes to strong synergy. Strong synergy is naturally a much rarer phenomenon and it is apt to depend on more complex forms of interaction within groups (Larson 2010). It is also important to note that the research designs used in studies of group performance have not always provided adequate measures for strong synergy. This comes down to the distinction between using an average member criterion and a best member criterion when comparing the performance of interacting groups to that of nominal groups ${ }^{3}$.

For the average member criterion, the performance standard is set by what can be accomplished by the "average member" of the nominal group. The notion is that the interacting groups are being compared to groups made up of all average or typical members. So, in this case, the means of the nominal groups are simply compared to the means of the interacting groups. Taking the measure of idea quantity as an example, it is the mean number of ideas produced by the nominal groups that is used for the comparison. This is the criterion that most research methodologies follow when assessing the ideational performance of collaborative teams.

On the other hand, for the best member criterion, the performance standard is set by what can be accomplished by the "best member" of the nominal group. The notion here is that the interacting groups are being compared to groups made up entirely of best members. This requires an additional analytic step whereby the individuals within the nominal groups who have achieved the best performance amongst their fellow members must be identified and their performance scores would be multiplied by the number of individuals in the group. Then the mean of these "best member" nominal groups is used for the performance comparison.

\footnotetext{
${ }^{3}$ "Nominal groups are groups that comprise the same number of members as the interacting groups with which they are compared, but those members perform the task independently without any interaction" (Larson 2010,13). See Taylor (1955) for a review of the nominal group process.
} 


\subsubsection{Creative Synergy}

Creative synergy is defined no differently than the broader concept of synergy except that it has to do with the group performance revolving specifically around ideational tasks and the generation of creative ideas. Kurtzberg and Amabile (2001) discuss this creative synergy as resulting from the simultaneous forming, sharing, adapting, and inspiring of ideas by more than one person. It occurs at the team level where the ideas are generated by groups instead of individuals. Furthermore, they affirm that the ideas produced by these collectives are something that no one person could have done on their own. This distinction of creative synergy is the basis for understanding the performance gains in teamwork when the tasks involve creativity and the generation of ideas.

\subsubsection{Creative Synergy and Idea-Generation}

Most of the research revolving around team performance and the effects of group interaction on idea-generation tasks examines the use of brainstorming as a means of achieving creative synergy. Brainstorming is a conference method where groups of individuals attempt to generate creative ideas which can serve as leads to a problem-solution (Osborn 1963). It is a method for generating a check-list of ideas that can subsequently be evaluated and further addressed in later processes. Osborn (1963) claims that group brainstorming sessions can produce much better ideas as compared to traditional conferencing methods and this is done by following four basic rules: (1) refrain from criticism and judgment, (2) encourage wild and unusual ideas, (3) focus on generating a large quantity of ideas, and (4) build and expand on the ideas of others.

One of the biggest contributors to ideational productivity, according to Osborn, is deferment of judgment and criticism. "You can think up almost twice as many good ideas (in the 
same length of time) if you defer judgment until after you have created an adequate check-list of possible leads to solution" (Osborn 1963, 124). Another major contributor as part of Osborn's hypothesis is the argument that quantity breeds quality. "The more ideas you think up, the more likely you are to arrive at the potentially best leads to solution" (Osborn 1963, 124). In this regard, the goal of brainstorming is to produce as many ideas as possible without concern for quality (Paulus and Yang 2000).

Early research by Parnes and Meadow (1959) aimed to test the effectiveness of these rules and found that they are actually quite effective in increasing the production of good quality ideas when working on certain creative thinking problems. There were two conditions in their study: a brainstorming condition and a non-brainstorming condition. In the brainstorming condition, the participants were instructed to think-up and document as many ideas as possible without any regard for quality. They were told that their productivity was being assessed strictly on the number of ideas produced. In the non-brainstorming condition, the participants were instructed to document only good ideas and it was stressed that any ideas that would be considered poor in quality should not be included. They were told that the total number of good ideas would represent their performance for the task.

The results indicated that those who were in the brainstorming condition produced a significantly greater number of good ideas as compared to those in the non-brainstorming condition. In other words, those who were encouraged to seek quantity instead of quality actually produced better, more high-quality ideas overall. This supported Osborn's (1963) claim that quantity breeds quality, and it provided some stimulating empirical evidence for the value of following the brainstorming rules for generating good and creative ideas. 
Osborn's (1963) claims about the synergistic power of brainstorming and the supportive empirical findings from Parnes and Meadow's (1959) study had set in motion a considerable amount of interest amongst small group researchers for validating the performance potential of brainstorming groups in generating creative ideas. Researchers and practitioners wanted to know if brainstorming really could facilitate this creative synergy that is expected from group collaboration. Surprisingly, the majority of studies assessing the performance gains of interacting groups indicate that the collective efforts of a group on ideational tasks using brainstorming typically result in consistent production loss and an inhibition of creativity (see Diehl and Stroebe 1987; Lamm and Trommsdorff 1973; Mullen, Johnson, and Salas 1991).

One of the very first studies assessing the effectiveness of brainstorming in groups was that done by Taylor, Berry, and Block (1958). In their study, there were twelve groups of four members each and another forty-eight individuals, all of whom were put to the task of generating ideas for three different problems while following the four basic rules of brainstorming. When the tasks were complete, the researchers randomly assigned each of the forty-eight individuals to one of twelve nominal groups for comparison purposes. The results showed that the nominal groups produced significantly more ideas - about twice as many ideas - than the brainstorming groups who had interacted with each other.

This was also found for the originality and uniqueness of the ideas whereby nominal groups produced roughly double the amount of unique ideas compared to the interacting groups; however, this may only have been because of the differences between the nominal and real groups in total number of ideas produced. Therefore, an analysis of covariance was conducted and the results indicated that there were actually no significant differences in the number of unique ideas produced between the two group conditions for two of the three problems. The 
other problem, however, did show a significant difference and in fact, it was in favor of the interacting groups - the interacting groups produced more unique ideas than the nominal groups when allowance was made for the difference in total number of ideas. This may have been because of the fact that the problem ${ }^{4}$ was a very unrealistic one whereas the other two were set in a more realistic context. People may be able to come up with more unique and different ideas when the problem is beyond reality. Also, the ideas for this problem represented more of anticipated consequences instead of suggested steps to a solution.

The quality of ideas was also assessed in this study and it was found that the total quality ratings were significantly higher for nominal groups compared to the interacting groups, but an analysis of covariance was, again, employed to adjust for the differences in the total number of ideas produced. The results from this indicated that there were no significant differences between the interacting and nominal groups for the two same problems whereas there was a significant difference in quality for the other problem, but this time in favor of the nominal groups. Altogether, the findings from this study have indicated that nominal groups drastically outperform real, interacting groups on idea-generation tasks when it comes to the number of ideas produced. From this, the authors concluded that creative thinking and idea production is inhibited when brainstorming in groups.

Over the next three decades that followed, several studies addressed the group brainstorming hypothesis and yielded very similar results; the majority of them all pointing towards greater ideational productivity amongst individuals working alone as compared to working together (e.g., Bouchard 1969; 1972; Bouchard, Drauden, and Barsaloux 1974;

\footnotetext{
${ }^{4}$ This problem was called the Thumbs Problem and it referred to the question: What practical benefits or difficulties would arise if people had an extra thumb on each of their hands? (see Taylor, Berry, and Block 1958, 28)
} 
Bouchard and Hare 1970; Dillon, Graham, and Aidells 1972; Dunnette, Campbell, and Jaastad 1963; Gurman 1968; Harari and Graham 1975; Jablin 1981; Madsen and Finger 1978; Maginn and Harris 1980; Milton 1965; Rotter and Portugal 1969; Street 1974; Vroom, Grant, and Cotton 1969). One of the major concerns about these findings though is that all of the studies have assessed group brainstorming in a laboratory setting. So, this raises the question: could there be a difference in a real-world situation? Would the tasks and problems situated in a real context, in a real organization, change the group dynamics and ultimately enhance productivity within the group? In fact, it has been found that there is no real difference; group brainstorming still leads to poorer ideational performance.

Paulus, Larey, and Ortega (1995) addressed this by testing for the effectiveness of group brainstorming in an organizational setting. They had groups of four generate ideas collaboratively or alone on a job-relevant issue with employees who had worked together on a daily basis and had been trained in so-called proper teamwork dynamics and practices. The results were consistent with those of the laboratory settings: interacting groups produced about half as many ideas as individuals working in the nominal groups. These findings suggest that training in group dynamics and the beneficial effects of social and task cohesion do not help individuals overcome the inhibiting mechanisms inherent in interactive brainstorming groups.

So, with all this evidence that group brainstorming actually inhibits creativity and ideation, why is it that organizations and various teams still promote the use of group brainstorming? Why is it that design firms continue to boast about the value it has for generating great ideas? For example, one of the leading firms in North America, IDEO, claims that "brainstorming is the idea engine of IDEO's culture" (Kelley and Littman 2001, 56). Furthermore, they claim that other businesses and organizations are not using brainstorming as a tool in the right way. They 
believe that organizations "can deliver more value, create more energy, and foster more innovation through better brainstorming" (Kelley and Littman 2001, 55).

One explanation may be attributed to what is termed the "illusion of group productivity" (Larson 2010; Paulus et al. 1993) or the "illusion of group effectivity" (Diehl and Stroebe 1991). This refers to the perception group brainstormers have that they perform better than individual brainstormers and that group brainstorming is more productive, even though the opposite is true. Participants who brainstorm in interacting groups tend to enjoy their experience more, are more enthusiastic about participating, and are more satisfied with their personal performance, than those who brainstorm alone (Milton 1965; Paulus, Larey, and Ortega 1995). They tend to believe that they personally generate relatively many ideas whereas individual brainstormers believe that they generate relatively few. This is also consistent with perceptions of idea quality (Paulus et al. 1993; Paulus, Larey, and Ortega 1995). Furthermore, group brainstormers typically believe that they would have produced many fewer and lower quality ideas if they had generated ideas alone whereas individual brainstormers believe in the superiority of their performance if they had brainstormed in a group (McGlynn et al. 2004; Paulus et al. 1993; Paulus, Larey, and Ortega 1995).

Another possible explanation as to why brainstorming is still used in practice today is offered by Sutton and Hargadon (1996). Going back to Kelley and Littman's (2001) claim that brainstorming is an essential component of IDEO's culture, Sutton and Hargadon wanted to find out why this is. They wanted to know if IDEO was wasting their time and money using such a technique when the empirical literature clearly shows that brainstorming is ineffective and should not be used. These researchers, however, approached the question of "effectiveness outcome" in a different way, following a more qualitative, ethnographic approach. They argued 
that the efficiency at idea-generation - which has been the dominant measure in the brainstorming literature - deserves no special status as the sole effectiveness outcome for group brainstorming. Their study suggested that there are six other important consequences of group brainstorming for the organization, its employees, and its clients. The authors concluded that, "in addition to generating possible design solutions, brainstorms support the organization's memory of technical solutions, provide skill variety, support an attitude of wisdom in and outside the session, create a status auction that maintains a focus on designing products, and they impress clients and generate income" (Sutton and Hargadon 1996, 710-711). So, even though brainstorming may not be the most effective for generating lots of ideas, it has other benefits which prove valuable for such design firms and organizations alike.

It must be reiterated here that the search for creative synergy is the search for ideational performance gains due to group interaction. The focus is on the generation of creative ideas and not on whether the organization can generate income, for example. Therefore, these positive values of brainstorming that have been found are irrelevant to whether creative synergy exists or not. So, the question then becomes: why do groups perform worse than individuals who work alone and combine their outputs? Why can't groups capitalize on the cognitive stimulation that theoretically occurs when sharing ideas? To answer, research has shown there to be certain procedural, social-psychological, and economic mechanisms that contribute to the performance loss in collective ideation (see Larson 2010; Mullen, Johnson, and Salas 1991). These include production blocking, evaluation apprehension, social loafing, free riding, and performance matching. 


\subsubsection{Production Blocking}

Production blocking is considered the most influential factor leading to poor ideational performance in group brainstorming (Diehl and Stroebe 1987; Larson 2010). Central to this inhibiting procedural mechanism is the fact that members must take turns to speak about their ideas which means that individuals have to wait for their chance to talk. While they wait, the individuals must contend with three different mental tasks at the same time. First, an individual must pay attention to the person who is currently speaking and he or she has to think about what is being said and process that information to build new ideas. This is the very purpose of hosting a brainstorming session and is the root of attaining synergy - sharing ideas and building off of them to come up with new ideas that no one person could have done alone. Secondly, once the individual has come up with an idea to share, he or she must hold that idea in memory until a turn arises for them to speak, which typically requires a certain amount of silent rehearsal to keep it fresh in mind. Lastly, in order to have a speaking turn, it is required that the individual continuously monitors the discussion for an appropriate time to jump in and take their turn. If this task is not closely attended to, he or she may lose the opportunity to speak making for an even longer period of time to wait.

These three mental tasks are often very difficult to deal with simultaneously and group members typically do not succeed in doing so. Each task acts as a distractor that prevents the members from effectively utilizing the waiting time before having a chance to speak about their idea (Diehl and Stroebe 1991). The most obvious issue is that, while waiting for a turn to speak, an individual may forget the new idea that they had just conceived. By trying to attend to the other two tasks, the silent rehearsal task may not be attended to enough and the idea can easily slip away from his or her short-term memory. Even if the idea is still in mind, and an 
opportunity to speak arises, the individual may take a short moment to collect his or her thoughts and to think of how best to explain the idea, and this can often times prompt another person to speak up and steal the turn. Then the waiting continues and the individual must keep rehearsing the idea for the next speaking opportunity.

Another major issue in relation to production blocking is that, while an individual waits for a turn to speak and continues to rehearse the new idea in mind, it becomes much more difficult to think of other new ideas. The process of idea rehearsal minimizes the cognitive resources available to think about other things and limits the individual's ability to attend to new information. In this case, it is the actual production of ideas that is blocked whereas with the issue of forgetting ideas, the group is blocked from capitalizing on the members' ideational productivity. Research has shown that it is this blocking of further idea-production that is the most prominent contributor to the productivity loss in brainstorming groups (Diehl and Stroebe 1987; 1991; Nijstad, Stroebe, and Lodewijkx 2003).

\subsubsection{Evaluation Apprehension}

Evaluation apprehension is a form of motivation loss in brainstorming groups that results from the concern an individual may have for being negatively judged or evaluated in regards to the ideas that he or she shares. Even though the rules of brainstorming clearly encourage people to generate ideas free from criticism, and that wild and crazy ideas are sought-after without concern for quality, certain people will still hold-back their ideas in fear of them being viewed as too silly, simplistic, impractical, irrelevant, or in any way unacceptable (Larson 2010).

Despite some conclusions that evaluation apprehension has no real effect on brainstorming groups and their ideational productivity (Maginn and Harris 1980), other research has shown that 
it does in fact have some relevance in contributing to group productivity loss. For example, Diehl and Stroebe (1987) found that the induction of evaluation apprehension in an individual brainstorming session resulted in much lower productivity, regardless of the topic being controversial or not, and whether the evaluations were being conducted by the individual's peers or some anonymous assessor. They also found that this was only the case when the individuals perceived the evaluations to be at a personal, individual level rather than at a group level. In other words, if a group member is held responsible for his or her own ideas, evaluation apprehension becomes a player in the poor group performance; but, if the evaluations are being done on the group as a whole and not on each individual's contributions separately, evaluation apprehension is minimized and has little effect.

Other research by Camacho and Paulus (1995) has shown that people with particular dispositions and personality characteristics such as high social anxiety tend to generate many fewer ideas in group brainstorming as compared to those with low levels of social anxiety. They found that this personal disposition has very little effect on idea production when individuals work alone which proves that evaluation apprehension is a social-psychological mechanism that only inhibits ideation in a collaborative group. Furthermore, Collaros and Anderson (1969) found that members of a brainstorming group are more reluctant to share their ideas when other people in the group are perceived to be experts on the given topic. The individuals may feel more pressure to generate better ideas in the presence of experts, and therefore, they tend to withhold certain ideas that they feel will be negatively judged or evaluated by the expert members.

Although there is clear evidence that evaluation apprehension can negatively affect brainstorming productivity, its impact is quite small in comparison to that of production blocking 
(Diehl and Stroebe 1987). However, there are a number of other social-psychological factors contributing to the production loss found in interacting groups such as social loafing and free riding.

\subsubsection{Social Loafing and Free Riding}

Social loafing is the term used to signify a decrease in a group member's effort as a result of the social presence of others within the group (Latané, Williams, and Harkins 1979). It is another form of motivation loss that results from the inability to identify the contributions that have been made by each individual member (Harkins 1987). The main tenet of this mechanism is that, when working together, group members often put out less effort than they do when working alone due to the fact that there is no opportunity to be evaluated for their personal contributions. This has been proven in research addressing member effort for physical tasks such as rope-pulling (Ingham et al. 1974) and shouting (K. D. Williams, Harkins, and Latané 1981) as well as various cognitive tasks such as evaluating poems (Petty et al. 1977) and solving simple mazes (Jackson and Williams 1985). Studies have also proven that social loafing occurs in idea-generation tasks using brainstorming (e.g., Harkins and Petty 1982). These studies have demonstrated that when the ideas contributed by each group member are not attributable to them and their ideational efforts are not identifiable, the members produce significantly fewer ideas in comparison to when their contributions can be identified (see Karau and Williams 1993).

Free riding is also another form of motivation loss that results from the perception that group members' efforts are dispensable. This mechanism is similar to social loafing as described by Latané, Williams, and Harkins (1979) in that it resembles a decrease in effort when working together as a group, but it is distinguished by the fact that the members feel that their input is not essential to the group product regardless of whether or not their contributions are identifiable 
(Kerr 1983). In this sense, individuals believe that their efforts and hard work will not help the group in producing a better outcome, so they are less motivated to contribute and will "free-ride" on the efforts of the others. Research has proven this to be the case for both physical tasks (e.g., Kerr and Bruun 1983) and cognitive tasks (e.g., Weldon and Gargano 1988). So, whereas social loafing is defined in terms of identifiability and evaluation potential (Harkins 1987; Williams, Harkins, and Latané 1981), free riding is defined more in terms of dispensability of effort (Kerr 1983; Kerr and Bruun 1983).

\subsubsection{Performance Matching}

Performance matching is a social-psychological mechanism whereby group members adjust their individual productivity rates to match more closely to those of the other members (Larson 2010). As individuals work together to generate ideas, they become aware of the rate at which one another's ideas are produced and they use this information to gauge the group's implicit productivity norm. Larson (2010) uses the phrase "press toward uniformity" to describe the group's implicit action as they gradually converge on a common rate of production. Research has shown that group members tend to generate ideas at fairly similar rates in interactive brainstorming groups, whereas nominal brainstorming groups do not show this similarity amongst its members' performances (Camacho and Paulus 1995; Paulus and Dzindolet 1993). Further findings have shown that this only occurs if the group members are actually aware of the other members' productivity rates (Munkes and Diehl 2003).

It is argued that this performance matching occurs as a result of a relatively low productivity norm being established within the group early-on in the brainstorming session (Paulus and Dzindolet 1993). Even though it may be easy to generate many ideas at the very beginning of a session, the production blocking effects (as discussed earlier) come into play 
preventing the members from generating and sharing their ideas at a high rate. Although the competition for speaking turns gradually diminishes as the session moves on, those members who are capable of producing ideas at a greater rate will tend to not do so because of the desire to avoid the unpleasant feeling that they are doing all the work and being taken advantage of by the other members. This notion is similar to what Kerr (1983) describes as the "sucker effect" whereby members of a group will reduce their effort on the account that other members are perceived to be free riding.

Although the productivity loss found in brainstorming groups can be attributed to motivational mechanisms such as this performance matching process, as well as evaluation apprehension, social loafing, and free riding, production blocking is still considered the most influential mechanism of them all, accounting for the greater majority of variance between real group and nominal group performances (Diehl and Stroebe 1987; Larson 2010). In response to these negative influences, researchers and practitioners have developed alternatives to the traditional brainstorming technique in an attempt to find a way to capitalize on the synergy potential of interacting groups. One such technique is electronic brainstorming.

\subsubsection{Electronic Brainstorming}

Electronic brainstorming is essentially the same thing as traditional brainstorming except that group members do not interact face-to-face but, rather, do so via computers using software specifically designed to facilitate the process. Each member uses their own computer connected to a common network, whether remote or colocated, and the ideas are documented and communicated by typing them out into the software program. In its most basic form, the 
software includes an entry field for entering ideas and a review field for reviewing all of the group's ideas simultaneously ${ }^{5}$.

Quoting Gallupe et al., "synergy can occur in electronic brainstorming groups through the sharing of ideas by way of the computer screen" $(1992,353)$. It is believed that this technique can achieve such synergy because it eliminates or at least minimizes the effects of production blocking and evaluation apprehension inherent in traditional, face-to-face brainstorming (Gallupe, Bastianutti, and Cooper 1991; Gallupe et al. 1992). Group members can share their ideas immediately upon conception without having to wait for a turn to contribute, and they can be held anonymous during the ideation session which reduces their identifiability and, ultimately, their fear of being judged or criticized.

Early research by Gallupe, Bastianutti, and Cooper (1991) found that four-member electronic brainstorming groups were significantly more productive than groups of equal size who used non-electronic, face-to-face brainstorming methods to generate ideas. Moreover, it was found that the electronic groups were able to produce more ideas compared to the nonelectronic nominal groups, showing some initial signs of creative synergy. However, they also found that the electronic nominal groups produced slightly more ideas than the electronic interacting groups, indicating that the computer itself may have some sort of enhancing effect on ideational productivity.

Extending upon these findings, Gallupe et al. (1992) found that the performance of electronic brainstorming groups increased substantially as group size increased. They tested two-, four-, six-, and twelve-person groups in both electronic and non-electronic conditions and

\footnotetext{
${ }^{5}$ For a review of an electronic brainstorming system, which is part of an Electronic Meeting System (EMS) called GroupSystems, see Valacich, Dennis, and Nunamaker (1991).
} 
found that as the number of members increased, the per-person output fell steadily for the nonelectronic groups but remained constant for the electronic groups. Other research has also found that larger electronic brainstorming groups are more productive in comparison to non-electronic nominal groups, providing some evidence of synergy in ideational performance (Dennis and Valacich 1993). These findings support the argument that one of the main factors in facilitating these performance gains is group size. A meta-analysis by Dennis and Williams (2005) showed that as group size increases, the performance of electronic groups drastically improves beyond that of non-electronic groups. However, the effect is different for interacting and nominal groups. Dennis and Williams concluded that for very small groups (two to three members), face-to-face brainstorming proves more effective than electronic brainstorming; but, at sizes of four members and up, electronic brainstorming is superior. And in the case of nominal groups, the pattern is different showing that for group sizes between three and eight, the performance of nominal groups exceeds that of electronic brainstorming groups; but, this effect is reversed once membership increases upwards from eight, showing clear signs of creative synergy.

These group size effects can be explained by the differential influence of production blocking and evaluation apprehension, as mentioned at the beginning of this section. Consistent with the literature on conventional brainstorming (Bouchard and Hare 1970), it seems that increasing group membership in face-to-face interactions creates less speaking opportunity and enhances the blocking effects as a result. Since production blocking is almost non-existent in electronic brainstorming sessions, it is proposed that idea-generation is not affected allowing the groups to be continuously productive regardless of how many members there are in the group (Gallupe et al. 1994). Furthermore, it seems that evaluation apprehension may increase in faceto-face brainstorming groups when groups become larger because there are more people to lay 
criticism on one's ideas. But, in electronic brainstorming, group members can be held anonymous and there may be less evaluation apprehension as a result, which tends to actually diminish to a certain extent as group size increases (Connolly, Jessup, and Valacich 1990; Cooper et al. 1998).

However, it should be noted here that the results of studies on evaluation apprehension and the effects of anonymity are equivocal; some studies have shown that anonymity has no significant effect on the quantity and quality of ideas (Jessup, Connolly, and Galegher 1990; Valacich, Dennis, and Nunamaker 1992). But, as Cooper et al. (1998) point out, such studies are bound by certain weaknesses in their methodologies (such as small sample sizes) which limit their validity. They have been able to demonstrate in their study that anonymity does actually matter and it is an important consideration for understanding the synergy potential of interacting groups.

One of the issues with this past research, as is the case with the conventional brainstorming literature, is that the focus has been on the quantity of ideas produced without any real concern for quality. Barki and Pinsonneault (2001) addressed this issue by comparing the ideational performance of electronic brainstorming groups with that of non-electronic nominal groups on a number of quality measures. Overall, they found that nominal groups generated ideas at least as good as, and sometimes even better than, the electronic brainstorming groups. However, they conducted their experiment with groups containing only six members, and as has been shown in previous research (see Dennis and Williams 2005), interacting groups should have at least eight or more members to outperform their nominal counterparts. These findings do, therefore, support that smaller electronic brainstorming groups are ineffective for generating good, highquality ideas. 
In contrast to some of the positive findings that promote the use of large electronic brainstorming groups, Pinsonneault et al. (1999) argue that there are a number of additional performance loss factors that researchers are not attending to and should be considering as influential to idea-generation. These include distraction, attention, striving for originality, cognitive complexity, and cognitive dispersion. Electronic brainstormers can easily be distracted by all of the other contributing members' ideas as they are displayed on screen which may get in the way of generating new ideas and writing them down. In contrast, brainstormers may place more of their attention on thinking and writing their own ideas with disregard for the contributions of others during that time. Brainstormers may also strive for originality in which, similar to the distraction factor, more focus is placed on sifting through the list of ideas to avoid writing down something that has already been added, causing a block of any new idea production that could be in progress. The cognitive complexity of having to attend to reading, understanding, and interpreting others' ideas causes further blocking of idea production. And, finally, electronic brainstormers can lose track of their thoughts as the exposure to many other lines of thought are manifest in the idea-sharing process. This can ultimately reduce the efficiency at which idea-generation occurs because no one line of thought is exploited fully before moving onto the next line of thought and brainstormers may bounce back and forth from one to another in a chaotic manner.

Most of these additional inhibitory mechanisms unique to electronic groups may actually increase in effect when the size of the group increases. For example, with a larger group, there can be many more ideas documented and shared all at once which can increase distraction because there are more ideas to filter through. This is counter to the positive effects of group size on ideational performance as indicated in the literature (see Dennis and Williams 2005). 
Although Pinsonneault et al. (1999) call for deeper investigation of these mechanisms in conjunction with the other performance loss and performance gain factors, another technique has been developed to build off of the benefits of simultaneous idea-generation and communication while avoiding some of the detrimental factors associated with electronic brainstorming. This technique has been coined brainwriting.

\subsubsection{Brainwriting}

Brainwriting is a method of generating ideas similar to face-to-face brainstorming but with one specific rule: no talking. Group members share their ideas by writing them down and presenting them visually, either in text or graphic form (VanGundy 1988). This can eliminate or at least reduce production blocking; no one has to wait for a turn to speak and everyone can contribute their ideas at the same time. It has also been proposed that brainwriting can minimize evaluation apprehension "since the written format eliminates the need for public speaking and is typically more anonymous than oral brainstorming" (Paulus and Yang 2000, 78). Though true anonymity is not really possible with this method, the fear of criticism and judgment may become less prominent due to the change in the social dynamic.

Brainwriting actually refers to a family of techniques, all involving slightly different ways of sharing and presenting ideas. One such technique, which can be considered as the most typical form of brainwriting, is when the group gathers together around a table and are instructed to follow the conventional brainstorming rules (see Osborn 1963) while writing down their ideas on paper. Each member starts with a blank sheet and writes down one initial idea. Each piece of paper is passed along in one direction to the next person who then reads that idea and generates a new one, attempting to build off of the former. The ideas are written down and the sheets are passed along again where now the members are exposed to two ideas. Another new set of ideas 
are written down and passed along, and this process is repeated until the sheets end up back at the original members who started them. Each member reads over the list of ideas on their sheet and they then generate another idea which is written on a fresh piece of paper. This new sheet is sent around again and the cycle continues until the idea-generation session comes to an end.

Following this technique, Paulus and Yang (2000) have determined that brainwriting has great potential for facilitating creative synergy. They conducted a study whereby interacting and nominal groups of four members each were assigned to an idea-generation task in which each group was required to write their ideas on paper and follow the brainwriting process as described above. The results showed that the interacting groups produced significantly more ideas than the nominal groups. They also showed that when the participants were assigned to produce additional ideas alone in a second session (in a condition identical to that of the nominal groups), those who had previously participated in the interacting group session produced almost twice as many additional ideas compared to those who had only participated in the nominal group condition. This finding supports that cognitive stimulation occurred during the interaction with other members and was successful in enabling synergy to emerge. Other research has also found similar synergistic effects even for dyadic interactions (Coskun 2005).

As Coskun (2005) has indicated, brainwriting is a very structured approach in the sense that everyone in the group follows the same procedures and they are forced, in a way, to attend to the ideas of others. This is in contrast to electronic brainstorming whereby participants have the choice of either attending to the large pool of ideas generated or focusing more on their own idea-generation in disregard of what has been produced by the others. Paulus and Yang (2000) argue that this is one of the main advantages of brainwriting over electronic brainstorming. Group members are exposed to the ideas of others in a structured way which compels them to 
read the ideas and think about them. Moreover, the ideas are shared amongst each other in relatively small batches making it much easier to process the information, reducing the amount of cognitive resources devoted to filtering through and attending to the ideas, and allowing more of those resources to be spent generating new, creative ideas. So, in a way, it can be reasoned that brainwriting promotes a balance of idea-sharing and idea-generating.

One of the biggest concerns about the research revolving around the effectiveness of brainwriting, as well as the other methods of collaborative idea-generation (conventional brainstorming and electronic brainstorming), is that the ideational tasks being assessed are often disassociated with real-world problems (e.g., possible uses of a paper clip, Paulus and Yang 2000) and the samples that are tested are not designers, often being undergraduates in psychology or some other non-design field. Therefore, recent attempts have been made in design research to address this problem by applying such techniques as brainsketching to collaborative teams rooted in real design problems.

\subsubsection{Brainsketching}

Brainsketching is a form of the general brainwriting technique which uses sketching as the primary means of recording and communicating ideas instead of sentential writing (van der Lugt 2002). As mentioned by van der Lugt, "there are vital differences between the ways designers usually work and the ways in which traditional tools for stimulating creativity are set up" (2000, 505). The tools and techniques that exist predominantly rely on written or spoken forms of communication and this is in contrast to the visual expression, such as sketching, that is so important in design practice. 
Initial research by van der Lugt (2002) has compared the ideational performance of design teams using brainsketching with those using conventional brainstorming (with post-it notes). The results of this study showed that those who used brainsketching as a means of ideation produced significantly less ideas than those who used brainstorming, but the ideas that were produced had many more links and connections with earlier ideas. This suggests that brainsketching does not facilitate the generation of a large amount of ideas but can facilitate greater creativity and the generation of good ideas due to its ability to help team members build off of each other's ideas. This facilitation of greater creativity was further supported by a later study evaluating the same ideational techniques (van der Lugt 2005).

Recent research by Linsey and Becker (2011) has also addressed the effectiveness of brainsketching in design ideation, but has done so more in line with the synergy framework that is relevant to this thesis. By comparing the performance of design teams using various versions of brainwriting and brainsketching to those in nominal groups who brainstormed alone, they found that the interacting groups were able to produce a significantly greater number of ideas than nominal groups. However, they found this to be most true when the teams used a combination of sketching and writing and shared their ideas by rotating them around the group rather than displaying them altogether at once. Furthermore, they found that the quality of ideas increased with sketching, but this was effective for both interacting and nominal groups showing that there were no significant differences between them. So, based on this study, there seems to be some evidence of synergy in design team performance when using brainsketching, but only for the quantity of ideas produced and not necessarily the quality.

Although van der Lugt (2002) has alluded to the possibility of successfully using brainsketching in a more interdisciplinary context with members from other non-design 
disciplines, there has been no empirical research done in assessing its effectiveness in such situations. Moreover, just as van der Lugt (2002) states, non-designers tend to disqualify themselves from being able to successfully sketch their ideas. They often times have little belief in their ability to communicate in such a visual manner. And when they do end up gaining the courage to sketch, they tend to be inclined to immediately accept the first idea that they sketch as the main direction for further ideation. So, despite the argument that non-designers can use brainsketching effectively if given the proper direction and guidance, it may not be the best method for facilitating creative synergy in interdisciplinary collaboration.

This then raises the question: Is there a good idea-generation technique suitable for facilitating creative synergy in an interdisciplinary context? In other words, is there a method of collective ideation that can overcome the challenges of interdisciplinary collaboration and aid in the generation of good, creative boundary spanning ideas? The answer to this question may be yes and it is called speedstorming.

\subsubsection{Speedstorming}

Speedstorming is a very recent development whereby the processes of brainstorming and speed dating are merged together. This technique has been developed by Grossman and his colleagues (Hey et al. 2009; Joyce et al. 2010) at the Center of Integrated Nanomechanical Systems at U.C. Berkeley as a means to promote new, creative collaborations amongst interdisciplinary researchers in the field of nanoscience. Just as with speed dating, equal numbers of different disciplines (rather than different genders) are paired together to share information regarding their research interests (rather than their romantic interests) in hopes of finding potential collaborative research partners (rather than romantic partners) to cross disciplinary boundaries and tackle creative and innovative research problems. Participants are 
given a short period of time to interact and brainstorm one-on-one with a member from another discipline to share information and generate ideas before switching to the next person in order. A round-robin format is used whereby one group of individuals (e.g., engineers) would rotate through to meet each member of another group of individuals (e.g., biologists), one at a time. This technique attempts to improve upon the processes of group brainstorming and other interactive methods of collaboration by attending to three key elements: structure, time limits, and one-on-one interactions (Hey et al. 2009).

\subsection{Structure and Time Limits}

"Speedstorming is a structured social interaction" (Hey et al. 2009, 79). This structure is provided by having a specific goal and purpose for the interaction, such as finding potential collaborators or generating ideas to solve certain problems. Participants of a speedstorming session are aware of these goals and this awareness guides them to keep the conversation focused and relevant. This structure also includes the mixing of people with different expertise and knowledge. The participants are forced to communicate with those from other disciplines providing greater opportunity for successful interdisciplinary exchange. Unlike traditional group brainstorming where members can free-ride on the efforts of others and not contribute to the task at hand, this cannot be done using speedstorming and members must actively take-part in the interaction.

Additionally, the structure of a speedstorming session makes sure that each participant of one group interacts with each participant of the other group. This is proposed to maximize an individual's exposure to various perspectives and ideas which ultimately increases the chances of cognitive stimulation and creative thinking. According to Hey et al. (2009), brainstorming may result in discussion revolving around one idea or topic for too long even if there are other ideas 
or topics that are lingering in the minds of some group members. This is not the case with speedstorming and it is ensured that participants are exposed to at least as many different ideas or topics as there are pairings in the session.

Part of the speedstorming structure is the enforcement of short time limits. A short time limit of five minutes or so can minimize the risks of working with other diverse people where clashes of personality and interests can lead to detrimental conflicts and reduced productivity for the given task. Short time limits also help focus the conversation during interaction. It encourages the participants to utilize the little bit of time effectively and "get to the point" with what it is that they are trying to accomplish. Moreover, short interactions leverage the innate human ability to assess a situation without having to filter through vast amounts of information. This comes down to what Gladwell calls "thin-slicing", which he describes as "the ability of our unconscious to find patterns in situations and behavior based on very narrow slices of experience" $(2005,23)$. It is about tapping into the adaptive unconscious; the part of the brain that quickly processes a lot of the data that is needed to function as human beings and allows for very quick judgments to be made with little information and little conscious thinking. So, by enforcing a short time limit on the speedstorming interactions, participants have to rely on this thin-slicing and their adaptive unconscious in order to make decisions in regards to the task at hand, whether it is assessing potential collaborators or generating ideas to solve a problem.

\subsection{One-on-One Interactions}

Speedstorming relies on one-on-one interactions for a number of reasons (Hey et al. 2009). First, the dyadic encounters keep the participants fully engaged and attentive to the discussion. This relates to what Goffman (1963) calls "focused interaction" whereby all attention is focused between the two participants. Second, one-on-one interactions can minimize the effects of status 
and hierarchy. According to Sutton and Hargadon (1996), larger brainstorming sessions are often times "status auctions" whereby individuals will compete for status as the best designers or engineers. Although this is viewed as being a positive aspect and that the friendly competition can enhance motivation, there are also status losses and negative emotions that result from such competitive auctions. The lack of observers in one-on-one encounters helps reduce these negative influences. Third, in a similar regard, dyadic interactions help reduce evaluation apprehension and social loafing. Participants are encouraged to be more open because there are much fewer observers to evaluate and criticize one's ideas and their efforts are identifiable so participants should have more motivation to contribute.

Fourth, one-on-one interactions also help minimize the effects of production blocking, which is the most powerful mechanism of productivity loss in group brainstorming. Since there are only two participants partaking in the discussion, there are greater opportunities to speak and to share one's thoughts with much less waiting time. Participants are able to speak 50-percent of the time, on average, compared to 10-percent of the time in a ten-person brainstorming group for example.

Lastly, dyadic interactions are less likely to suffer from the unique challenges of interdisciplinary activity. Any prejudice one may have about other disciplines can be minimized because the interaction becomes more personal allowing the participants to look beyond the typical stereotypes that may exist. Since there is no audience during the interaction, the pressure to defend one's discipline or denigrate another is diminished as well. In regards to language barriers and communication issues that exist within an interdisciplinary situation, one-on-one encounters also allow for immediate questioning and clarification of terms or assumptions that 
may be confusing to the opposing individual, rather than having to wait for a break in the conversation or until the end of a session.

As proposed by Hey et al. (2009), these key factors of structure, time limits, and one-onone interactions provide many benefits over traditional brainstorming techniques and other conventional collaboration methods, as discussed above. However, these assumptions are based mostly on anecdotal information and there have only been a few empirical investigations thus far to validate these assumptions and assess the effectiveness of speedstorming as a tool for interdisciplinary collaboration.

\subsection{Empirical Research on Speedstorming}

All of the research that has been done to date on speedstorming has been done by Grossman and his colleagues (Hey et al. 2009; Joyce et al. 2010) in the context of enhancing interdisciplinary collaborations in the field of nanoscience research. As reported by Hey et al. (2009), they have conducted a total of five pilot studies in which they ran workshops in multiple settings, including a social event at a conference and other organized events with established interdisciplinary research groups and selective disciplinary participants. In each event, participation ranged from twelve to thirty-five individuals with durations between one to two hours. The participants were required to produce a joint research proposal title (i.e. topic) during each short round of the speedstorming sessions and these topics were then assessed for their creativity and interdisciplinary uniqueness.

Preliminary findings of these early studies have shown great potential in the use of speedstorming for generating ideas and assessing potential collaborators. Hey et al. state that "while many submitted proposal titles were the result of a simple melding of each others' 
research areas, preliminary analyses by domain experts have shown a high number of exciting and creative topics" $(2009,80)$. Furthermore, participant responses to the speedstorming sessions and its process were quite positive and there was a lot of enthusiasm for utilizing speedstorming in future events. Much of the responses reflected that the speedstorming sessions were fun to take-part in, informative of other discipline's perspectives, effective for learning about others' interests and sharing ideas, and revealing of one's own research and ideas in the sense that the continuous knowledge exchange makes one think differently about their material. There were also some mixed responses in regards to the time constraints that were placed on each round of the speedstorming sessions. Some people felt that the time pressure was helpful because it kept the participants focused whereas others felt that it was too quick and there was not enough time to share knowledge and come up with a good output.

The most recent empirical study on speedstorming is that presented by Joyce et al. (2010). In this study, speedstorming was compared to brainstorming to assess the effectiveness of each in their abilities to connect and qualify collaborators and to produce high-quality ideas. The experiment was organized as an event that was held before a university-sponsored grant competition for innovative ideas, with a focus on the category of 'bio-innovation' ${ }^{\text {, }}$. There were 27 participants, all graduate students from engineering and biology. These participants were split into two groups of equal engineers and biologists, and each group was assigned to a different method of collaboration - one for speedstorming and the other for brainstorming. The speedstorming group rotated through seven engineer-biologist encounters of five minutes each whereas the brainstorming group used the four brainstorming rules (see Osborn 1963) to collaborate for a total of 50-minutes. At the end of the sessions, the participants filled out a

\footnotetext{
${ }^{6}$ 'Bio-innovation' is a burgeoning interdisciplinary field that attempts to mimic or employ biological phenomena to produce practical effects (Joyce et al. 2010, 60).
} 
survey in which they rated their experience and the people they had met during the session. The groups then switched to try the other method of collaboration; however, the data from this second session was not included in the analysis due to participant attrition.

The results of this study, based on the survey responses, were consistent with the past pilot studies using speedstorming, as mentioned above. Participants had many positive things to say about the speedstorming process and their experience using it. In contrast, their reactions to brainstorming were not so positive. The majority of the responses were that the lack of a "prompt" was challenging and that the group members seemed to be on "different pages". It was noted that the process was a bit scattered and seemed to lack some sort of form or structure. The participants also mentioned that there were lulls at points during the interaction and that some group members were not really contributing all that much. When the participants rated the people they had met during each session as to whether they would be interested in following up with them to do research or not, the results concluded that speedstorming was a much more effective method for qualifying potential collaborators as compared to brainstorming.

The more important findings from this experiment, in regards to this thesis, are those relating to the quality of the proposal ideas generated during the speedstorming and brainstorming sessions. In this study, quality was defined by four constructs: business and practical usefulness, specificity, demonstration of specialist knowledge, and comprehensibility. The results showed that speedstorming groups generated ideas with more specialist knowledge, less comprehensibility to an educated layperson, and similar specificity as compared to the ideas generated by the brainstorming groups. Business and practical usefulness proved to be an unreliable measure and was, therefore, removed from the analysis. These results suggest that while speedstorming and brainstorming allow for the production of ideas with no real differences 
in specificity, speedstorming allows for more specialized and technical ideas to be produced. Therefore, it has been concluded that speedstorming does allow participants to make more productive use of their expertise while capitalizing on their boundary-spanning intellectual resources to generate ideas. In quoting Joyce et al., the structure of speedstorming results in "a higher potential for generating creative, high-quality interdisciplinary ideas" $(2010,64)$, and this is the value that this technique brings to the search for creative synergy in ideational collaboration.

\subsection{SUMMARY}

This chapter has provided an extensive review of the pertinent literature revolving around the topic of creative synergy in interdisciplinary design collaboration. There were two major sections that have introduced important definitions relevant to this thesis research as well as the empirical findings of several studies that have tackled some aspect of creative synergy in team performance. The first section focused on creativity and the defining characteristics of the construct itself, idea-generation as a process, and creative ideas as the embodiment of creativity. The second section discussed synergy in team performance, specifically focusing on ideational performance when using techniques such as traditional brainstorming, electronic brainstorming, brainwriting, and brainsketching. Furthermore, it introduced a new technique called speedstorming and discussed the implications it has for enhancing interdisciplinary collaboration and idea-generation.

Based on this literature review, it becomes clear that there is a need to find some applicable technique that will aid in the development of creative solutions to complex problems while building off the diversity of knowledge and perspectives that are inherent in an interdisciplinary design team. Although group brainstorming is used extensively by many organizations - even 
extremely successful design firms like IDEO - it has been proven time and time again that it is not a good technique to use when trying to achieve creative synergy. Electronic brainstorming has shown some benefits, but these tend to get masked by other inhibitory mechanisms that act on larger teams interacting over computers. Brainwriting has shown great potential for creative synergy, but the limited attention and research findings have not been enough to confirm its true value. Brainsketching has also shown great potential except that it may only be beneficial when the team is made up of all designers who are well-equipped to communicate in a visual manner. The latest technique called speedstorming has shown some preliminary findings that attest its suitability for interdisciplinary collaboration. Furthermore, its structure and process suggest interesting benefits for such collaborative engagement which may have a positive contribution to enhancing the creativity of a design team. It is with this that the search for creative synergy may come to a halt and that speedstorming may become the next best tool in an organization's tool box. 


\section{CHAPTER 3}

\section{METHODS}

As organizations are faced with rapidly advancing technologies and an increasingly competitive and fast-paced marketplace, there is a growing need to be creative and to develop innovative products, services, and processes (Chen 2006; Farh, Lee, and Farh 2010). In order to do so, organizations need to utilize teams to take advantage of the synergies that may exist, making the outcome greater than what can possibly be done by the individual members on their own (Holtzman and Anderberg 2011). However, as problems become more complex, existing knowledge becomes inadequate in supporting innovative development (Leenders, van Engelen, and Kratzer 2003), sprouting the need for a more interdisciplinary approach to creative problemsolving. In this regard, it is argued that teams need to promote diversity amongst their members in terms of backgrounds, experiences, and perspectives, and share their diverse knowledge to maximize their creative performance and improve the quality of the design process (BadkeSchaub, Goldschmidt, and Meijer 2010).

This need for greater creativity and the establishment of diverse, interdisciplinary teams has led to a number of questions: How can interdisciplinary design teams take advantage of their diversity to enhance their creative performance? How can these teams improve their collaborative efforts to realize the synergy that they were put together exclusively to achieve? More specifically, how can these teams generate good, creative ideas that no one member alone could have produced? These general questions have been the starting point for the development of this thesis and have led to the refinement of the following research questions and hypotheses: 
Question 1: How do interdisciplinary interacting groups using speedstorming compare to equivalent nominal groups using individual brainstorming, in terms of their creative performance with respect to the quantity and quality of ideas produced? Hypothesis 1a: The interacting groups using speedstorming will generate more ideas than the nominal groups using individual brainstorming.

Hypothesis $1 b$ : The interacting groups using speedstorming will generate ideas of greater quality as compared to the nominal groups using individual brainstorming.

Hypothesis Ic: The interacting groups using speedstorming will generate more good ideas than the nominal groups using individual brainstorming.

Question 2: How does speedstorming facilitate or inhibit creative synergy in interdisciplinary design collaboration for idea-generation tasks?

To answer these questions and test the hypotheses, a mixed methods approach was used by which both quantitative and qualitative data were collected. A quasi-experimental betweensubjects two-group design was employed in two workshops to compare the quantitative differences in idea-generation between the interdisciplinary interacting groups using speedstorming and the equivalent nominal groups using individual brainstorming. The workshops consisted of the two treatment conditions in which four groups of six participated in both conditions for two different topics, counterbalanced across the workshops - two groups were assigned to the nominal group condition for the first topic and to the interacting group condition for the second topic; and the other two groups were assigned to the nominal group condition for the second topic and to the interacting group condition for the first topic. In addition, behavioural observations, a survey questionnaire, and semi-structured interviews were conducted to gather supporting qualitative information.

The ideas that were produced during the workshops were then evaluated by condition-blind evaluators on counts of non-redundant ideas and three measures of idea quality: novelty and 
originality, utility and effectiveness, and feasibility. This allowed for the appropriate comparisons between the interacting groups' performance and that of the nominal groups' in answering the first research question and testing the three associated hypotheses. The notes from the observations and the interviews, along with the responses to the survey questionnaires, were reviewed and coded, leading to the emergence of specific themes and patterns that provided insights into answering the second research question.

\subsection{SETTING}

The workshops took place in a midsize room located on the Carleton University campus in Ottawa, Ontario. The room was very open with moveable furniture that allowed for adaptations of the space and its organization. There were several tables, chairs, and dividers that were set up in a manner to facilitate both group and individual activities throughout the duration of the study. As can be seen in figure 3.1, the room was split into two halves. Each half was equipped with six small tables pushed up against the walls and three larger tables centered in the middle, all separated from one another. The small tables were set up for the individual activities whereas the larger tables were set up for the group activities.

It was important to try to maintain the same layout on both sides of the room so that those participants who were on the one side did not have a different experience of their environment as compared to those on the other side. It was also maintained that there were no objects or materials laying on shelves or hanging on walls that could have potentially influenced the participants' thoughts and actions during the study. The goal was to keep the room setting as sterile as possible to avoid any confounds from the participants' surroundings. 

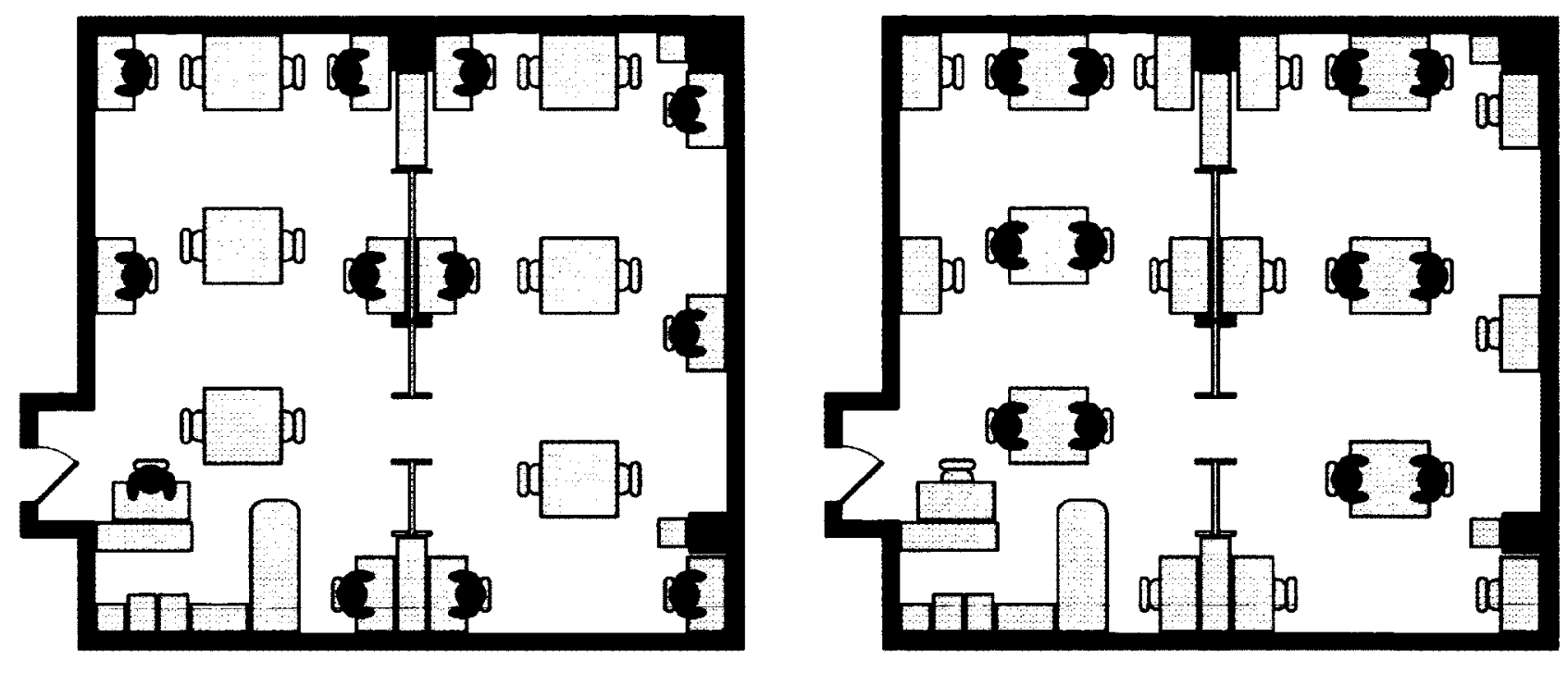

Figure 1. Workshop Room Layout for the Individual (left) and Group (right) Activities

Within a number of days after the workshops were finished, several interviews were conducted in a few different locations on the Carleton University campus. Most of the interviews were held in the same room as the workshops, but others were held in a café, a small boardroom, and one of the undergraduate Industrial Design studios. The locations were chosen by the participants for reasons of convenience and comfort. The researcher wanted the interviews to be relaxed and casual as more of an informal discussion, so it was deemed important that the participants felt comfortable in the given setting.

\subsection{SAMPLE}

The sampling method that was used for this study was a combination of purposive and convenience sampling. It was important that the participants selected to participate in this study were representative of a diverse, interdisciplinary mix and that each treatment group within the sample were matched to be as similar as possible to one another. This matching was essential in order to make more accurate comparisons between the groups in later analyses. Therefore, it 
was necessary to be selective of those who were considered the right fit for each of the groups. Furthermore, due to reasons of feasibility and accessibility, participants were also selected based on their interest, their willingness, and their availability to participate in the study.

The participants were recruited by means of recruitment posters around the university campus, targeted emails to students from specific departments, and word of mouth. Some candidates were not accepted for participation as there were certain criteria that had to be met. The main criterion was that there needed to be a certain amount of people from each discipline, and there needed to be the same disciplines in each treatment group. Other criteria that were considered were the year of study and gender; however, due to feasibility, these factors were accommodated as best as possible after recruitment during the purposive assignment process.

A total of 24 participants were selected and matched to create four groups of six diverse individuals. Each group consisted of three members from Industrial Design and three members from other varied disciplines (see table 1 for participant distribution). These other disciplines included Cognitive Science, Psychology, Human-Computer Interaction (HCl), Information Technology, Civil Engineering, Aerospace Engineering, Biochemistry, Biology and Chemistry, Law and Sociology, and Kinesiology. As can be seen in table 1, Group A and Group B, and Group C and Group D, were matched as best as possible with each other. The participant sample ranged from first-year through to fourth-year undergraduate students with a few recent alumnae (within 1 to 2 years out) and first-year masters students. The participants ranged in age from 19 to 45 years of age, with a mean age of 22.8 years $(\mathrm{SD}=5.2)$. 
Table 1. Participant Demographics and Groupings

\begin{tabular}{|c|c|c|c|c|}
\hline GROUP & DISCIPLINE & YEAR OF STUDY & AGE & GENDER \\
\hline \multirow{6}{*}{ A } & Industrial Design & $2^{\text {nd }}$ & 20 & Female \\
\hline & Industrial Design & $3^{\text {rd }}$ & 21 & Female \\
\hline & Industrial Design & $4^{\text {th }}$ & 21 & Male \\
\hline & Information Technology & $3^{\text {rd }}$ & 21 & Male \\
\hline & Psychology & $3^{\text {rd }}$ & 21 & Female \\
\hline & Law \& Sociology & $3^{\text {rd }}$ & 22 & Female \\
\hline \multirow{6}{*}{ B } & Industrial Design & $1^{\text {st }}$ & 25 & Female \\
\hline & Industrial Design & $3^{\text {rd }}$ & 20 & Female \\
\hline & Industrial Design & Alumni $^{1}$ & 45 & Male \\
\hline & Cognitive Science & $4^{\text {th }}$ & 22 & Female \\
\hline & Psychology & $3^{\text {rd }}$ & 21 & Female \\
\hline & Kinesiology & Alumni $^{1}$ & 25 & Male \\
\hline \multirow{6}{*}{$\mathrm{C}$} & Industrial Design & $2^{\text {nd }}$ & 21 & Male \\
\hline & Industrial Design & $2^{\text {nd }}$ & 27 & Female \\
\hline & Industrial Design & $3^{\text {rd }}$ & 19 & Male \\
\hline & Engineering, Civil & $4^{\text {th }}$ & 21 & Female \\
\hline & Psychology \& HCI & $1^{\text {st }}$ Masters & 25 & Male \\
\hline & Biology \& Chemistry & Alumni ${ }^{1}$ & 22 & Female \\
\hline \multirow{6}{*}{ D } & Industrial Design & $2^{\text {nd }}$ & 21 & Female \\
\hline & Industrial Design & $3^{\text {rd }}$ & 20 & Female \\
\hline & Industrial Design & $3^{\text {rd }}$ & 23 & Male \\
\hline & Engineering, Aerospace & $2^{\text {nd }}$ & 19 & Male \\
\hline & Psychology \& HCI & $1^{\text {st }}$ Masters & 26 & Female \\
\hline & Biochemistry & $2^{\text {nd }}$ & 19 & Male \\
\hline
\end{tabular}

'Within 1 to 2 years out from studies.

\subsection{INTERVENTION}

The independent variable in this study was the type of session conducted (individual vs. group). In the individual session, participants generated ideas alone in isolation, independent of 
one another's presence and contributions. This session is referred to as the nominal group condition. In the group session, participants interacted and worked together to generate ideas by following the procedures of the speedstorming technique. This session is referred to as the interacting group condition. By manipulating the session type, it was possible to compare the ideational performance between the nominal group condition and the interacting group condition in order to gauge whether or not speedstorming facilitated creative synergy in the ideageneration process.

The dependent variables measured in this study were idea quantity, idea quality, and the number of good ideas generated. Quantity refers simply to the number of non-redundant ideas produced. All of the ideas from the individuals that made up a team were pooled together with any duplicate ideas counted only once. This was necessary to allow for a comparison of idea production between the individuals working together (interacting groups) and the individuals working alone (nominal groups). Although it was once believed that quantity leads to quality (Osborn 1963), it has been shown that this is not necessarily the case and it is, therefore, important to assess the quality of ideas as well (Briggs and Reinig 2007; 2010; Reinig and Briggs 2008).

For this study, idea quality was defined by three factors: novelty and originality, utility and effectiveness, and feasibility. Novelty and originality refer to ideas that are new, unusual, unfamiliar, or fresh, and that are different from that which has been done before. Utility and effectiveness refer to ideas that are useful, fit for a purpose, or advantageous, and that are effective in solving the problem at hand. Feasibility refers to ideas that are capable of being done, executed or implemented. These factors have been used extensively as measures of the 
quality and creativity of ideas in many previous studies (e.g., Barki and Pinsonneault 2001; Diehl and Stroebe 1987; 1991; Miura and Hida 2004; Taylor, Berry, and Block 1958).

Furthermore, it has been argued that the main goal of brainstorming and collective ideation is to produce many good ideas and that this is a more appropriate measure of quality (Dennis et al. 1997; Diehl and Stroebe 1987). A good idea was defined as one having a quality score above a certain cut-off point. This cut-off point was determined by the overall average of the quality scores for all ideas produced by all groups (for a given topic). So, the number of good ideas for each group was measured by counting the ideas that had a quality score greater than the overall average for that topic. This is consistent with past research addressing idea quality in brainstorming activities (Barki and Pinsonneault 2001).

\subsection{MATERIALS}

The materials that were used for this study included ball-point pens and blank paper for writing down or sketching out ideas, as well as a briefing script and information sheets to inform the participants of the purpose of the study, the relevant topics being addressed, and to provide facts and examples for ideational inspiration (see appendix $A$ and appendix $B$ for samples of the briefing script and the information sheets respectively). These information sheets were created also to align the participants' understanding and awareness of the given topics in an attempt to provide a common reference point for each individual. All participants received the same materials in both treatment conditions.

The two topics that were selected for this study are presented in table 2 . These two were chosen from a bank of topics that were developed by the researcher in preparation for the workshop activities. The topics were developed to be suitable for interdisciplinary collaboration 
whereby each participant would have an equal opportunity to contribute knowledge to the given task. Each topic was reviewed and discussed with the researcher's advisor and co-advisor in deciding upon which were the most suitable for this study. The Modern-Day Slavery and Human-Trafficking topic was developed in conjunction with a campaign effort organized by a student group on campus whereby they were planning a week-long campaign to raise awareness of such issues. It was chosen based on the mutual benefits it provided for this study and for the campaign efforts, as well as the fact that it is potentially controversial in nature and may have introduced a different collaborative dynamic. On the other hand, the Restaurant Experience topic was chosen in contrast to the former as something that is less controversial, more familiar and relatable, and may perhaps allow for more creative thinking. The goal was to have two diverse topics in order to increase the external validity and the generalizability of the findings.

Table 2. Workshop Topics with Associated Titles, Problems, and Questions

\begin{tabular}{|c|c|c|}
\hline & TOPIC 1 & TOPIC 2 \\
\hline Title & $\begin{array}{l}\text { Modern-Day Slavery and Human- } \\
\text { Trafficking }\end{array}$ & Restaurant Experience \\
\hline Problem & $\begin{array}{l}\text { Modern-day slavery and human- } \\
\text { trafficking is a major global issue and } \\
\text { many people are not aware of such } \\
\text { atrocities that occur in the world } \\
\text { today. }\end{array}$ & $\begin{array}{l}\text { With the plans of introducing a new } \\
\text { restaurant in the Ottawa area, the } \\
\text { competition is heavy and there is a need } \\
\text { to be innovative and to provide dine-in } \\
\text { customers with an experience that is } \\
\text { different from what exists today. }\end{array}$ \\
\hline Question & $\begin{array}{l}\text { How can we raise awareness of } \\
\text { modern-day slavery around the } \\
\text { Carleton University campus? }\end{array}$ & $\begin{array}{l}\text { What can we do to enhance the dine-in } \\
\text { experience of this new restaurant } \\
\text { venture? }\end{array}$ \\
\hline
\end{tabular}




\subsection{MEASUREMENT INSTRUMENTS}

There were four measurement instruments used for this study: one for the quantitative data and the other three for the qualitative data. The quantitative measure was the generated ideas as written or hand-drawn on paper by the participants. The three qualitative measures were behavioural observations during the workshops, a post-workshop survey questionnaire, and postworkshop interviews with select participants. These instruments were chosen as a means of triangulating the data to increase the validity of the findings. Each instrument is discussed in the following sections.

\subsubsection{Participant-Documented Ideas}

The ideas that were produced during each workshop session were documented by having the participants manually write or draw them out on the blank paper that was provided. The participants were asked to write or draw their ideas in any way that they felt best for communicating the content of each idea. These documented ideas were then analyzed postworkshop by using the Consensual Assessment Technique (Baer and McKool 2009) whereby two evaluators assessed the quantity and quality of the ideas produced in each condition of the study. This technique is the most typical method for assessing creative products (i.e. ideas) and is considered as one of the best methods for doing so (Baer and McKool 2009; Hennessey and Amabile 2010; Kaufman, Plucker, and Baer 2008).

The Consensual Assessment Technique has been well validated throughout its wide use in creativity research (Baer and McKool 2009; Kaufman, Plucker, and Baer 2008). Studies have shown that this technique is a reliable method, having yielded good to excellent inter-rater reliability estimates in the range of 0.70 to 0.90 (Amabile 1983; 1996; Baer 1993; Hennessey 1994). 


\subsubsection{Behavioural Observations}

The goal of the observations was to take note of certain behaviours that were occurring during the idea-generation sessions which may have been valuable in explaining why speedstorming and interdisciplinary team interaction facilitates or inhibits creative synergy. These behaviours included signs of excitement, enjoyment, laughter, smiling, boredom, frustration, heavy discussion, silence, body language, and any other action or expression worthy of noting. The observations were conducted by the researcher by taking written notes and photographs throughout the course of each workshop activity.

The types of behaviours and actions that were considered relevant for the observations were discussed with the researcher's advisor and co-advisor. This allowed for the researcher to conduct the observations having been primed to look for those particular behaviours and actions. Furthermore, the observation protocol was developed with consideration of the observational methods as outlined by Berg (2007).

\subsubsection{Survey Questionnaire}

The survey questionnaire was developed by the researcher to gather basic demographic information and to tap into the perceptions of the participants about their performance during the workshop, their preferred method for generating ideas, their overall position on working with other people, and their belief in the effectiveness of using speedstorming to collaborate with other disciplines. The participants received the survey questionnaire immediately following the completion of the speedstorming session and were asked to fill them out alone (see Appendix C for a sample of the survey questionnaire). 
The survey questionnaire was reviewed by the researcher's advisor and co-advisor and slight changes were made to the questions to improve its structure and ultimately increase its reliability.

\subsubsection{Interviews}

Semi-structured interviews were conducted with select participants after the workshops were finished. The goal was to dig deeper into the perceptions of the participants about ideageneration in design, collaborating with others in an interdisciplinary way, and the use of speedstorming as an idea-generation technique. There were nine base questions with an initial, informal question asking "What did you think of the workshop?" (see Appendix D for a sample of the interview questions). Some additional probing questions were also asked during each interview, such as "Can you explain that in a bit more depth?" or "What do you think about the communication between disciplines?”.

The interview questions were developed and employed following a similar semi-structured qualitative interviewing method as that outlined by Berg (2007). These questions and the interviewing procedures were pilot-tested with a volunteer participant and slight modifications were made to enhance the reliability of the interview protocol.

\subsection{PROCEDURES}

This study consisted of two idea-generation workshops held on two consecutive days. Both workshops occurred in the late evenings and were conducted in the same manner. At the beginning of the workshops, refreshments were served in an attempt to create a relaxed, comfortable atmosphere and to "break the ice" in a sense since most of the participants did not know each other. Once everyone arrived and got a chance to grab a snack and a drink, the 
participants were briefed by the researcher as to what the study was about, why the study was taking place, and how the study was going to proceed. The consent forms were handed out, read through collectively, and then signed by each participant (see Appendix $E$ for a sample of the consent form). This briefing process also included specific details about how to generate and document ideas and how those ideas would be evaluated upon completion, with some examples of what characterize good versus poor quality ideas (see Appendix A for full briefing script). Each participant received a small card with a number on it representing their participant number. This number was specifically for identifying the idea-sheets and the survey questionnaire answers for each participant in the study, and for management purposes later on in the data analysis process. At the end of the initial briefing, the researcher answered any questions that the participants had before continuing on with the study.

The 12 participants in each workshop were then split into two groups of six and were assigned to a specific side of the room. There were two idea-generation sessions for these workshops - the first being the individual session for the nominal group condition and the second being the group session, or the speedstorming session, for the interacting group condition.

For the first session, each participant was asked to seat themselves at one of the small tables that were pushed up against the walls, separated away from each other. The information sheet for the first topic (Restaurant Experience for the first workshop and Modern-Day Slavery and Human-Trafficking for the second workshop) was handed out and reviewed together. The participants were prompted to be creative and open their minds, to think outside the box, and to explore the uncommon. They were also told that no idea is wrong and that each will have value somewhere along the idea-generation process. The researcher answered any last questions before signalling the idea-generation session to begin. 
A total of 15 minutes was allotted for the individual session and a one-minute warning was signalled near the end to allow for the participants to finish their last idea and mark it down on paper. Throughout the 15 minute session, the researcher made observations of the participants' actions by taking hand-written notes and photographing the individuals in the process. At the end of the 15 minutes, the researcher prompted the participants to write their participant number on the back of their idea-sheets and then proceeded to collect them. Once all of the sheets were collected, the participants were told to take a short 5-minute break before the second session began.

After the break, the participants were asked to seat themselves at the larger tables in the centers of each side of the room, with the Industrial Design students seated along one side of the tables and the other students seated along the other side. There was no specific seating order and the participants chose a seat at random. The information sheet for the second topic (Modern-Day Slavery and Human-Trafficking for the first workshop and Restaurant Experience for the second workshop) was handed out and reviewed together. The participants were, again, prompted to be creative and open their minds, to think outside the box, and to explore the uncommon, and were told that no idea is wrong and that each will have value somewhere along the idea-generation process. The researcher answered any last questions before signalling the speedstorming session to begin.

Three rounds of 5 minutes each were allotted for the speedstorming session with a total of 15 minutes altogether. The participants interacted one-on-one at each table and generated ideas together, writing or sketching out the ideas on their own individual sheets. A one-minute warning was signalled near the end of the 5-minute round to allow for the participants to finish their last idea and mark it down on paper. After the 5 minutes were up, the researcher prompted 
the Industrial Design students to stay seated while the other students rotated to the table next to them in an orderly fashion, taking their idea-sheets with them. This same procedure occurred for another two rounds so that each Industrial Design student had interacted with each of the other students in their group. Again, observations were made by the researcher throughout the session by taking notes and photographing the participants in action. After completing the three rounds, the researcher then directed the participants to write their participant number on the back of their idea-sheets and proceeded to collect them. Once all of the sheets were collected, a survey questionnaire was handed-out and the participants were asked to answer the questions alone (see Appendix $\mathrm{C}$ for a sample of the survey questionnaire).

After the survey questionnaires were completed and handed back, the researcher thanked all of the participants for their participation and encouraged them to enjoy more refreshments before leaving the workshop for the night. At this point, select individuals were approached by the researcher and asked to partake in an interview. These individuals were selected based on their discipline and some things that were noticed during the observations (e.g., very excited and talkative or very quiet). The interviews were scheduled for various dates, times, and places within a week after the workshop in order to accommodate the participants' schedules.

A total of eight interviews were conducted one-on-one between the researcher and the participant. Four of the interviews were held in the same location as the workshop whereas two were held in a café, one in a small boardroom, and another in one of the undergraduate Industrial Design studios. The audio from the interviews were recorded using a built-in laptop microphone and typed-notes were taken during the discussion. The interviews consisted of nine questions with an initial, informal question asking "What did you think of the workshop?" (see Appendix D for a sample of the interview questions). Some additional probing questions were also asked 
during each interview when the participant gave too short of an answer or brought up something interesting that was not addressed in the questions that were prepared.

\subsection{DATA ANALYSIS}

After the data were collected from the workshop activities, the behavioural observations, the survey questionnaires, and the interviews, the data analysis procedures consisted of two steps. The first step was to analyze all of the quantitative data that resulted from the workshop activities to answer the first research question and to test the associated hypotheses. The second step was to analyze all of the qualitative data from the other three measurement instruments to answer the second research question in support of the quantitative findings.

\subsubsection{Quantitative Data Analysis}

The quantitative data were analyzed through the use of the Consensual Assessment Technique (Baer and McKool 2009) whereby a number of evaluators independently assessed the generated ideas on measures of quantity and quality. There were three evaluators for this process: two evaluators were design professors from the School of Industrial Design at Carleton University and the third was an industrial designer and graduate student in the Masters of Design program, also at Carleton. First, the two professors independently evaluated the generated ideas on measures of quantity and quality at an individual level. They reviewed each participant's idea-sheets and filtered out all redundant ideas for each participant alone. They then rated the quality of the non-redundant ideas on their novelty and originality, their utility and effectiveness, and their feasibility using 7-point scales for each factor, where 1 represented very low and 7 represented very high (see Appendix $\mathrm{F}$ for a sample of the evaluation guidelines). 
The two evaluations were then compared to assess inter-rater reliability using the Case 2 Intraclass Correlation Coefficient (ICC) statistic (Shrout and Fleiss 1979) for the quantity and quality measures, and a basic percentage of agreement calculation for quality. For idea quantity, it was found that there was good to excellent reliability estimates of 0.83 for the Modern-Day Slavery and Human-Trafficking topic and 0.94 for the Restaurant Experience topic. However, when it came to quality, the reliability estimates were extremely low ranging from 0.04 to 0.42 for the different quality dimensions included in the evaluations. Table 3 presents the ICC indexes for these measures.

Although the inter-rater reliability estimates for idea quality are very low based on the ICC indexes, the percentage of agreement between the evaluators does show support for the reliability of the assessments. Since the evaluations were conducted on a 7-point scale, the evaluators were considered to be in agreement when each quality rating fell within two points of each other. For example, if evaluator one gave a feasibility score of 6 and evaluator two gave a feasibility score of 4 , they would be considered in agreement on this rating. This approach has been adopted from previous research studies using 7-point rating scales on idea quality (Barki and Pinsonneault 2001). Accordingly, it was found that the evaluators were in agreement for $82 \%$ of the idea ratings on average. The specific agreement scores are presented as follows in table 3.

Table 3. ICC Indexes and Agreement Scores for Idea Quantity and Quality Measures

\begin{tabular}{lcccccccccc}
\hline & \multicolumn{3}{c}{ SLAVERY TOPIC } & \multicolumn{4}{c}{ RESTAURANT TOPIC } \\
\hline & Quantity & \multicolumn{3}{c}{ Quality } & \multicolumn{4}{c}{ Quantity } & \multicolumn{3}{c}{ Quality } \\
\hline & N\&O & U\&E & F & Total & & N\&O & U\&E & F & Total \\
\hline ICC & 0.83 & 0.42 & 0.04 & 0.19 & 0.28 & 0.94 & 0.35 & 0.27 & 0.24 & 0.18 \\
$\begin{array}{l}\text { Agreement } \\
\text { Scores }\end{array}$ & 0.74 & 0.78 & 0.88 & 0.80 & & 0.82 & 0.88 & 0.83 & 0.84 \\
\hline $\begin{array}{l}\text { Note: N\&O represents the Novelty and Originality dimension, U\&E represents the Utility and Effectiveness } \\
\text { dimension, F represents the Feasibility dimension, and Total represents the mean of all three dimensions. }\end{array}$
\end{tabular}


The two evaluators were then brought together to discuss the divergences in their evaluations and to come to a consensus on what ideas were redundant or not and what the scores were to be for each divergent rating. This provided a final set of ideas and scores that were then brought into a second phase of the evaluations. In this second phase, all of the participants' ideas were arranged into their respective groups and the third evaluator was required to filter out the redundant ideas within each group. All of the ideas that were considered the same were aggregated into one idea and the average of those quality ratings combined was used as the new quality score for that aggregated idea. This process provided a final set of ideas and scores that were then used for the hypothesis testing.

\subsubsection{Hypothesis Tests}

In order to test the three hypotheses in relation to the first research question, Welch's two sample t-tests with unequal variances were conducted to compare the ideational performance of nominal groups brainstorming alone to that of interacting groups using speedstorming. This was done following the average member criterion ${ }^{7}$ followed by the best member criterion ${ }^{8}$ when it was deemed appropriate. For the first hypothesis, in regards to idea quantity, the total number of non-redundant ideas produced by each group in each condition was counted. From this, the sample means and variances for each condition were calculated for the two topics separately and as an overall aggregate. The t-score $(t)$ and degrees of freedom $(d f)$ were then calculated followed by a calculation of the probability value $(p)$. This allowed the researcher to determine

\footnotetext{
${ }^{7}$ The average member criterion compares the mean performance of the interacting groups to the mean performance of the nominal groups.

${ }^{8}$ The best member criterion compares the mean performance of the interacting groups to the mean of the best members' performance from each nominal group multiplied by the number of members. The notion is that the nominal groups being compared to are made up entirely of best members.
} 
whether the comparison results were statistically significant and whether the hypothesis was supported or not.

For the second hypothesis, relating to the quality of ideas, the means and variances were calculated for each of the three quality dimensions separately and as an overall average. This was done again for the topics separately and combined. Then, $t, d f$, and $p$ were determined and the hypothesis was concluded as being supported or not.

Finally, for the third hypothesis regarding the number of good ideas, the average overall quality of all ideas in all conditions for all groups was calculated as the cut-off point for determining what counts as a good idea. A frequency count was then conducted whereby all ideas that had an overall quality score above the cut-off value were counted. Again, the sample means and variances for each condition were calculated for the two topics in isolation and aggregated, followed by calculations of $t, d f$, and $p$ and the determination of whether the hypothesis was supported.

\subsubsection{Qualitative Data Analysis}

Once the quantitative data was analyzed and the first research question was answered, the qualitative data was addressed to answer the second question. The data from all three measurement instruments used were analyzed in a very similar manner. First, the researcher conducted a basic review of the notes, responses, audio recordings, and photographs to get a general sense of the content in each. Then the researcher conducted a more thorough analysis of the information whereby the data collected from each instrument was reorganized and categorized into different themes and patterns. This was done by typing out all of the notes from the observations and interviews, and the responses from the survey questionnaires, into a 
spreadsheet document. Each individual note and response was identified by its source with a particular marking. These were then printed out onto paper and cut-up into their individual units. Each unit was reviewed one by one and placed into a certain area representing a particular category. Sticky notes were used to denote key terms and phrases in response to the emerging themes and were placed above the categorized note piles. Once all of the notes and responses were reviewed and categorized, the process was done again to reorganize the data into more meaningful themes. This was done numerous times until clear, concise themes and patterns emerged.

Although the photographs from the behavioural observations did not provide much depth in the data analysis process, they were still used to provide any visual support to the observation notes. Furthermore, the audio recordings provided verbal support to the interview notes whereby the researcher listened to certain sections of the interviews to pull specific quotes and to clarify any ambiguities in the written observations. 


\section{CHAPTER 4}

\section{RESULTS}

The results of the quantitative and qualitative data analyses are presented in this chapter. Descriptive and inferential statistics provided answers to the first research question whereas coding of the questionnaire responses, the interview notes and recordings, and the behavioural observation notes produced key insights into themes and patterns that were emerging in response to the second question.

\subsection{QUANTITATIVE RESULTS}

In order to answer the first research question and to test the proposed hypotheses, the mean ideational performances of nominal groups were compared to that of equal interacting groups using speedstorming. A Welch's two sample t-test with unequal variances was conducted for each variable measured to assess the significance of any differences that were found between them. This was done both following the average member criterion and the best member criterion (where appropriate) to indicate any existence of weak and strong forms of synergy. The following sections present the results from this comparison for the measures of idea quantity, idea quality, and number of good ideas.

\subsubsection{Idea Quantity}

Table 4 presents the mean total number of non-redundant ideas produced in both the nominal and interacting group conditions. These means are presented for the two topics separately as well as for the overall aggregate. As can be seen, interacting groups using speedstorming to generate ideas produced more ideas overall $(\mathrm{M}=35.75, \mathrm{SD}=2.63)$ in 
comparison to nominal groups $(M=29.50, \mathrm{SD}=13.92)$; however, these results were not significant ${ }^{9}, t(3)=0.883, n s$. This may be due to the evident performance differences between the two idea-generation topics used in the study. When the groups generated ideas for the Modern-Day Slavery and Human-Trafficking topic, nominal groups seemed to have produced slightly more ideas $(M=41.50, S D=2.12)$ than the interacting groups $(M=33.50, S D=0.71)$. Although these mean differences were not very significant, $t(1)=5.060, \mathrm{p}<0.12$, those for the Restaurant Experience topic were, $t(1)=41.000, \mathrm{p}<0.02$, but in support of the interacting groups. The groups that used speedstorming generated more than twice as many ideas $(M=$ $38.00, \mathrm{SD}=0.00)$ than the nominal groups $\operatorname{did}(\mathrm{M}=17.50, \mathrm{SD}=0.71)$, indicating the existence of weak synergy in ideational productivity.

Since the interacting groups showed traces of weak synergy for the Restaurant Experience topic, another step was taken to analyze the possibility of strong synergy by following the best member criterion for conducting the comparison. Table 5 presents the mean total number of ideas produced in the interacting group condition and in the nominal group condition as an estimate based on the performance of the best members in each nominal group. The results

Table 4. Mean Quantity of Ideas Produced

\begin{tabular}{|c|c|c|c|c|c|c|c|}
\hline TOPIC & CONDITION & $n$ & $M$ & $S D$ & $t$ & $d f$ & $p$ \\
\hline \multirow{2}{*}{ SLAVERY } & Nominal & 2 & 41.50 & 2.12 & \multirow{2}{*}{5.060} & \multirow{2}{*}{1} & \multirow{2}{*}{0.124} \\
\hline & Interacting & 2 & 33.50 & 0.71 & & & \\
\hline \multirow{2}{*}{ RESTAURANT } & Nominal & 2 & 17.50 & 0.71 & \multirow{2}{*}{41.000} & \multirow{2}{*}{1} & \multirow{2}{*}{0.016} \\
\hline & Interacting & 2 & 38.00 & 0.00 & & & \\
\hline \multirow{2}{*}{ OVERALL } & Nominal & 4 & 29.50 & 13.92 & \multirow{2}{*}{0.883} & \multirow{2}{*}{3} & \multirow{2}{*}{0.442} \\
\hline & Interacting & 4 & 35.75 & 2.63 & & & \\
\hline
\end{tabular}

${ }^{9}$ Statistical significance was determined by using the conventional significance (alpha) level of 0.05 ; however, it must be noted that, since the sample size is small, there is less statistical power to identify substantive effects in the study. By using the alpha level of 0.05 , we conducted conservative tests of the primary hypotheses. 
Table 5. Mean Quantity of Ideas Produced Following the Best Member Criterion'

\begin{tabular}{cccccccc}
\hline TOPIC & CONDITION & $n$ & $M$ & $S D$ & $t$ & $d f$ & $p$ \\
\hline \multirow{2}{*}{ RESTAURANT } & Nominal & 2 & 54.00 & 25.46 & \multirow{2}{*}{0.889} & \multirow{2}{*}{1} & \multirow{2}{*}{0.537} \\
& Interacting & 2 & 38.00 & 0.00 & & \\
\hline
\end{tabular}

'The best member criterion takes the average of the best members' performance from each nominal group and multiplies that by the number of members (6), resulting in a final sum that represents a nominal group made up entirely of best members.

indicate that the interacting groups using speedstorming did not produce more ideas $(\mathrm{M}=38.00$, $\mathrm{SD}=0.00)$ than the nominal groups made-up of best members $(\mathrm{M}=54.00, \mathrm{SD}=25.46)$, signifying that strong synergy was not achieved, $t(1)=0.889, n s$.

\subsubsection{Idea Quality}

Table 6 presents the mean overall quality ${ }^{10}$ scores for the ideas produced in both the nominal and interacting group conditions. Again, these means are presented for the two topics separately as well as for the overall aggregate. The results indicate that there were no significant differences between nominal $(M=4.80, S D=0.27)$ and interacting groups $(M=4.54, S D=0.15)$ when it comes to the overall quality of ideas produced, $t(4)=1.734, \mathrm{p}<0.16$. Despite this lack of significance, however, there is a small but consistent difference in support of nominal groups across both the Modern-Day Slavery and Human-Trafficking topic (for nominal groups, $\mathbf{M}=$ $4.84, \mathrm{SD}=0.17$; for interacting groups, $\mathrm{M}=4.65, \mathrm{SD}=0.10 ; t(1)=1.388, n s)$ and the Restaurant Experience topic (for nominal groups, $M=4.77, \mathrm{SD}=0.42$; for interacting groups, $M$ $=4.42, \mathrm{SD}=0.10 ; t(1)=1.109, n s)$.

\footnotetext{
${ }^{10}$ Idea quality represents the average of the scores given for the three quality dimensions used: Novelty and Originality, Utility and Effectiveness, and Feasibility. The score values range from 1 to 7 .
} 
Table 6. Mean Quality of Ideas Produced

\begin{tabular}{|c|c|c|c|c|c|c|c|}
\hline TOPIC & CONDITION & $n$ & $M$ & $S D$ & $t$ & $d f$ & $p$ \\
\hline \multirow{2}{*}{ SLAVERY } & Nominal & 2 & 4.84 & 0.17 & \multirow{2}{*}{1.388} & \multirow{2}{*}{1} & \multirow{2}{*}{0.398} \\
\hline & Interacting & 2 & 4.65 & 0.10 & & & \\
\hline \multirow{2}{*}{ RESTAURANT } & Nominal & 2 & 4.77 & 0.42 & \multirow{2}{*}{1.109} & \multirow{2}{*}{1} & \multirow{2}{*}{0.467} \\
\hline & Interacting & 2 & 4.42 & 0.10 & & & \\
\hline \multirow{2}{*}{ OVERALL } & Nominal & 4 & 4.80 & 0.27 & \multirow{2}{*}{1.734} & \multirow{2}{*}{4} & \multirow{2}{*}{0.158} \\
\hline & Interacting & 4 & 4.54 & 0.15 & & & \\
\hline
\end{tabular}

\subsubsection{Number of Good Ideas}

Table 7 presents the mean total number of good ideas ${ }^{11}$ produced in both the nominal and interacting group conditions for the topics separately and as an overall aggregate. For the topics combined, nominal groups seemed to have produced more good ideas $(M=16.50, S D=5.26)$ than the interacting groups using speedstorming $(\mathrm{M}=14.25, \mathrm{SD}=1.71)$; however, this was not statistically significant $t(3)=0.814, n s$. Similar to the idea quantity measure, there were opposing results across the topics. As can be seen, interacting groups produced more good ideas $(M=15.50, S D=0.71)$ in comparison to nominal groups $(M=13.00, S D=5.66)$ when generating ideas for the Restaurant Experience topic whereas the opposite occurred when generating ideas for the Modern-Day Slavery and Human-Trafficking topic (for nominal groups, $\mathrm{M}=20.00, \mathrm{SD}=1.41 ;$ for interacting groups, $\mathrm{M}=13.00, \mathrm{SD}=1.41$ ). The mean difference found for the Restaurant Experience topic was not significant, $t(1)=0.620, n s$, but that which was found for the Modern-Day Slavery and Human-Trafficking topic was, indeed, significant, $t$ $(2)=4.950, \mathrm{p}<0.04$.

\footnotetext{
"A good idea is one that has an overall quality score that is above a certain cut-off point. This cut-off point is determined by the the overall average of the quality scores for all ideas produced by all groups (for a given topic). So, the number of good ideas for each group is measured by counting the ideas that had a quality score greater than the overall average for that topic (Barki and Pinsonneault 2001).
} 
Table 7. Mean Number of Good Ideas Produced

\begin{tabular}{cccccccc}
\hline TOPIC & CONDITION & $n$ & $M$ & $S D$ & $t$ & $d f$ & $p$ \\
\hline \multirow{2}{*}{ SLAVERY } & Nominal & 2 & 20.00 & 1.41 & \multirow{2}{*}{4.950} & 2 & 0.039 \\
& Interacting & 2 & 13.00 & 1.41 & & & \\
\multirow{2}{*}{ RESTAURANT } & Nominal & 2 & 13.00 & 5.66 & & & \multirow{2}{*}{0.620} \\
& Interacting & 2 & 15.50 & 0.71 & & & \\
\multirow{2}{*}{ OVERALL } & Nominal & 4 & 16.50 & 5.26 & & & \\
& Interacting & 4 & 14.25 & 1.71 & 0.814 & 3 & 0.475 \\
\hline
\end{tabular}

\subsection{QUALITATIVE RESULTS}

Since the results from the quantitative data analysis provided mixed answers to the first research question, the second question can be split into two relevant parts. First is why speedstorming facilitates creative synergy, and second is why it inhibits creative synergy. In order to answer these two parts, the survey responses and notes from the interviews and observations were analyzed and coded. This process resulted in the emergence of specific themes and patterns that provided meaningful insights into answering the question and supporting the quantitative findings. Each of these themes are presented in the following sections in regards to understanding both the facilitation and inhibition of creative synergy when using speedstorming to generate ideas.

\subsubsection{Speedstorming Facilitates Creative Synergy}

The results from the quantitative analysis have shown that at least weak synergy is achievable, in terms of idea quantity, when using speedstorming to collaborate on ideageneration tasks. There are several reasons why this is possible and it may be due to the belief in the benefits of collaboration and idea-sharing, the type of topic or problem being addressed, and 
the forced interaction and time constraints inherent in the structure of the speedstorming process. These key themes are discussed in the following sections.

\subsubsection{Importance of Idea-Sharing}

As one participant alluded to, speedstorming "promotes interactive sharing of ideas". This has been found to be a key tenet in support of why speedstorming may facilitate creative synergy. Participants had a strong positive bias towards group work and the ability to produce more and better ideas through collaborative idea-sharing and the use of speedstorming. When asked the question "In general, which method of idea-generation do you believe allows for more creativity and results in better quality ideas? Briefly explain why", all but one participant expressed that the ability to bounce ideas off of another person and to share ideas allows for the generation of more and different ideas that one would not be able to think of alone. For example, participants stated that "bouncing ideas off each other sprouts many more ideas"; "[speedstorming] allows for exchange of ideas triggering new ideas which is not possible in the individual idea-generation condition"; and "hearing about someone else's ideas fuels you to think of new situations - it alters your train of thought and stream of consciousness, allowing you to come up with ideas that may not have been generated alone".

There were also some comments made about the benefits of having different perspectives from other disciplines to influence the generation of ideas. For example, one participant noted that "you can feed off each other's ideas, expand together, and they give you another perspective". Another participant stated that "we can come up with ideas that are unique, which one person may not think of - the different areas of study allow a broader range of ideas". Furthermore, another participant noted that "it's great to work with people from other disciplines because they view the world a bit differently and may bring up things you would never think of'. 


\subsubsection{Topic/Problem Dependency}

Many participants indicated that the topic had a strong influence on the generation of ideas and the interaction within each pairing session. Specifically in the case of facilitating creative synergy, participants expressed that the Restaurant Experience topic was very open, allowing everyone to make a significant contribution. For example, one participant who had speedstormed on the Restaurant Experience topic stated that "the topic was more open and didn't make for issues in the process of collaboration".

The participants also expressed that it was a fun topic to work on which made for engaging discussion during collaboration. In quoting one participant, "the restaurant topic was more exciting than the awareness campaign for human trafficking - it allowed for more playful and fun ideas". Another stated "I felt like you could be more creative". Even some of the participants who used speedstorming to generate ideas for the Modern-Day Slavery and HumanTracking topic commented that the Restaurant Experience topic was better and that it would have been good to collaborate with others on it. One such participant noted that "it was easier to come up with things for the first topic [restaurant] - it would've been better to do the first topic with speedstorming".

It was also noted from the behavioural observations that the speedstorming sessions with the Restaurant Experience topic were much more animated and lively. The room was loud with excited discussion and the participants seemed to have been having a lot of fun while collaborating. Behaviours such as laughing, animated gestures, and lack of silence were noted as positive expressions in support of facilitating creative synergy. 


\subsubsection{Forced Interaction}

There were several remarks made in regards to the benefits of one-on-one interactions and the point that participants are forced to contribute to the collaboration in a speedstorming session. One particular interview quote asserts that,

It's kind of like working in a group, but you're also just one-on-one ... it kind of forces you to speak your ideas; like, if you are in a group of five people, and the four other people are conversing, there's nothing really forcing you to talk about your own ideas. I think the fact that, even though you are still in a group of six, but it's just one-on-one at the time, it forces you to talk and it forces you to think of new ideas.

Other participants also mentioned similar things such as "when in a larger group, some people get nervous and don't speak up"; "[speedstorming] is more intimate and it forces you to say something"; and "[speedstorming] is more effective than large groups because you have to speak and not just agree with someone else". Some comments were also made regarding the benefits of this forced interaction for aiding in the collaboration between different disciplines. One participant stated that speedstorming "forces discussion across disciplines", and another participant mentioned that it allows them to build on each other's ideas, "especially in this case where people from different disciplines, and perhaps different thinking methods, are forced to develop ideas".

The behavioural observations provided some insight into this as well. It was noted that, in some pairs, one of the participants would question the other as to their thoughts and opinions, forcing them in a way to contribute some knowledge or idea. The participants would call on each other to take a turn in speaking and sharing their ideas and thoughts, ultimately forcing discussion and idea-generation. 


\subsubsection{Time Dependency}

Time seemed to be another influencing factor in the facilitation of creative synergy when using speedstorming. One of the participants stated that "a lot more ideas can be generated in the same amount of time, resulting in a broader view of the topic and better ideas". Another participant noted that "it's really good to get ideas out as quickly as possible ... the time constraint helps". Furthermore, another participant stated that "you can move from idea to idea really quickly because of the time constraint, so we don't really have time to point out the negatives in an idea, we just move on to the next one". There were also some comments alluding to the point that the specific time limit for each speedstorming session was of a good amount. As an example, one participant mentioned that "it had a good amount of time for us to get our ideas out before slowing down".

Although it was not brought up much in the interviews or questionnaire responses, one participant made reference to the time constraint and how it prevented her from experiencing any bias or issues that may result from collaboration with diverse disciplines. During an interview, she stated that "you don't really notice the different biases, I guess, since it's so fast". She also said “yesterday's session was so quick that we didn't really think about it [the diversity] - just, 'this is a person who's talking to me'".

\subsubsection{Speedstorming Inhibits Creative Synergy}

The quantitative analysis has also demonstrated that speedstorming may, in fact, inhibit creative synergy for idea-generation tasks. A number of themes have been identified to provide insight into why this may be the case. These themes relate to the type of topic or problem being addressed, the evaluation apprehension and lack of confidence resulting from the group members' 
personalities and dispositions towards collaboration, the time constraints inherent in the speedstorming process, and the desire for more interaction and extended collaborative exchange.

\subsubsection{Topic/Problem Dependency}

As was mentioned earlier, several participants had conveyed that the topic and problem being considered was highly influential in the generation of ideas and the way they interacted together during the speedstorming sessions. Unlike the findings formerly presented, there were many indications that the Modern-Day Slavery and Human-Trafficking topic caused an inhibition of creative synergy, resulting in the nominal groups outperforming the interacting groups by a significant difference (in terms of number of good ideas generated). During one of the interviews, when asked "Were there any challenges in using speedstorming to collaborate and generate ideas?", the participant responded by saying that the slavery topic was a bit tough to generate ideas for and that it was the topic itself which seemed to be the most challenging part of the speedstorming process.

Some of the survey questionnaire responses also alluded to this with statements such as "I personally found it harder to think of more original/creative ideas for modern-day slavery" and "I think speedstorming could be more effective, but the topic was much more intense - easier to ideate for less consequential topics". This latter comment introduced the point that the ModernDay Slavery and Human-Trafficking topic was more consequential and, perhaps, controversial in its subject matter, which was also supported by another participant's statement saying that "being told that the speedstorming problem was affiliated with a Christian organization influenced me with a certain attitudinal bias towards the exercise". One participant noted that the topic gave a sense that some ideas or opinions might actually offend their partner and this made them approach the discussion with a bit of caution. 
The behavioural observations also revealed a difference between the two topics used in the study. In contrast to the Restaurant Experience topic, the speedstorming sessions with the Modern-Day Slavery and Human-Trafficking topic were quieter and less animated. It seemed that the participants would often times find themselves sitting in silence, staring at the information sheets, trying to think of an idea or waiting for their partner to share an idea. The behaviours that were noted consisted of shyness, nervousness, and short periods of silence. However, it was noted that discussion became more fruitful during the second round.

Many of the participants expressed that the interaction between different disciplines is influenced by the topic as well. They indicated that the success or failure of collective, interdisciplinary idea-generation relies on the type of problem being addressed, its scope, and its complexity. Although these were general comments about interdisciplinary collaboration and the considerations of the topic or problem, it became evident from the data that the topics used for the study did not necessarily utilize the participants' disciplinary knowledge but, rather, relied more on their personal experiences. As one participant mentioned in an interview, it was like "normal, person-to-person interaction". When the participant was asked "When you were coming up with ideas and you were sharing ideas, were you pulling anything from Industrial Design?", the response was "no, not really - it was all about personal experience".

\subsubsection{Evaluation Apprehension and Personality Factors}

There were several insights from the qualitative data that conveyed signs of evaluation apprehension and the tendency for participants to hold back their thoughts and ideas in fear of being judged or criticized when using speedstorming to collaborate. Some participants expressed that they prefer working alone because of this. For example, one participant stated "I like working alone because sometimes I may not feel confident enough to discuss my ideas with 
others, so working alone allows me to execute my thoughts without that fear". Another stated that there is "less judgment by others, [and you] don't need to be concerned with criticism". In similar regards, there were comments suggesting that the social aspects of speedstorming and the one-on-one interactions were a challenge. Such comments as "you don't want them to judge you" and "it was a little intimidating not knowing them" provided support for this notion. In fact, two participants suggested that there should be a warm-up round or session in order for everyone to introduce themselves to each other and build more of a "comfort zone" for the collaboration.

One interesting thing about this was that the signs of evaluation apprehension were not coming from any of the industrial design participants but, rather, from the participants in psychology, cognitive science, and civil engineering. However, there was one industrial design participant who mentioned that "you're kind of more self-conscious about your ideas ... like, if I was working with an industrial design student, I wouldn't want to propose crappy ideas as much as I would if I was with a non-design student". This statement was also supported by one of the non-design participants who said "I guess there is an element of 'oh, this person is a designer" followed by "if you're just one-on-one, the person more experienced will just be like, 'my idea's better, I'm a designer, I know what I'm talking about'".

A big part of why evaluation apprehension existed comes down to personality and the dispositions the participants had towards collaboration and social interaction. As one participant stated, "working in groups can be beneficial depending on the type of person they are". Other participants supported this statement by arguing that personality influences the process and that the type of people can shape the collaboration and, ultimately, the focus of the ideas generated. One of the participants in an interview stated that 
With one person, it seemed like she was really shy. It's hard to brainstorm with someone who is really shy because ... I don't really know how to explain it but, you feel like the creative juices are not flowing or anything.

Another interviewee stated that,

There is a difference between how comfortable the different people are at generating ideas I think, but I don't think that really had to do with the process or anything, but more about who the person is. Like, I did find it easier to work with some of the participants to generate ideas than it was with others.

Furthermore, one of the participants made reference to her own personality and described herself as more of the "type" to work alone rather than in groups. She regarded herself as not being confident in a collaborative situation and feeling like her ideas might not be good enough to bring up. Another participant mentioned that she experienced a bit of anxiety in the speedstorming sessions and that this came down to her sensitivity in social interactions.

\subsubsection{Time Dependency}

Although time seemed to be helpful in facilitating creative synergy, it was also found to be a possible avenue for inhibiting it. Several participants commented that the speedstorming process was too fast and there should have been more time to generate ideas and collaborate. For example, one of the participant's survey responses stated that "speedstorming may be too quick to fully form ideas". Another participant responded in an interview that "I think on a longer time span with more individuals, I would have come up with more ideas". A particularly insightful quote from one of the interviews states,

I feel like the whole timing situation is what makes it less effective. I think having that time to actually think about it, and step away from the ideas and come back to it - I think that's a really important process when you're discussing concepts. Especially when you're collaborating just because with different groups of people, you have to view the topic and kind of understand the other person's point of view as well. 
One thing that seemed to surface from the data was that there was an expressed need for more time in the later rounds. Participants brought up the point that, with each switch of partners, there was a period of time at the beginning of each round in which the ideas from the previous discussion were introduced and there was no idea-generation occurring. One of the participants recommended that maybe a progression of 5-minutes, 6-minutes, and 6-minutes would have been suitable for the three rounds, having that extra minute in the beginning to share the previous ideas. Another participant alluded to a progressive increase in productivity with each round and stated,

I think that, with each session, maybe the time could have been increased because with each session, we had more and more ideas. The first session was good because it was short and you get your mind thinking of the topic, the second a bit more because you are expanding on each other's ideas, and then the third one was collaborating to come up with even more ideas.

Another thing that seemed to come up a number of times was the fact that writing down the ideas took quite a bit of time away from interacting and collectively generating ideas. For example, one participant stated "I found that I was literally writing the whole time; like, I was talking to them about ideas but it did kind of slow down the process a bit". Another participant expressed that there was not enough time to write down the ideas. She said that she talked a lot during each session and would often forget to write the ideas down on paper. This insight was also supported by the behavioural observation data. It was noted that there were several short, silent periods in each pairing session where there was no discussion occurring and each member was writing down their ideas. It seemed that almost half of the time was spent writing. 


\subsubsection{Limited Interactions}

Parallel with the dependency of time, there were insights from the data suggesting that there were not enough rounds in the speedstorming session and the participants would have liked to have collaborated and interacted with more people. Consistent across most of the responses, participants suggested that two or three more rounds (i.e. having groups of eight or ten) would have been good and could have aided in better idea-generation. For example, one participant stated that "more ideas may have developed with more people and more time" while another stated that "more people would allow for more creativity".

There were also some comments made about having more interaction with other disciplines and more diverse people. As an example, one participant mentioned that it "would be nice to get different input from different disciplines". Another participant stated "I only worked with three people, and all were designers ... [it] would be interesting to speedstorm with people in the actual restaurant industry". It is important to note here that these comments were coming from the non-design participants because they only interacted with the industrial designers. However, some of the industrial design participants expressed interest in being able to collaborate with the other industrial designers as well. All of this is in support of the insight that there was a concern for the lack of interaction due to the limited number of rounds.

\subsection{SUMMARY}

The results have shown that speedstorming can both facilitate and inhibit creative synergy, and that this may depend on a number of influential factors. The quantitative analysis indicated that, for the Restaurant Experience topic, interacting groups using speedstorming were able to significantly outperform nominal groups brainstorming alone when it came to the measure of idea quantity, and that they were able to produce slightly more good ideas (although not at a 
significant level). In contrast, the results show that nominal groups were able to outperform the interacting groups when working on the Modern-Day Slavery and Human-Trafficking topic whereby the nominal groups produced more good ideas (at a significant level) and more ideas in general with slightly greater quality (but not at a significant level).

The qualitative analysis indicated that there are four facilitative and four inhibitive factors that may have influence on the existence of creative synergy when using speedstorming. The four facilitative factors include the importance of sharing ideas, the dependency of the topic or problem, the forced interactions that are structured into the speedstorming process, and the dependency of the inherent time constraints. Two of these factors also seem to contribute to the inhibition of creative synergy, which includes the dependency of the topic or problem and the dependency of the time constraints. Additionally, the existence of evaluation apprehension and the effects of personality, and the limited interactions that occur during the speedstorming session are also inhibiting factors. In this next chapter, these results will be discussed in greater detail and each finding will be examined to provide an understanding as to how creative synergy is fostered or hindered when using speedstorming to collaborate. 


\section{CHAPTER 5}

\section{DISCUSSION}

The results from this study have shown that speedstorming can facilitate creative synergy in interdisciplinary design collaboration, but it can also inhibit it, depending upon a number of key factors. These factors have been found to relate to the sharing of ideas, the type of topic or problem being addressed, the forced interactions and time constraints inherent in the speedstorming process, the evaluation apprehension resulting from social interaction and the influence of personality, and the limited number of interactions there are when conducting a speedstorming session.

This chapter is divided into two main sections: the first providing a discussion around the results that support the facilitation of creative synergy, and the second providing a discussion around the results that support the inhibition of creative synergy. Each section is broken down further into sub-sections specifically describing the interpretations of the research findings relevant to the major illustrative themes identified in the research.

\subsection{FACILITATING CREATIVE SYNERGY}

In answering the first research question - How do interdisciplinary interacting groups using speedstorming compare to equivalent nominal groups using individual brainstorming, in terms of their creative performance with respect to the quantity and quality of ideas produced? the results of the quantitative data analysis have indicated that speedstorming can facilitate creative synergy, at least for when the goal is to generate a large quantity of ideas. Those who used speedstorming to collaborate on the Restaurant Experience topic generated more than twice 
as many ideas as did those who brainstormed alone and pooled their ideas together. This was found to be statistically significant; however, it must be noted that the opposite was found for the Modern-Day Slavery and Human-Trafficking topic, although not at a significant level. Therefore, there was only partial support for hypothesis 1a (that interacting groups using speedstorming would generate more ideas than the nominal groups using individual brainstorming), dependent upon the topic in question. There was also a small but noticeable performance gain for speedstorming groups on the Restaurant Experience topic in regards to the number of good ideas (those above average in quality); however, this was not a statistically significant result and, therefore, did not provide enough evidence to support hypothesis 1c (that interacting groups using speedstorming would generate more good ideas than the nominal groups using individual brainstorming).

To further examine the nature of these findings, behavioural observations, survey questionnaires, and interviews were conducted and the data were analyzed in pursuit of answering the second research question: How does speedstorming facilitate creative synergy in interdisciplinary design collaboration for idea-generation tasks? Four major themes emerged from the analysis including the importance of idea-sharing, the dependency of the topic or problem, the forced interaction that occurs in one-on-one collaborations, and the dependency of time constraints that are part of the speedstorming structure.

\subsubsection{Importance of Idea-Sharing}

With no real surprise, there was a strong perception among the participants that being able to collaborate and share ideas is a very important process for generating more ideas, and ideas of better quality and creativity. These findings are consistent with much of the literature discussing the performance perceptions of collaborative ideation and group brainstorming (e.g., McGlynn et 
al. 2004; Paulus et al. 1993; Paulus, Larey, and Ortega 1995). Even though this is often referred to as the "illusion of group productivity" (Larson 2010; Paulus et al. 1993) or the "illusion of group effectivity" (Diehl and Stroebe 1991) whereby group members believe that they had performed much better than they actually did, recent empirical research has shown that ideasharing, if done in the right way, does enhance collective ideational performance (Kohn, Paulus, and Choi 2011). Therefore, it is possible that the sharing and combining of ideas has a strong influence on the enhanced ideational productivity of speedstorming groups.

There was also the perception that the interdisciplinary aspects of speedstorming and the sharing of ideas between different disciplines can enhance idea-generation by providing diverse perspectives which can trigger new thoughts and creative conceptions. As argued by Dennis and Valacich, "groups that are more heterogeneous with respect to task information and skills are more likely to experience synergy because they are less likely to have overlapping knowledge domains and redundant ideas" $(1993,535)$. This has been supported empirically in several studies (Kurtzberg 2005; Miura and Hida 2004; Diehl 1992, as cited in Stroebe and Diehl 1994), meaning that the diversity within the speedstorming groups and the sharing of diverse ideas could have contributed to the performance gains in ideational productivity.

\subsubsection{Topic/Problem Dependency}

What seemed to be one of the most influential factors in facilitating (and inhibiting) creative synergy was the type of topic being addressed. The participants acknowledged that the Restaurant Experience topic was much more open, fun, playful, and exciting, allowing for more creativity and more productive idea-generation. This dependency of the topic or problem is not a shocking discovery as it has been found before in other studies (e.g., Graham 1977; Harari and Graham 1975; Taylor, Berry, and Block 1958). Such studies have determined that brainstorming 
groups are able to generate more ideas when working on innocuous, trivial problems than when working on salient, realistic ones. Although the Restaurant Experience topic was developed to be as realistic as possible, it may have been perceived more fictional because the ideas were not being applied in any real sense. Therefore, the lack of pressure to produce implementable concepts may have promoted the speedstorming groups to be less hesitant and more productive.

Furthermore, the notion of playfulness seems to be a facilitating factor in ideational performance. This is in line with research revolving around the relations between creativity and play. It is argued that play can promote creativity and that it has a positive and powerful influence on the creative process (Mainemelis and Ronson 2006; Russ 2003). Mainemelis and Ronson even propose that "play gives birth to new ideas" $(2006,117)$. This influence of play essentially comes down to the role of affect in facilitating creative thinking.

Much research has shown that positive affect can enhance creativity (see Isen 1999). For example, Isen, Daubman, and Nowicki (1987) found that positive affect - as induced by a comedy film or a small gift of candy - improved creative performance on two different tasks. They concluded that creativity can be facilitated by a transient pleasant affective state. More recently, and in the context of work and organizational practice, Amabile et al. (2005) also found that positive affect relates positively to creativity at work. They determined that a positive affective state is an antecedent of creative thinking. Based on these findings, it is possible that the topic or problem being addressed can provide a foundation for inducing positive affect, ultimately resulting in greater ideational performance in the end. 


\subsubsection{Forced Interaction}

Speedstorming was developed specifically to have one-on-one dyadic interactions between collaborators. This was meant to keep them fully engaged and attentive to the discussions when collaborating (Hey et al. 2009). Part of this is also that the collaborators are forced, in a sense, to interact and to share ideas. Since there are only two members in the interaction, it is very obvious when one person is not contributing which may drastically minimize any social loafing or free riding effects that can occur in larger groups. The results from this study have supported this provision whereby the participants had expressed that the one-on-one structure forces them to speak and contribute something. It was also shown through the behavioural observations that the participants would prompt each other to share their ideas. So, this prompting and prodding of mutual interactions may motivate participants in speedstorming groups to be more productive and generate more ideas.

Another explanation may be that the participants felt a sense of friendly competition during the interaction, wanting to be just as or more creative and produce just as many or more ideas than their session partners. This increase in motivation has been found in previous research by Paulus et al. (1993) where brainstorming dyads improved their ideational performance when each individual was made aware that their partner had generated more ideas than themselves in prior sessions.

The results of this study also pointed to the benefits of dyadic encounters for the sake of interdisciplinary collaboration. The one-one-one structure may force discussion across disciplinary boundaries. Because there are only two collaborators, it is not possible to avoid this; there is no opportunity for the collaborators to shift their focus and discussion to others from the same discipline because they are not available to speak with. In this regard, it is possible that the 
diversity amongst the participants within each pairing allowed for the sharing of diverse thoughts and, ultimately, the generation of more ideas.

\subsubsection{Time Dependency}

Time was another factor that may be influential in both the facilitation and the inhibition of creative synergy. Specifically in the case of facilitation, the results indicated that the participants felt as if the time constraints were helpful in getting ideas out quickly and not allowing for any negative evaluations. There were also notions that the timing was good because it didn't allow for any slowing-down and the sessions were constantly productive. As was discussed in the literature review (section 2.2 .2 .8 .1 ), the time constraints are specifically implemented in the speedstorming process for similar reasons as evidenced by the qualitative data. Specifically, a short time limit is expected to help focus the conversation during interaction and encourage the participants to "get to the point" with their ideas effectively (Hey et al. 2009).

The short time limit is also expected to minimize the risks of working with other disciplines where detrimental conflicts can arise resulting in poor collaboration and a loss in performance (Hey et al. 2009). This point is supported by one of the participant's comments in an interview, stating that "you don't really notice the different biases, I guess, since it's so fast". It seems that there is not enough time for any major communication issues or prejudices to arise, which may be good for the sake of productivity. However, this lack of experiencing disciplinary biases might be due to the fact that the topics were very open and relied more on personal experience rather than any domain-specific knowledge. In any case, it is proposed that the structured time constraints may be a contributor to the production gains achieved when using speedstorming to generate ideas. 


\subsection{INHIBITING CREATIVE SYNERGY}

Going back to the first research question and the results from the quantitative data analysis, it was found that speedstorming can also inhibit creative synergy. In particular, there were statistically significant results indicating that individuals who brainstormed alone and pooled their ideas together for the Modern-Day Slavery and Human-Trafficking topic generated more good ideas (those above average in quality) than did the speedstorming groups. This provided some evidence contradicting hypothesis $1 \mathrm{c}$ (that the interacting groups using speedstorming would generate more good ideas than the nominal groups using individual brainstorming). Although not at a significant level, there was also a hint of performance loss on the overall quality of ideas across both topics, providing further evidence that is inconsistent with hypothesis $1 \mathrm{~b}$ (that the interacting groups using speedstorming would generate ideas of greater quality as compared to the nominal groups using individual brainstorming).

To further explore the nature of these findings, the flipside of the second research question - How does speedstorming inhibit creative synergy in interdisciplinary design collaboration for idea-generation tasks? - was answered by determining four other major themes that have come out of the qualitative data analysis. These themes include the dependency of the topic or problem, the existence of evaluation apprehension and the effects of personality, the dependency of time constraints inherent in the speedstorming process, and the limited interactions that occurred in the speedstorming sessions.

\subsubsection{Topic/Problem Dependency}

Just as the topic was described earlier as being influential in allowing creative synergy to flourish, it has been proposed to be equally as influential in stifling it. Some of the participants who used speedstorming for the Modern-Day Slavery and Human-Trafficking topic had 
expressed that this topic was more difficult to generate ideas for and that it didn't allow for as much creativity as the Restaurant Experience topic did. Although it may be true to some degree, this point on its own does not really support the fact that individuals who generated ideas alone outperformed the groups using speedstorming.

One possible explanation is that the topic is controversial in a way. It relates to a very powerful social issue and can be considered as a sensitive subject for some people. This was recognized by some of the participants and they acknowledged that it did have an influence on the ideas that they produced and shared. Part of this may be reflected in the apparent evaluation apprehension in speedstorming groups, which is discussed in the next section more thoroughly. The sensitivity of the subject may have caused the participants to withhold their ideas in fear of offending the other participants. Also, the topic was introduced as being part of a campaign effort hosted by a religious student group on campus, and this evidently introduced a bias from some participants into the idea-generation process.

Following on this latter point, one interesting thing that may have had an influence on the impairment of idea-generation is that the participants were told that their ideas for the ModernDay Slavery and Human-Trafficking topic had the potential of being implemented in the campaign program. The topic was actually selected in consideration of this campaign effort as an attempt to help their group come up with creative ways of raising awareness about the issues. In this regard, the participants' perceptions of the applicability and the relevance of the generated ideas may have been different for this topic in comparison to the Restaurant Experience topic. It is possible that this topic was approached more seriously as a result which may have inspired a different motivation. As was previously introduced, research has shown that when the topic is inherently salient or relevant to a particular real-world application, the ability to brainstorm is 
depressed and groups produce many fewer ideas in comparison to group performance on topics that are innocuous and irrelevant (Dillon, Graham, and Aidells 1972; Harari and Graham 1975; Graham 1977). So, there is a chance that this had some inhibiting effect on the speedstorming groups' ideational performance.

\subsubsection{Evaluation Apprehension and Personality Factors}

Evaluation apprehension was found to be a possible predictor of the poor performance of speedstorming groups. Many participants expressed that they often times feel a bit uncomfortable or intimidated in collaborative settings and not very confident with their ideas, so they hold them back in fear of being judged or criticized. Some had indicated that they preferred working alone for this reason. They also alluded to the fact that it depended upon their personality and what type of person they or the collaborators are. Based on this, it seems that personality factors and the dispositions the participants had towards collaborative group work and interacting with others they didn't know were quite influential in the generation of ideas.

Just as Camacho and Paulus (1995) have shown, people who have certain personality characteristics such as high social anxiety tend to generate many fewer ideas when brainstorming in groups as compared to when they generate ideas alone or to others who have low social anxiety. Although personality was not a variable measured in this study, it is very possible that this had a powerful impact on the ideational performance of speedstorming groups.

What is interesting about these findings is that the concerns for being judged and criticized were coming mainly from the non-design participants. There are two possible reasons why this might be. Firstly, industrial designers are typically trained to collaborate with others when generating ideas. They are very aware of brainstorming and the processes of sharing ideas with 
others in collaborative settings. They are constantly exposed to interactions with others, whether it is for idea-generation or for conducting research or doing user testing. So, in this sense, perhaps the industrial design participants were more experienced and comfortable with the social, interactive aspects of speedstorming. Secondly, the industrial design participants may have been viewed as "experts". In fact, this was alluded to by some of the non-design participants in the interviews. It seemed that these participants perceived the industrial designers to be better at generating ideas and more versed in the ideational process. It seemed that they felt as if the industrial designers were more knowledgeable and, therefore, were considered somewhat almighty. This was even indirectly evidenced through one of the industrial design participant's comments stating that "if I was working with an industrial design student, I wouldn't want to propose crappy ideas as much as I would if I was with a non-design student".

This latter reason can be connected to some of the research literature on brainstorming and evaluation apprehension. For example, Collaros and Anderson (1969) found that members of brainstorming groups tend to withhold certain ideas when other members of the group are perceived to be experts on the topic. There is a sense of greater pressure to generate better ideas and they feel that they may be judged more critically due to the other members' knowledge and expertise. So, it is quite possible that this sense of expertise in the industrial design participants induced evaluation apprehension and, ultimately, hindered the speedstorming groups' ideational performance in the end.

\subsubsection{Time Dependency}

As was previously mentioned, time was found to be a possible influencer for not only the facilitation of creative synergy, but also for its inhibition. Many participants indicated that there was not enough time in the speedstorming sessions to take advantage of the collaboration and to 
fully exhaust their ideas. It was also expressed that the time constraint did not allow for the ideas to fully form and become good ideas and there was a sense of rush. Therefore, speedstorming may not have allowed for the ideas to really develop in quality which may have resulted in many fewer good ideas altogether. Because the time constraint was so tight and the participants felt rushed to get their ideas out, there may have been more focus on the quantity of ideas over the quality. It is also possible, in speculation, that the participants have a belief in the "quantity breeds quality" conjecture that Osborn (1963) once proposed. Therefore, they may have consciously focused on quantity more in expectation that the quality would naturally follow. Although this belief would affect idea-generation in any case, whether in an interacting group or alone, it may have been exacerbated by the pressures of a short time limit.

Furthermore, it may be possible that the short time limits designed into the speedstorming process are not as suitable for design ideation as they may be for identifying potential interdisciplinary research partnerships or generating proposal ideas for research projects. Ideas for design solutions may require more depth, and the output is something different than a simple title (as part of the previous study on speedstorming; Joyce et al. 2010). Therefore, more time for ideation might be important in a design context. This is also indirectly supported by Joyce et al. (2010) in their suggestion that more time in each round would be needed if the goal is to produce more thorough, fully developed proposals.

Another finding from the qualitative analysis was that the lack of time was more concerning for later rounds rather than earlier. As the participants moved from round to round, there were progressively more ideas being brought to the table from the previous interactions and, therefore, the participants spent more time trying to explain the previous ideas and not much time generating new ones. In this sense, there may have been wasted time at the beginning of the later 
rounds which hindered the generation of new ideas and, ultimately, inhibited creative synergy. This can be considered as a form of production blocking and, as is well-known from the brainstorming literature, production blocking is a major contributor to performance loss in collaborative idea-generation (e.g., Diehl and Stroebe 1987; 1991; Nijstad, Stroebe, and Lodewijkx 2003).

Time was also found to be a factor because of the method of writing or drawing out the ideas on paper. Participants expressed that documenting the ideas slowed down the process and took away from the interaction and the actual generating of ideas. This was also supported by the behavioural observations in that there were periods of silence within the group-pairings when they were each writing or drawing. Again, this can be considered as another form of production blocking in the sense that it is preventing the sharing of ideas and, potentially, the conception of new ideas. Although it is possible to be thinking of new ideas while writing or drawing, there are certain cognitive resources that are being used that may limit the amount of conceptual thinking that can be done at that moment.

\subsubsection{Limited Interactions}

The results from the interviews and survey questionnaires indicated that there may not have been enough rounds in the speedstorming process. Several participants expressed that they would have liked to have met with more people to get even more perspectives on the given problems, even if it was with someone from the same discipline as their own. They thought that more interactions would have allowed for more productive and creative idea-generation. Furthermore, it was found that there was a desire for more disciplinary diversity with more rounds. This was primarily evident from the non-design participants most likely because they only interacted with industrial designers during the speedstorming sessions. So, in fact, they 
only interacted with one other discipline. Perhaps if there were collaborative partnerships between two non-design disciplines or other design disciplines, it could have been possible that more unique ideas would be generated, resulting in greater ideational performance for the speedstorming groups.

Based on these findings, it is quite possible that the limited interactions played a role in preventing creative synergy from flourishing. However, it does not necessarily predict why nominal groups significantly outperformed the speedstorming groups. There is no justification in the performance loss of speedstorming groups that can be attributed to the lack of rounds and the limited interactions that occurred; however, these findings provide meaningful insights into how the speedstorming process can be improved in attempt to reach a state of creative synergy. 


\section{CHAPTER 6}

CONCLUSION

This study has provided several key insights into understanding how interdisciplinary design teams can foster creative synergy when using speedstorming to generate ideas. Based on these insights, there are three major conclusions that can be drawn. The first conclusion is that there are certain pros and cons to the structure of the speedstorming technique and the protocol used which make it more or less effective as a collaborative tool for idea-generation. The second conclusion is that speedstorming may only be suitable for certain types of topics or problems and that individual ideation could possibly be more useful in some situations. And the third conclusion is that the diversity inherent in interdisciplinary design teams introduces a variety of personality types and brings about different dispositions towards collective ideation that make for difficulties in the idea-sharing process.

As described by Hey et al. (2009; see also Joyce et al. 2010), speedstorming was developed as a structured social interaction by having a specific goal or purpose, enforcing purposeful mixing and discussion amongst diverse collaborators, and enforcing short time limits for each pairing session. When speedstorming is brought into a design context for idea-generation, these structural elements seem to have both positive and negative influences on the generation of good, creative ideas and the achievement of creative synergy. Specifically, the forced interactions that result from one-on-one encounters may provide synergistic benefits whereas the control of mixing and the limited interactions that result may present certain drawbacks that prevent synergy from flourishing. Moreover, the strongly enforced time constraints could possibly be a 
point of both positive and negative influence on the ideational performance of a speedstorming team.

Dyadic interactions create a "focused interaction" (Goffman 1963) whereby all of the attention is concentrated between the two collaborators. This creates a situation where the collaborators are forced, in a way, to speak, interact, and share their ideas with each other and it seems to promote mutual engagement whereby each collaborator will prompt and motivate the other to contribute. There also may be an induction of friendly competition that motivates the collaborators to perform better than their given partner. This can reduce much of the social loafing and free riding effects that are evident in larger group brainstorming situations. Additionally, since the interactions are between different individuals coming from diverse disciplinary backgrounds, the forcing of discussion between each pairing may allow for a more successful integration of diverse knowledge and the generation of good, creative boundaryspanning ideas.

Controlling the interactions and the mixing of particular participants is presumed to be very beneficial for successful interdisciplinary collaboration. In fact, this relates to the previous benefits described based on the forced interactions that occur during one-on-one encounters. However, these benefits can be limited by preventing certain interactions to occur and conducting only a certain number of rounds during speedstorming sessions. It may be more advantageous to allow each collaborator to interact and generate ideas with every other team member. This would permit more sharing of ideas and, ultimately, may result in greater ideational performance overall. 
Finally, the time constraints seem to have a mix of pros and cons. On the one hand, the time constraints can keep the collaborators focused and constantly engaged while preventing them from having the opportunity to negatively evaluate each other's ideas. It keeps the ideation sessions productive since there is no time for any slack in performance. But, on the other hand, the time constraints may not allow for the full exhaustion of thoughts and ideas, reducing the chances for that one great, radical idea to surface. Moreover, it may not allow for the development of good, high-quality ideas since there is a rush to move onto the next idea quickly. This might induce a greater concern for the quantity of ideas over their quality. Furthermore, there may be different forms of production blocking as a result of the time constraints. As each session progresses on to the next, more ideas are brought to the interactions requiring more time to share them with the new partners. Also, the writing or sketching of ideas may block ideageneration as certain cognitive resources are being utilized during that time. So, the sharing and the documentation of ideas leave less and less time for actual ideation to occur.

The second conclusion is in regards to the importance of the topic or problem being addressed. Speedstorming, and collaborative ideation in general, may only be suitable for certain topics depending on the content and the context of the associated problem. Topics that are more open, fun, and playful seem to bring about greater excitement and more positive affect, allowing for more creative thinking and productive idea-generation in a collaborative setting. Furthermore, a more innocuous topic or problem that is limited in realism or applicability can induce a different motivation in the collaborators whereby they feel freer to come up with ideas that don't necessarily lead to any implementations. In this regard, speedstorming seems to be an effective technique to use. 
However, topics that are more difficult or controversial in some way can often change the social dynamic in a collaborative environment whereby certain individuals may become more hesitant in contributing to the interaction due to particular biases or fears of offending others. This can induce evaluation apprehension since collaborators may not want to be negatively judged for suggesting an offensive idea. Additionally, topics or problems that are more realistic and directed towards actual implementation can change the collaborators attitudes towards the task. The collaborators may become more sensitive to the necessity of good concept solutions which causes them to be more selective in the ideas they share. For these types of topics, individual brainstorming may provide greater value to a team's ideational performance.

The notion of the topic or problem being more or less realistic becomes a major challenge for collaboration as design is rooted in innovation and the application of ideas for real solutions. However, there are certain things that may be done to address this challenge and improve ideageneration for such topics. Leaders or facilitators of speedstorming sessions may attempt to reframe the problems and questions being addressed and convert them into something that is presented as more playful with less expression or focus on the need for a successful, implementable solution. Even though the end goal would still be to implement the ideas for innovation, this reframing would potentially reduce evaluation apprehension and make speedstorming more effective than individual brainstorming in generating good, creative ideas.

The last conclusion is that the interdisciplinarity in speedstorming inevitably introduces different personalities and dispositions towards collaboration that make for certain difficulties in the idea-sharing process. Having team members who have high levels of social anxiety can reduce ideational performance since it incites evaluation apprehension and the fear of being judged or criticized (Camacho and Paulus 1995). As is recalled from the literature review 
(section 2.2.2.2), this evaluation apprehension is an inhibiting mechanism that prevents creative synergy from prospering. Collaborators that experience this tend to hold back their ideas and not share them with their partners, which prevents the opposing partner from being exposed to new thoughts, ultimately reducing the chances of cognitive stimulation and the generation of new ideas.

A big part of this may be associated with the inherent diversity of the teams and the supposed hierarchy that non-design collaborators place within the social context. Designers can often times be looked at as "experts" in idea-generation by the non-designers. There can be a sense that the designers are more right and, therefore, they are "above all" in the collaborative activity. This is the feeling that non-designers seem to have since the collaboration is addressing design problems. This may also be associated with the fact that designers come across as quite confident in their ideas and in collaborative situations due to their experience and training, and the constant interactions that occur in typical design practice. Even though it has been argued that the one-on-one structure of speedstorming reduces this hierarchy and desire for status (Joyce et al. 2010), there still seems to be an expectation from the non-designers that this is a factor.

It is proposed that leaders or facilitators of speedstorming sessions should make it clear to all team members that there is no hierarchy and that everyone has equally great ideas to contribute. More so, it may be valuable to express that the non-designers have more value and expertise than the designers since they bring a new perspective to the table which is essential for interdisciplinary design activity. If this can motivate non-designers to contribute more to the interaction and to not be afraid of sharing their ideas, then evaluation apprehension can be reduced and creative synergy may be achieved. 


\subsection{CONTRIBUTION TO THE FIELD}

This research has provided a number of contributions to the field of design, both at the research level and the practical level. Firstly, in consideration of the fact that there has been very little empirical investigation into how design teams can effectively foster creativity (Dahl 2011), these findings have provided valuable information in contribution to the progressive knowledge and understanding that revolves around creativity and collaboration in design practice. Rather than relying on research findings that are derived from non-design related settings - as is much of the brainstorming and collaborative idea-generation literature (see Diehl and Stroebe 1987; Lamm and Trommsdorff 1973; Mullen, Johnson, and Salas 1991) - this study provides applicable and relevant knowledge specific to the field of design. Furthermore, it has contributed to our understandings of interdisciplinary design collaboration and the processes of ideageneration in such collective action, which is an emerging phenomenon relevant to contemporary design activity that needs to be addressed (Dykes, Rodgers, and Smyth 2009).

Secondly, this research has introduced a new and promising technique for idea-generation into the field of design. It builds off of the previous work done by Joyce et al. (2010) by extending speedstorming's application past idea-generation for research proposals and into ideageneration for design execution. Furthermore, by introducing this as a new technique for design ideation, it institutes a potential avenue for further empirical investigation. It provides a foundation for future research to build off of in attempts to validate and improve on the speedstorming technique for practical application. Researchers can learn from this study and create new research ventures that will continue to strengthen our understandings of creativity and interdisciplinarity in design, and ultimately provide effective solutions to fostering creative synergy in collaborative activities. 
Lastly, organizations and design teams can implement speedstorming into their ideational processes and take advantage of the creative synergies that can result from collaborative ideageneration. These teams can follow the speedstorming protocol in an attempt to generate good and creative ideas that will lead to innovative solutions (refer to Appendix $G$ for the speedstorming protocol). However, it is important to note that the use of speedstorming must be approached with caution. The positive findings from this study are not completely conclusive and, therefore, the effectiveness of speedstorming is not guaranteed. But, there are certain modifications that can be made to the given protocol in an attempt to optimize its utility. Such modifications can be an increase in the amount of time provided during each pairing session. So, instead of 5-minute sessions, perhaps 7-minutes would be more adequate. Or, as was suggested by one of the participants in this study, three rounds with 5-minutes, 6-minutes, and 6-minutes respectively may be good to try. Furthermore, the number of rounds can be increased to provide more one-on-one interactions between the team members. Instead of having three rounds (with six members), six rounds could be used so that each member meets every other member at least once. Or, each pairing can be repeated once or twice whereby each member would bring new ideas to each repeated session.

\subsection{LIMITATIONS}

Although this study provides valuable insights into the effectiveness of speedstorming for facilitating creative synergy in interdisciplinary design collaboration, there were a number of limitations that affect the validity of the study and its findings. Such limitations relate to the sample and the sampling methods used, the procedures followed for collecting data, and the challenges involved in the data analysis process. 
One of the main limitations was the small sample size used. Having conducted the analysis at a group level, the comparisons were made between four groups for two separate topics. So, even though there were a total of twenty-four participants, the statistical sample size was only four (and two when comparing the data from the two topics in isolation). This may have reduced the chances of finding statistically significant results which limited the ability to make any strong conclusions about the benefits and/or detriments of speedstorming for ideational tasks. This also minimized the external validity of the research findings and limited the generalizability of the results to other group compositions and settings. Nevertheless, as an exploratory pilot study utilizing both quantitative and qualitative methods, this study was able to provide valuable preliminary insights into the use of this new idea-generation technique. Future research should now replicate this study while including a larger sample size to increase its external validity and find more conclusive quantitative results.

Another limitation of this study was in regards to the sampling methods used and the compositions of the sample groups. All four groups were composed of diverse individuals which was a necessity for the study - but the group compositions themselves varied slightly between the groups. Since purposive sampling was used in conjunction with convenience sampling, it was difficult to recruit participants who had similar characteristics in order to create perfectly matching group compositions. The challenge was rooted in the need for diverse, interdisciplinary groups, but with each group needing to be as similar as possible (identical in an ideal sense) so that the between-subjects (i.e. between-groups) comparisons would be reliable and valid. Although this proved to be a challenge in the sampling process, this study was successful in achieving group compositions that were heterogeneous and naturally interdisciplinary which goes beyond the majority of previous research on collective ideation 
using only homogenous, mono-disciplinary groups. Future studies assessing speedstorming's effectiveness for interdisciplinary design collaboration must continue to strive for heterogeneous sample groups that are as close to identical as possible.

A limitation that became evident during the workshops, and was supported by some of the interview and survey questionnaire data, was the use of writing or drawing as a method for the participants to document their ideas. The participants were required to discuss their thoughts and ideas together but to also document them on paper for later analyses. This documentation method, in conjunction with the structured time constraints, may have impeded the process of generating ideas during collaboration which, in turn, may have influenced the end results. However, the choice of following this method was considered appropriate based on past research suggesting that the external documentation of ideas while brainstorming in groups may be helpful in preventing production blocking and improving ideational performance (Diehl and Stroebe 1991; Mullen, Johnson, and Salas 1991). Since the time constraints are an integral part of the speedstorming process, it may be beneficial for future research to utilize audio recording as an alternative approach for documenting and collecting the ideas, as is commonly used in brainstorming research.

Another limitation in regards to data collection that became evident during the analysis was the freedom participants were given in documenting their ideas on paper. The participants were instructed to write or sketch their ideas in any way they wanted. Many wrote out their ideas in a linear fashion with some actually numbering them and deciphering one from another; but, others would sketch their ideas and create mindmaps with no linearity or clear distinction between ideas. This latter method of documentation created difficulties for the evaluators when trying to distinguish each idea and give appropriate quality ratings. Inter-rater reliability may have been 
affected by this limitation, resulting in lower reliability scores between the independent evaluations. Although this is considered as a limitation due to its effects on the data analysis and evaluation process, it was regarded as important because idea-generation benefits from sketching and the externalization of ideas (van der Lugt 2005; Vyas, Heylen, and Nijholt 2009). One way of addressing this limitation in future research is to instruct the participants to label or number their ideas.

The acceptance of an idea as an idea was yet another limitation. Based on Kim's (1990) distinction between elementary and compound ideas, it seemed difficult to evaluate both types as some elementary ideas did not have much depth to give a thorough rating and some compound ideas had several elementary ideas within them which could have been isolated and rated separately. There was also some confusion in regards to direct solutions versus indirect insights. In this sense, some ideas were clear in solving the given problem whereas others were not as clear and seemed to be more of an insight that could lead to a solution. This made it difficult for the evaluators to interpret the value of an idea and whether it should be counted as an idea or not. Again, this may have reduced inter-rater reliability of the measurements as it introduces greater opportunity for different biases to take effect. Similar to the last suggestion, perhaps asking participants to label or number their ideas would help clarify this for the evaluators in future research endeavours.

\subsection{RECOMMENDATIONS FOR FUTURE RESEARCH}

In addition to the recommendations as described in response to the study limitations, there are a number of other recommendations that should be considered for future research initiatives. One such recommendation would be to address the proposed answers from the second research question in an experimental design. This would determine whether each theme or variable that 
was found does, in fact, contribute to the facilitation (or inhibition) of creative synergy. This would improve the validity of the findings and would give practitioners greater confidence in the use (or abandonment) of the speedstorming technique for ideational practices. It would also allow for further development and refinement of the speedstorming process to enhance its value for practical application. As an example, researchers may test the effects of the topic or problem by setting up an experiment whereby various diverse topics are used in both nominal and interacting group conditions and creative synergy is measured to see if there are any differences between the topics.

Since this was the first time speedstorming has been introduced into the design field for collaborative ideation, there was no set procedure for how speedstorming was to be structured or implemented in such a setting. Perhaps the protocol that was proposed by the researchers who created it is not as suitable for finding good, creative ideas in interdisciplinary design practice as it may be for finding interdisciplinary research partnerships or generating proposal ideas for research projects. Therefore, different variations of speedstorming and manipulations to its process would be valuable to test in the context of design. For example, as was alluded to in the discussion chapter (section 5.2.3), more time can be given for each pairing session to allow for more ideas and potentially better quality ideas to be generated. Moreover, the time given in each consecutive session can be progressively increased as each round is completed. This change in the time constraints can be compared to the original protocol to see if there are any benefits in increasing the time available for idea-generation. Another example is to introduce more rounds in the speedstorming process to see if additional one-on-one interactions can result in greater ideational performance. So, instead of having just three rounds (with six participants), there could be six rounds in which each participant is able to meet with everyone else at least once. 
There could also be repeated rounds whereby the paired participants get to interact for a second time after having met with the other designated participants.

Future studies may also explore more complex problems that would require greater discipline-specific knowledge in generating ideas for potential solutions. As was found in this study, if the topics are too open or general, idea-generation relies more on personal experience rather than disciplinary knowledge; the collaborators don't necessarily bring unique knowledge founded from their functional backgrounds to the collaboration. In this sense, different and more specific topics or problems would allow for gaining a better understanding of the benefits or detriments of speedstorming for interdisciplinary collaboration.

\subsection{FINAL COMMENTS}

It is clear that there is much more research that needs to be done to confidently determine the effectiveness of speedstorming for interdisciplinary design collaboration. However, the results have indicated that there is great potential for speedstorming to be a valuable tool for design ideation and that it may facilitate the creative synergy that teams are put together specifically to achieve.

The structured process of the speedstorming technique may allow collaborators to take advantage of their diverse perspectives by forcing interaction and discussion during each pairing session and by imposing a strict time constraint (with slightly more time for each interaction) to keep collaborators constantly engaged and focused on the given task. Using speedstorming to generate ideas for fun, playful, and less controversial topics or problems that are presented in a more trivial manner may allow collaborators to be more creative and less afraid to share their ideas. Furthermore, recognizing the different personality types and dispositions inherent in 
interdisciplinary design teams and enforcing an equality between designers and non-designers may allow collaborators to fully engage themselves and contribute their diverse, valuable knowledge to generate good, creative boundary-spanning ideas.

By using the right topic, with the right people who have the right motivation, and following the right process for the right amount of time, speedstorming may be able to enhance a diverse design team's creativity and ideational performance. So, as the need for innovative solutions to complex design problems becomes more and more important, organizations may look to using speedstorming for capitalizing on collective creativity and the facilitation of creative synergy in interdisciplinary design collaboration. 


\section{REFERENCE LIST}

Amabile, Teresa M. 1983. The social psychology of creativity. New York: Springer Verlag.

1996. Creativity in context: Update to "The social psychology of creativity". Boulder, CO: Westview Press.

Amabile, Teresa M, Sigal G Barsade, Jennifer S Mueller, and Barry M Staw. 2005. "Affect and creativity at work." Administrative Science Quarterly 50 (3): 367-403.

Amabile, Teresa M, Regina Conti, Heather Coon, Jeffrey Lazenby, and Michael Herron. 1996. "Assessing the work environment for creativity." Academy of Management Journal 39 (5): 1154-1184.

Badke-Schaub, Petra, Gabriela Goldschmidt, and Martijn Meijer. 2010. "How does cognitive conflict in design teams support the development of creative ideas?" Creativity and Innovation Management 19 (2): 119-133.

Baer, John. 1993. Creativity and divergent thinking: A task-specific approach. Hillsdale, NJ: Lawrence Erlbaum Associates.

Baer, John, and Sharon S McKool. 2009. Assessing creativity using the Consensual Assessment Technique. In Handbook of Assessment Technologies, Methods, and Applications in Higher Education, ed. C. Schreiner, 1-13. Hershey, Pennsylvania: IGI Global.

Barczak, Gloria, Felicia Lassk, and Jay Mulki. 2010. "Antecedents of team creativity: An examination of team emotional intelligence, team trust and collaborative culture." Creativity and Innovation Management 19 (4): 332-345.

Barki, Henri, and Alain Pinsonneault. 2001. "Small group brainstorming and idea quality: Is electronic brainstorming the most effective approach?" Small Group Research 32 (2): 158205.

Barron, Frank, and David M. Harrington. 1981. "Creativity, intelligence, and personality." Annual Review of Psychology 32: 439-476.

Bassett-Jones, Nigel. 2005. "The paradox of diversity management, creativity and innovation." Creativity and Innovation Management 14 (2): 169-175.

Berg, Bruce L. 2007. Qualitative research methods for the social sciences. 6th ed. Boston: Pearson Education, Inc. 
Bouchard, Thomas J Jr. 1969. "Personality, problem-solving procedure, and performance in small groups.” Journal of Applied Psychology 53 (1): 1-29.

_. 1972. "A comparison of two group brainstorming procedures." Journal of Applied Psychology 56 (5): 418-421.

Bouchard, Thomas J Jr., Gail Drauden, and Jean Barsaloux. 1974. "A comparison of individual, subgroup, and total group methods of problem solving." Journal of Applied Psychology 59 (2): 226-227.

Bouchard, Thomas J. Jr., and Melana Hare. 1970. "Size, performance, and potential in brainstorming groups." Journal of Applied Psychology 54 (1): 51-55.

Briggs, Robert O, and Bruce A Reinig. 2007. Bounded ideation theory $\square$ : A new model of the relationship between idea-quantity and idea-quality during ideation. In 40th Howaii International Conference on System Sciences, 1-10.

- 2010. "Bounded ideation theory." Journal of Management Information Systems 27 (1) (July 1): 123-144.

Camacho, L Mabel, and Paul B Paulus. 1995. "The role of social anxiousness in group brainstorming." Journal of Personality and Social Psychology 68 (6): 1071-1080.

Cattell, Raymond B. 1957. Personality and motivation: Structure and measurement. Yonkers, NY: World Book Co.

Chen, Ming-Huei. 2006. "Understanding the benefits and detriments of conflict on team creativity process." Creativity and Innovation Management 15 (1): 105-116.

Collaros, Panayiota A, and Lynn R Anderson. 1969. "Effect of perceived expertness upon creativity of members of brainstorming groups." Journal of Applied Psychology 53 (2): 159-163.

Collins, B. E., and H. Guetzkow. 1964. A social psychology of group processes for decision making. New York: Wiley.

Connolly, T, Leonard M Jessup, and Joseph S Valacich. 1990. "Effects of anonymity and evaluative tone on idea generation in computer-mediated groups." Management Science 36 (6): 689-703.

Cooper, William H, R Brent Gallupe, Sandra Pollard, and Jana Cadsby. 1998. "Some liberating effects of anonymous electronic brainstorming." Small Group Research 29 (2): 147-178.

Coskun, Hamit. 2005. "Cognitive stimulation with convergent and divergent thinking exercises in brainwriting: Incubation, sequence priming, and group context." Small Group Research $36(4): 466-498$. 
Dahl, Darren W. 2011. "Clarity in defining product design: Inspiring research opportunities for the design process." Journal of Product Innovation Management 28: 425-427.

Dennis, Alan R, Joseph S Valacich, Traci A Carte, Monica J Garfield, Barbara J Haley, and Jay E Aronson. 1997. "Research report: The effectiveness of multiple dialogues in electronic brainstorming." Information Systems Research 8 (2): 203-211.

Dennis, Alan R, and Joseph S Valacich. 1993. "Computer brainstorms: More heads are better than one." Journal of Applied Psychology 78 (4): 531-537.

Dennis, Alan R, and Michael L Williams. 2005. "A meta-analysis of group size effects in electronic brainstorming: More heads are better than one." International Journal of eCollaboration 1 (1): 24-42.

Diamond, Patrick. 1987. "Synergy: Working together to make one plus one equal four." Human Resource Management Australia: 73-79.

Diehl, Michael, and Wolfgang Stroebe. 1987. "Productivity loss in brainstorming groups: Toward the solution of a riddle." Journal of Personality and Social Psychology 53 (3): 497509.

-1991. "Productivity loss in idea-generating groups $\square$ : Tracking down the blocking effect." Journal of Personality and Social Psychology 61 (3): 392-403.

Dillon, Peter C., William K. Graham, and Andrea L. Aidells. 1972. "Brainstorming on a 'hot' problem: Effects of training and practice on individual and group performance." Journal of Applied Psychology 56 (6): 487-490.

Dunnette, Marvin D, John Campbell, and Kay Jaastad. 1963. "The effect of group participation on brainstorming effectiveness for two industrial samples." Journal of Applied Psychology $47(1): 30-37$.

Dykes, Thomas H, Paul A Rodgers, and Michael Smyth. 2009. "Towards a new disciplinary framework for contemporary creative design practice." CoDesign 5 (2): 99-116.

Farh, Jiing-Lih, Cynthia Lee, and Crystal I. C. Farh. 2010. "Task conflict and team creativity: A question of how much and when." Journal of Applied Psychology August: 1-8.

Fox, S. I. 1996. Human physiology. 5th ed. Dubuque: Wm. C. Brown.

Furnham, Adrian, and Velicia Bachtiar. 2008. "Personality and intelligence as predictors of creativity." Personality and Individual Differences 45: 613-617.

Gallupe, R Brent, Lana M Bastianutti, and William H Cooper. 1991. "Unblocking brainstorms." Journal of Applied Psychology 76 (1): 137-142. 
Gallupe, R Brent, William H Cooper, Mary-llz Grisé, and Lana M Bastianutti. 1994. "Blocking electronic brainstorms." Journal of Applied Psychology 79 (1): 77-86.

Gallupe, R Brent, Alan R Dennis, William H Cooper, Joseph S Valacich, Lana M Bastianutti, and Jay F Jr. Nunamaker. 1992. "Electronic brainstorming and group size." Academy of Management Journal 35 (2): 350-369.

Gladwell, Malcolm. 2005. Blink: The power of thinking without thinking. New York: Little, Brown and Company.

Goffman, E. 1963. Behaviour in public spaces: Notes on the social organisation of gatherings. New York: Free Press.

Goldschmidt, Gabriela, and Dan Tatsa. 2005. "How good are good ideas? Correlates of design creativity." Design Studies 26 (6): 593-611.

Graham, William K. 1977. "Acceptance of ideas generated through individual and group brainstorming." The Journal of Social Psychology 101: 231-234.

Gurman, Ernest B. 1968. "Creativity as a function of orientation and group participation." Psychological Reports 22: 471-478.

Harari, Oren, and William K Graham. 1975. "Tasks and task consequences as factors in individual and group brainstorming." The Journal of Social Psychology 95: 61-65.

Harkins, Stephen G. 1987. "Social loafing and social facilitation." Journal of Experimental Social Psychology 23: 1-18.

Harkins, Stephen G, and Richard E Petty. 1982. "Effects of task difficulty and task uniqueness on social loafing." Journal of Personality and Social Psychology 43 (6): 1214-1229.

Hennessey, Beth A. 1994. "The consensual assessment technique: An examination of the relationship between ratings of product and process creativity." Creativity Research Journal 7: 193-208.

Hennessey, Beth A, and Teresa M Amabile. 2010. "Creativity." Annual Review of Psychology 61: 569-598.

Hertel, Guido. 2011. "Synergetic effects in working teams." Journal of Managerial Psychology 26 (3): 176-184.

Hey, Jonathan, Caneel K Joyce, Kyle E Jennings, Thomas Kalil, and Jeffrey C Grossman. 2009. "Putting the discipline in interdisciplinary: Using speedstorming to teach and initiate creative collaboration in nanoscience." Journal of Nano Education 1 (1): 75-85. 
Holtzman, Yair, and Johan Anderberg. 2011. "Diversify your teams and collaborate: Because great minds don't think alike." Journal of Management Development 30 (1): 75-92.

Ingham, Alan G, George Levinger, James Graves, and Vaughn Peckham. 1974. "The Ringelmann effect: Studies of group size and group performance." Journal of Experimental Social Psychology 10: 371-384.

Isen, Alice M. 1999. On the relationship between affect and creative problem solving. In Affect, Creative Experience, and Psychological Adjustment, ed. Sandra W Russ. Philadelphia, PA: Brunner/Mazel.

Isen, Alice M, Kimberly A Daubman, and Gary P Nowicki. 1987. "Positive affect facilitates creative problem solving." Journal of Personality and Social Psychology 52 (6): 1122-1131.

Jablin, Fredric M. 1981. "Cultivating imagination: Factors that enhance and inhibit creativity in brainstorming groups." Human Communication Research 7 (3): 245-258.

Jackson, Jeffrey M, and Kipling D Williams. 1985. "Social loafing on difficult tasks: Working collectively can improve performance." Journal of Personality and Social Psychology 49 (4): 937-942.

Jacobs, Jerry A, and Scott Frickel. 2009. "Interdisciplinarity: A critical assessment." Annual Review of Sociology 35 (1): 43-65.

Jessup, Leonard M, Terry Connolly, and Jolene Galegher. 1990. "The effects of anonymity on GDSS group process with an idea-generating task." MIS Quarterly: 313-322.

de Jong, Jeroen, and Deanne den Hartog. 2010. "Measuring innovative work behaviour." Creativity and Innovation Management 19 (1): 23-36.

Joyce, Caneel K, Kyle E Jennings, Jonathan Hey, Jeffrey C Grossman, and Thomas Kalil. 2010. "Getting down to business: Using speedstorming to initiate creative cross-disciplinary collaboration." Creativity and Innovation Management 19 (1): 57-67.

Karau, Steven J, and Kipling D Williams. 1993. "Social loafing: A meta-analytic review and theoretical integration." Journal of Personality and Social Psychology 65 (4): 681-706.

Katzenbach, Jon R, and Douglas K Smith. 1993. "The discipline of teams." Harvard Business Review: 111-120.

Katzung, B. G. 1998. Basic and clinical pharmacology. 7th ed. Stamford, CT: Appleton and Lang.

Kaufman, James C. 2009. Creativity 101. New York: Springer Publishing Company. 
Kaufman, James C, Jonathan A Plucker, and John Baer. 2008. Essentials of creativity assessment. New Jersey: John Wiley \& Sons, Inc.

Kelley, Tom, and Jonathan Littman. 2001. The art of innovation: Lessons in creativity from IDEO, America's leading design firm. New York: Doubleday.

Kerr, Norbert L. 1983. "Motivation losses in small groups: A social dilemma analysis." Journal of Personality and Social Psychology 45 (4): 819-828.

Kerr, Norbert L, and Steven E Bruun. 1983. "Dispensability of member effort and group motivation losses $\square$ : Free-rider effects." Journal of Personality and Social Psychology 44 (1): 78-94.

Kim, Steven H. 1990. Essence of creativity: A guide to tackling difficult problems. Oxford: Oxford University Press.

Kohn, Nicholas W, Paul B Paulus, and YunHee Choi. 2011. "Building on the ideas of others: An examination of the idea combination process." Journal of Experimental Social Psychology 47 (3): 554-561.

Kurtzberg, Terri R. 2005. "Feeling creative, being creative: An empirical study of diversity and creativity in teams." Creativity Research Journal 17 (1): 51-65.

Kurtzberg, Terri R, and Teresa M Amabile. 2001. "From Guilford to creative synergy $\square$ : Opening the black box of team-level creativity." Creativity Research Journal 12 (3/4): 285294.

Lamm, Helmut, and Gisela Trommsdorff. 1973. "Group versus individual performance on tasks requiring ideational proficiency (brainstorming): A review." European Journal of Social Psychology 3 (4): 361-388.

Larson, James R Jr. 2010. In search of synergy in small group performance. New York: Psychology Press.

Lasker, Roz D., Elisa S. Weiss, and Rebecca Miller. 2001. "Partnership synergy: A practical framework for studying and strengthening the collaborative advantage." The Milbank Quarterly 79 (2): 179-205.

Latané, Bibb, Kipling D Williams, and Stephen Harkins. 1979. "Many hands make light the work: The causes and consequences of social loafing." Journal of Personality and Social Psychology 37 (6): 822-832.

Leenders, Roger Th. A. J., Jo M. L. van Engelen, and Jan Kratzer. 2003. "Virtuality, communication, and new product team creativity: A social network perspective." Journal of Engineering and Technology Management 20: 69-92. 
Linsey, Julie S, and Blake Becker. 2011. Effectiveness of brainwriting techniques: Comparing nominal groups to real teams. In Design Creativity 2010, ed. Toshiharu Taura and Yukari Nagai, 165-171. London: Springer.

van der Lugt, Remko. 2000. "Developing a graphic tool for creative problem solving in design groups." Design Studies 21 (5): 505-522.

- 2002. "Brainsketching and how it differs from brainstorming." Creativity and Innovation Management 11 (1): 43-54.

- 2005. "How sketching can affect the idea generation process in design group meetings." Design Studies 26 (2): 101-122.

Madsen, Daniel B, and John R Jr. Finger. 1978. "Comparison of a written feedback procedure, group brainstorming, and individual brainstorming." Journal of Applied Psychology 63 (1): $120-123$.

Maginn, Barbara K, and Richard J Harris. 1980. "Effects of anticipated evaluation on individual brainstorming performance." Journal of Applied Psychology 65 (2): 219-225.

Mainemelis, Charalampos, and Sarah Ronson. 2006. "Ideas are born in fields of play: Towards a theory of play and creativity in organizational settings." Research in Organizational Behavior 27 (6): 81-131.

Marieb, E. N. 2004. Human anatomy and physiology. 6th ed. New York: Benjamin Cummings.

McGlynn, Richard P, Dennis McGurk, Vicki Sprague Effland, Nancy L Johll, and Deborah J Harding. 2004. "Brainstorming and task performance in groups constrained by evidence." Organizational Behavior and Human Decision Processes 93 (1): 75-87.

Milton, G. A. 1965. "Enthusiasm vs effectiveness in group and individual problem-solving." Psychological Reports 16: 1197-1201.

Miura, Asako, and Misao Hida. 2004. "Synergy between diversity and similarity in group-idea generation." Small Group Research 35 (5): 540-564.

Mullen, Brian, Craig Johnson, and Eduardo Salas. 1991. "Productivity loss in brainstorming groups: A meta-analytic integration." Basic and Applied Social Psychology 12 (1): 3-23.

Munkes, Jörg, and Michael Diehl. 2003. "Matching or competition? Performance comparison processes in an idea generation task." Group Processes \& Intergroup Relations 6 (3): 305320.

Nijstad, Bernard A, Wolfgang Stroebe, and Hein F. M. Lodewijkx. 2003. "Production blocking and idea generation: Does blocking interfere with cognitive processes?" Journal of Experimental Social Psychology 39 (6): 531-548. 
Osborn, Alex F. 1963. Applied imagination. 3rd ed. New York: Charles Scribner's Sons.

Overstreet, H. A. 1925. Influencing human behavior. New York: Norton.

Parnes, Sidney J, and Arnold Meadow. 1959. "Effects of 'brainstorming' instructions on creative problem solving by trained and untrained subjects." Journal of Educational Psychology 50 (4): 171-176.

Paulus, Paul B. 2000. "Groups, teams, and creativity: The creative potential of idea-generating groups." Applied Psychology: An International Review 49 (2): 237-262.

Paulus, Paul B, Mary T Dzindolet, George Poletes, and L Mabel Camacho. 1993. "Perception of performance in group brainstorming: The illusion of group productivity." Personality and Social Psychology Bulletin 19 (1): 78-89.

Paulus, Paul B, Timothy S Larey, and Anita H Ortega. 1995. "Performance and perceptions of brainstormers in an organizational setting." Basic and Applied Social Psychology 17 (1/2): 249-265.

Paulus, Paul B, and Mary T Dzindolet. 1993. "Social influence processes in group brainstorming." Journal of Personality and Social Psychology 64 (4): 575-586.

Paulus, Paul B., and Huei-Chuan Yang. 2000. "Idea generation in groups: A basis for creativity in organizations." Organizational Behavior and Human Decision Processes 82 (1): 76-87.

Petty, Richard E, Stephen G Harkins, Kipling D Williams, and Bibb Latané. 1977. "The effects of group size on cognitive effort and evaluation." Personality and Social Psychology Bulletin 3: 579-582.

Pinsonneault, Alain, Henri Barki, R Brent Gallupe, and Norberto Hoppen. 1999. "Electronic brainstorming: The illusion of productivity." Information Systems Research 10 (2): 110-134.

Plucker, Jonathan A, Ronald A Beghetto, and Gayle T Dow. 2004. "Why isn't creativity more important to educational psychologists? Potentials, pitfalls, and future directions in creativity research." Educational Psychologist 39 (2): 83-96.

Reinig, Bruce A, and Robert O Briggs. 2008. "On the relationship between idea-quantity and idea-quality during ideation." Group Decision and Negotiation 17 (5): 403-420.

Rhodes, Mel. 1961. “An Analysis of Creativity." The Phi Delta Kappan 42 (7): 305-310.

Rietzschel, Eric F, Bernard A Nijstad, and Wolfgang Stroebe. 2010. "The selection of creative ideas after individual idea generation: Choosing between creativity and impact." British Journal of Psychology 101 (1): 47-68. 
Roberge, Marie-Élène, and Rolf van Dick. 2010. "Recognizing the benefits of diversity: When and how does diversity increase group performance?" Human Resource Management Review 20 (4): 295-308.

Rotter, George S, and Stephen M Portugal. 1969. "Group and individual effects in problem solving." Journal of Applied Psychology 53 (4): 338-341.

Russ, Sandra W. 2003. "Play and creativity: Developmental issues." Scandinavian Journal of Educational Research 47 (3): 291-303.

Scarnati, James T. 2001. "On becoming a team player." Team Performance Management: An International Journal 7 (1/2): 5-10.

Shrout, Patrick E, and Joseph L Fleiss. 1979. "Intraclass Correlations: Uses in Assessing Rater Reliability.” Psychological Bulletin 86 (2): 420-428.

Simonton, Dean Keith. 1988. Creativity, leadership, and chance. In The Nature of Creativity: Contemporary Psychological Perspectives, ed. Robert J. Sternberg, 386-426. Cambridge: Cambridge University Press.

Stein, Zachary. 2007. "Modeling the demands of interdisciplinarity: Toward a framework for evaluating interdisciplinary endeavors." Integral Review 4: 91-107.

Street, Warren R. 1974. "Brainstorming by individuals, coacting and interacting groups." Journal of Applied Psychology 59 (4): 433-436.

Stroebe, Wolfgang, and Michael Diehl. 1994. "Why groups are less effective than their members $\square$ : On productivity losses in idea-generating groups." European Review of Social Psychology 5 (1): 271-303.

Sutton, Robert I, and Andrew Hargadon. 1996. "Brainstorming groups in context: Effectiveness in a product design firm." Administrative Science Quarterly 41 (4): 685-718.

Taura, Toshiharu, and Yukari Nagai. 2011. Discussion on direction of design creativity research (part 1) - new definition of design and creativity: Beyond the problem-solving paradigm. In Design Creativity 2010, ed. Toshiharu Taura and Yukari Nagai, 3-8. London: Springer.

Taylor, Donald W. 1955. "Problem solving by groups." Acta Psychologica 11: 218-219.

Taylor, Donald W, Paul C Berry, and Clifford H Block. 1958. "Does group participation when using brainstorming facilitate or inhibit creative thinking?" Administrative Science Quarterly 3: 23-47.

Valacich, Joseph S, Alan R Dennis, and Jay F Jr. Nunamaker. 1991. "Electronic meeting support: The GroupSystems concept." International Journal of Man-Machine Studies 34: 261-282. 
. 1992. "Group size and anonymity effects on computer-mediated idea generation." Small Group Research 23 (1): 49-73.

VanGundy, Arthur B. 1988. Techniques for structured problem solving. 2nd ed. New York: Van Nostrand Reinhold.

Vizjak, Andrej. 1994. "Exploiting Your Synergy Potential: Promoting Collaboration Between Business Units." Long Range Planning 27 (1): 25-35.

Vroom, Victor H., Lester D. Grant, and Timothy S. Cotton. 1969. "The consequences of social interaction in group problem solving." Organizational Behavior and Human Performance 4: 77-95.

Vyas, Dhaval, Dirk Heylen, and Anton Nijholt. 2009. Collaborative practices that support creativity in design. In ECSCW'09: Proceedings of the 11th European Conference on Computer Supported Cooperative Work, ed. I Wagner, E Tellioglu, E Balka, C Simone, and L Ciolfi, 151-170. Vienna, Austria: Springer.

Weldon, Elizabeth, and Gina M Gargano. 1988. "Cognitive loafing: The effects of accountability and shared responsibility on cognitive effort." Personality and Social Psychology Bulletin 14 (1): 159-171.

West, Michael A. 2002. "Sparkling fountains or stagnant ponds: An integrative model of creativity and innovation implementation in work groups." Applied Psychology: An International Review 51 (3): 355-424.

Williams, Kipling D, Stephen Harkins, and Bibb Latané. 1981. "Identifiability as a deterrent to social loafing $\square$ : Two cheering experiments." Journal of Personality and Social Psychology 40 (2): 303-311. 


\section{GLOSSARY}

Brainsketching

Brainstorming

Brainwriting

Creative Idea

Creative Synergy

Creativity
Brainsketching is a form of the general brainwriting technique which uses sketching as the primary means of recording and communicating ideas instead of sentential writing (van der Lugt 2002).

Brainstorming is a conference method where groups of individuals attempt to generate creative ideas which can serve as leads to a problem-solution. It is a method for generating a check-list of ideas that can subsequently be evaluated and further addressed in later processes (Osborn 1963).

Brainwriting is a method of generating ideas whereby group members do not talk with each other but, rather, share their ideas by writing them down and presenting them visually, either in text or graphic form (VanGundy 1988).

See "good idea".

Creative synergy refers to a performance gain due to group interaction when working on idea-generation tasks (Kurtzberg 2005; Larson 2010) whereby the performance is measured against the creativity and the quality of ideas produced.

Creativity is "the interaction among aptitude, process, and 
environment by which an individual or group produces a perceptible product that is both novel and useful as defined within a social context" (Plucker, Beghetto, and Dow 2004, 90).

Electronic Brainstorming

Good Idea

Group

Idea
Electronic brainstorming refers to "the use of computer technology to facilitate the entry and automatic dissemination of ideas to all members of a group, each of whom might be stimulated to generate other ideas and then immediately express them" (Gallupe, Bastianutti, and Cooper 1991, 137).

A good idea is one that is considered to be of high-quality, defined as being highly novel, original, or unusual; highly useful and effective in achieving a goal or providing a solution; and highly feasible for successful implementation (Briggs and Reinig 2010; Hennessey and Amabile 2010; Rietzschel, Nijstad, and Stroebe 2010). This term is used interchangeably with the term creative idea.

A group is a collection of individuals who work together on a common task and are interdependent with a shared goal or objective (Larson 2010). This term is used interchangeably with the term team.

"An idea is a concept that may serve as a component of a solution" (Kim 1990, 13). The idea could be directly related to some aspect of a solution or it could be an indirect insight that aids in finding a solution. It could also be either elementary (very basic conceptions that cannot 
be reasonably divided into smaller concepts) or compound (those which are made up of multiple ideas packaged into one aggregate concept that serves as a solution to a problem) (Kim 1990).

Idea-Generation

Ideation

Interdisciplinarity

Speedstorming

Strong Synergy
Idea-generation "is the process of generating ideas useful for attaining some desired state or outcome" (Briggs and Reinig 2010,123), often in an attempt to solve a particular problem. This term is used interchangeably with the term ideation.

See "idea-generation".

For the purpose of this thesis, the terms interdisciplinary and interdisciplinarity are used very loosely to generally mean the communication and collaboration of multiple disciplines, and the exchange and integration of knowledge towards achieving a common goal or objective (Jacobs and Frickel 2009).

Speedstorming is a new idea-generation technique that combines the processes of brainstorming and speed dating whereby participants interact one-on-one to generate ideas together for a short period of time, and then switch to a new partner to do the same thing over again. It was specifically developed for interdisciplinary collaboration (Joyce et al. 2010; Hey et al. 2009).

Strong synergy refers to "group performance that exceeds the solo performance of even the best group member" (Larson 2010, 7). 
Synergy

Team

Weak Synergy
Synergy is a gain in performance that results from the collective interaction of a group by which the output is greater than the simple combination of individual members' efforts alone. It is a performance gain due to group interaction (Larson 2010).

See "group".

Weak synergy refers to "group performance that exceeds the performance of the typical group member when working alone" (Larson 2010, 6). 
APPENDIX A

WORKSHOP BRIEFING SCRIPT 
Hello everyone and welcome to this idea-generation workshop!

As you all know, my name is Tim and I have brought you here together to test out a new brainstorming technique called Speedstorming. Speedstorming is a new approach to generating creative ideas. It combines brainstorming with the process of speed dating whereby participants interact one-on-one to generate ideas together for a short period of time, and then switch to a new partner to do the same thing over again. At the end of the Speedstorming session, all of the ideas that are generated are pooled together leading into another process of idea-evaluation, which is beyond the scope of this workshop.

There are three reasons why I have organized this workshop. The first reason is that I am doing my Masters of Design thesis research on the topic of interdisciplinary collaboration and creative idea-generation. More specifically, I am assessing the value of this Speedstorming technique as a way of increasing creativity in early design collaboration and allowing for the crossing of disciplinary boundaries. This will be the first time this technique is used in a design-like situation as it has been developed and tested for the field of nanoscience research. The second reason is that I believe this Speedstorming technique is an exciting new development and can be applied to a variety of projects in many areas of study, and it is with great opportunity for you all to get first-hand experience with it and perhaps take the concept with you into your own projects outside of this workshop. The third reason is that one of the topics we will be working on in this workshop revolves around the campaign efforts of the Power To Change organization on campus here, and the ideas we generate tonight may provide an opportunity for them to initiate and further implement the ideas to make a difference in what they are trying to achieve with their campaign.

Before I get into the details of what is going to happen tonight in this workshop, there are a few important things that we have to go over as part of standard procedure for doing any sort of research.

[Hand out consent form]

Here is a consent form that we will read over together which describes some of the main points about this research and your participation.

[Read consent form]

Are there any questions about this consent form and what you are consenting to? [Answer questions if there are any]

Okay, great! Please sign the form now and we will move on to the fun stuff!

So here's what's going to happen. As you can see, I have divided the room in half. Six of you will work on the one side and the other six will work on the other side. There will be two parts to this workshop: the first part will include idea-generation alone as individuals, for one of the given topics, and the second part will include idea-generation together using Speedstorming to collaborate for the other topic. Each part or session will take approximately 15 minutes. In the individual session, you will have a total of 15 minutes to generate as many good ideas as possible alone, in isolation from everyone else. Each of you will sit at a separate desk as you see here. I will signal a one-minute warning to allow for you to finish up your last idea and get it on paper. Once that minute is up, I will collect all of the papers from you and we will then setup the desks appropriately for the Speedstorming session. Once we are setup, each person will be seated in a designated seat 
to begin the Speedstorming session. There will be three pairs of two on both sides of the room and there will be 5 minutes allotted for a one-on-one brainstorming session between each pair. Again, I will signal a one-minute warning to allow for you to finish up your last idea and get it on paper. Once that minute is up, the industrial design students will remain seated as the opposing partners switch seats with the person to their left. The 5 minute brainstorm is repeated with the new partnerships, and a final switch is made for a total of three rounds. After the three rounds are over, I will collect all of the papers from you and hand out a final questionnaire for you to fill out. When you hand the completed questionnaire back to me, I may ask you to take part in an interview which can be scheduled either after the workshop or at a convenient time in the following few days. At this point, you are all welcome to stay for more refreshments or leave for the night.

Now, I need to mention one thing about the idea-generation process. When you come up with an idea, write it or sketch it down right away. The only way that we are going to know about your ideas is from the paper that you hand in. I have two professors from the School of Industrial Design who will be reviewing the ideas that are generated by each of you and assessing them on a number of quality measures; so, in order for them to effectively do that, it is important that your ideas are on the paper and that they are readable and understandable. Also, try your best to distinguish one idea from the next; this will make the reviewing process easier.

Your goal for generating ideas is to come up with as many good ideas as you can, relating to the given topic. I encourage you not to disregard ideas that you think are stupid or silly. We want quantity! But, we also want quality, so build on those crazy ideas and come up with other ideas that are more feasible and effective. We are measuring your ideas based on novelty or originality, utility or usefulness, feasibility, and effectiveness, so keep that in mind.

Let's take a tennis ball for an example. What can we use a tennis ball for other than for its intended use? How about we cut one in half, attach an arched piece of metal around with small screws, and use it as ear muffs! In terms of originality and novelty, this would score quite high because it is something that has not really been done before, except for this example of course [show the example image]. In terms of utility and usefulness, this would score quite high given that it is very practical. In terms of feasibility, it would again score very high because it is easily doable; it does not require fancy machinery or anything to make it happen and it's a very cheap solution. And finally, in terms of effectiveness, it would score fairly high again because it would actually do a good job of muffling the sound. So here's a good example of a great idea.

Something not so great would be a modified USB flashdrive for people with dexterity issues [show the example image]. Good thought, which gives it a decent rating for originality but when it comes to utility and effectiveness, it receives a low score because it would not work for any laptop and would disrupt access to any of the other ports on either side of it. A low score on originality would result from an idea like using the tennis ball to play baseball.

Alright, are there any questions about anything before we start?

[Answer questions if there are any]

Great! Let's get started!

[Direct participants to their designated seats] 


\section{Topic 1 Briefing}

Here is an information sheet for the first topic. This first topic is about "Modern-Day Slavery and Human-Trafficking". The sheet includes a number of statistics and facts about this topic which will give you an idea of what it is all about. If you look at the bottom, you can see that I have included a problem statement as well as a question which will guide the ideageneration session. [Read problem statement and question]

This session is geared towards the campaign efforts of Power to Change and it is possible that what comes out of this workshop may be useful for their continuing efforts to raise awareness of this world issue. So be creative - open your mind, think outside the box, and explore the uncommon. No idea is wrong - they all have value somewhere along the process. You may begin now!

\section{Topic 2 Briefing}

Here is an information sheet for the second topic. This second topic is about "Restaurant Experience". If you look at the bottom, you can see that I have included a problem statement as well as a question which will guide the idea-generation session. [Read problem statement and question]

This sheet includes some images of examples which most of you should be familiar with.

The Rainforest Café is a great example of creating a jungle experience when dining. The entire décor is set like a jungle environment and there are realistic statues of various animals throughout the restaurant. There are also lights and sounds that add to the jungle experience such as various bird and animal noises and a periodic thunder storm that rolls through every once in a while. It's an exciting place to eat and the kids love it!

Some of you may be wondering about the females at the bottom left. Well, you guessed it, they are Hooters girls. This is no offense to the women here today, but it is another good example of creating an experience for the customers, who are obviously targeted as men, which has proven successful for their restaurant service.

The last example is Cora's breakfast. What makes Cora's unique is the way that they serve their dishes. Often times, they will cut the fruit into different shapes, such as Swans, and present them in an intriguing fashion.

So what I want to stress here is that the ideas you come up with do not have to be based on one thing. For example, the Rainforest Café is more of a theme restaurant whereas Cora's approach is more in the presentation of the food. So be creative - open your mind, think outside the box, and explore the uncommon. No idea is wrong - they all have value somewhere along the process. You may begin now! 

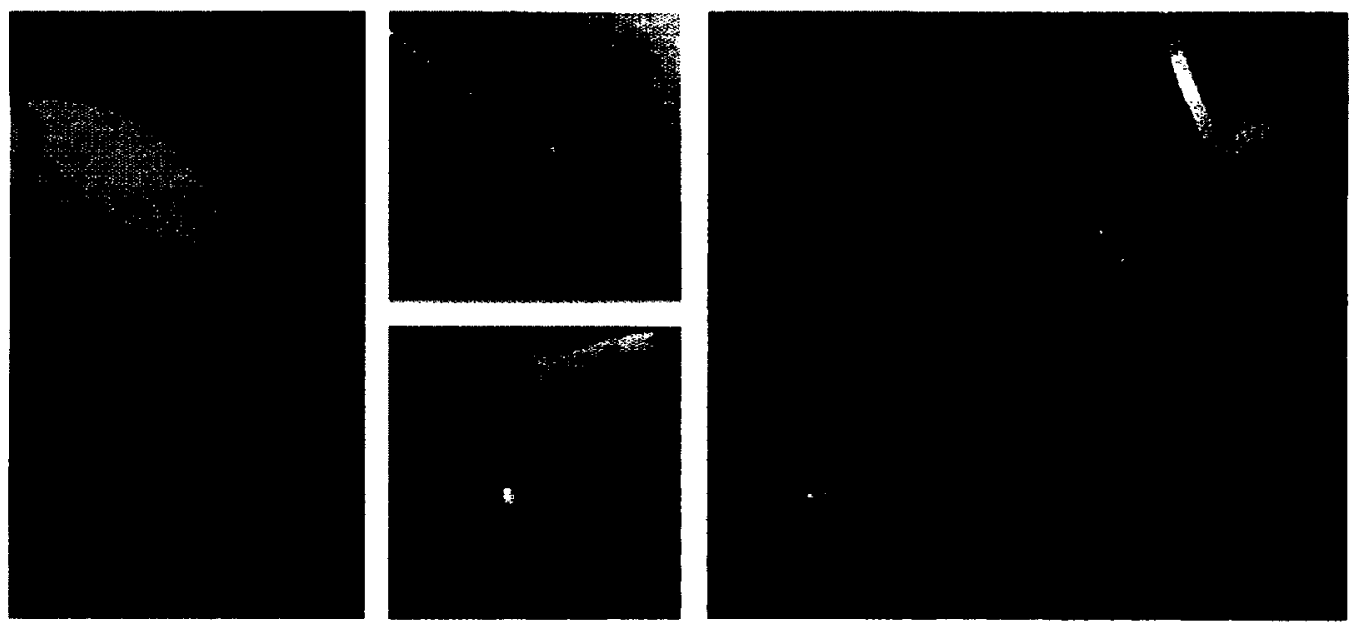

Andrade, Luana. 2008. Santa Luna. Accessed 7 January, 2012. Available from https://picasaweb.google.com/103996034637134669162/SantaLunał520843637824153022 6.

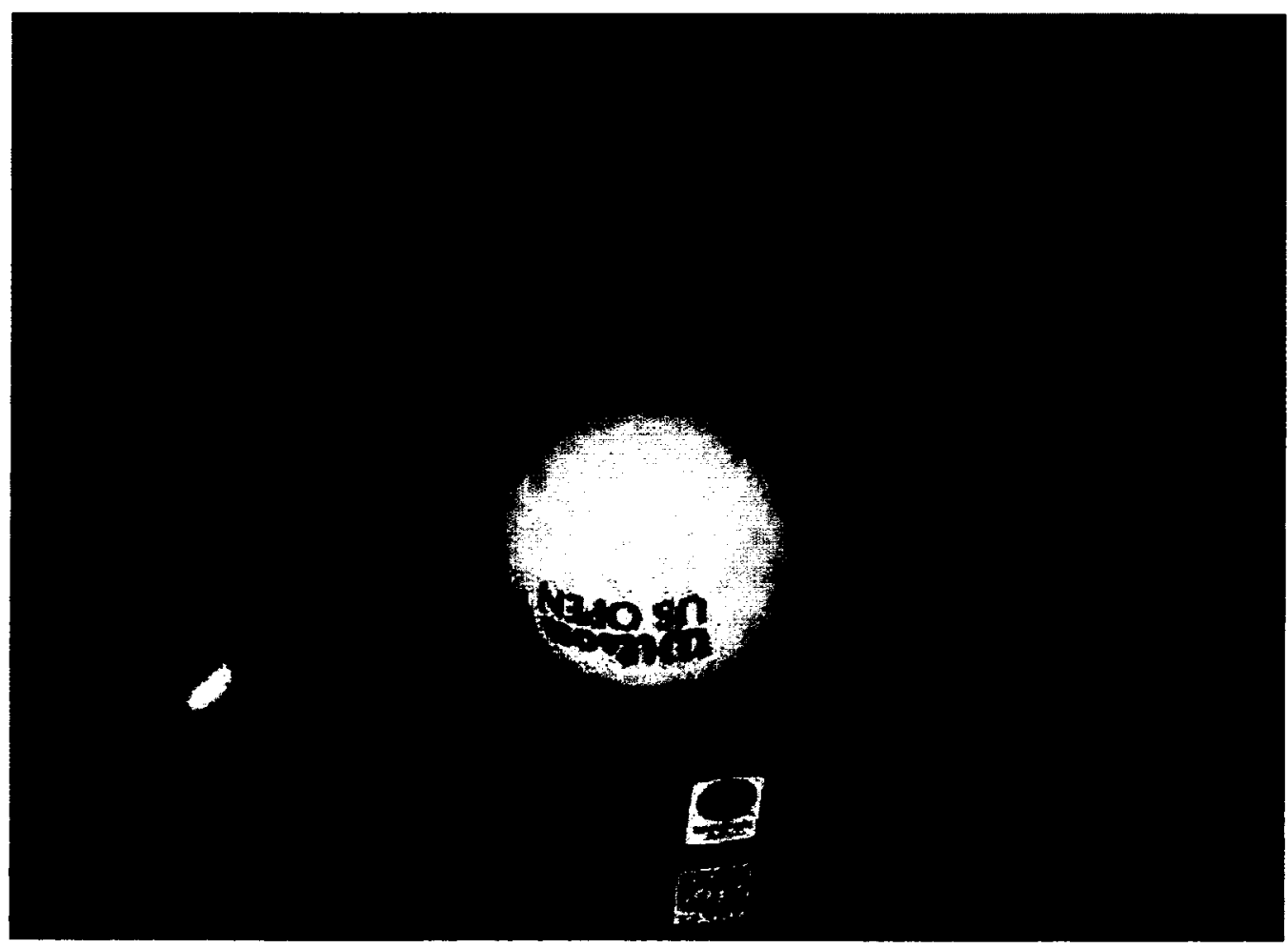

Instructables. 2009. Tennis ball USB mod. Accessed 7 January, 2012. Available from http://www.instructables.com/image/F2R1 WR2FTK8AP62/Tennis-ball-usb-mod.jpg. 
APPENDIX B

TOPIC INFORMATION SHEETS 


\section{MODERN-DAY SLAVERY AND HUMAN-TRAFFICKING TOPIC}
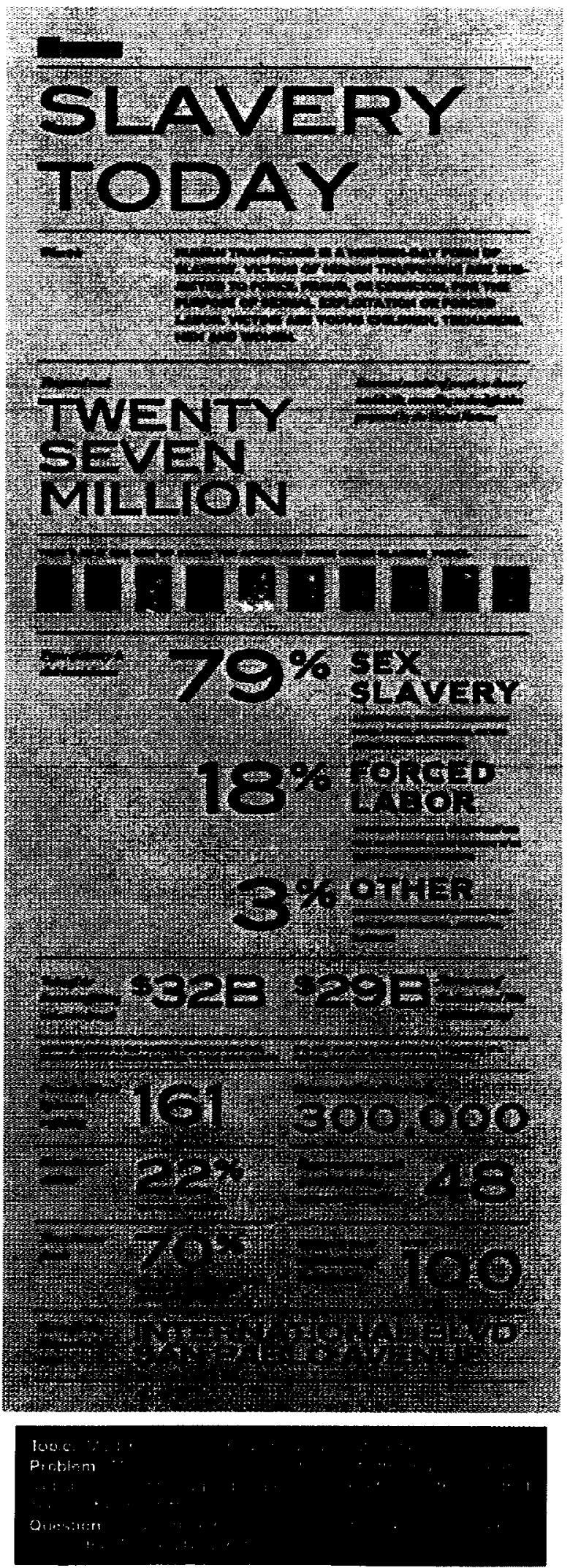


\section{RESTAURANT EXPERIENCE TOPIC}

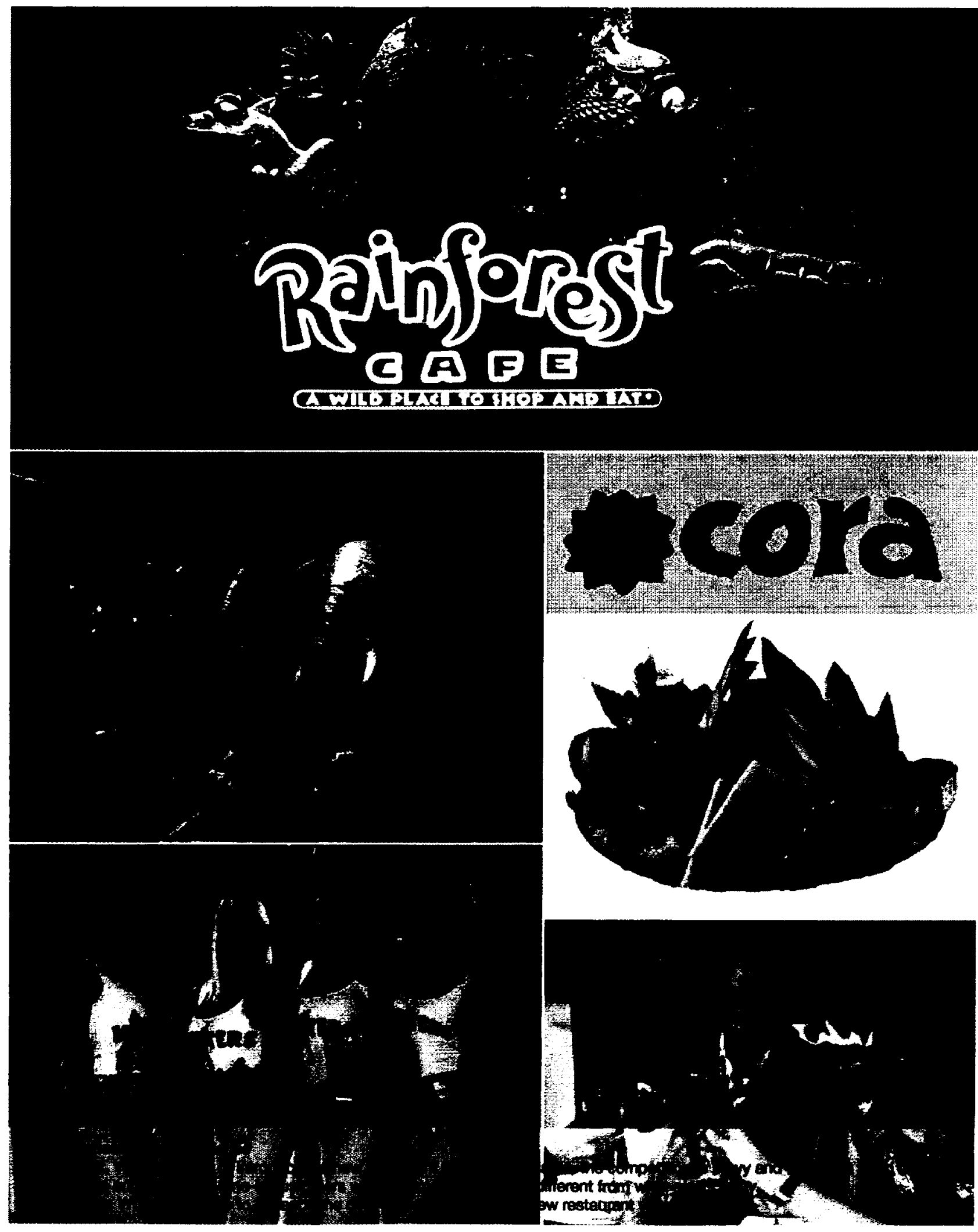




\section{INFORMATION SHEET IMAGE SOURCES}

\section{MODERN-DAY SLAVERY AND HUMAN-TRAFFICKING TOPIC}

Infographic:

Hao, Andrew. 2011. Slavery Today Infographic (Freedom Sunday). Accessed 4 January, 2012. Available from http://www.flickr.com/photos/andrewhao/5523317386/.

\section{RESTAURANT EXPERIENCE TOPIC}

Top Left:

WDWLive. 2009. Rainforest Cafe Desktop Wallpaper. Accessed 4 January, 2012. Available from http://www.wdwlive.com/walt-disney-world-photos.html?sl=30\&s2=556\&s3=4626.

Middle Left:

Outings.ca. n.d. Rainforest Cafe Toronto Photos. Accessed 4 January, 2012. Available from http://img1.outings.ca/static/photos/rainforest-cafe-toronto/RainforestCafeTO12-84b2.jpg.

Middle Right:

Markhameats.com. n.d. Cora Breakfast \& Lunch. Accessed 4 January, 2012. Available from http://www.markhameats.com/photos/listing_photos/45350-291.jpg.

Bottom Left:

Siddharth Deswal's Blog. 2012. What Hooters and Apple Genius Bars can teach us about Customer Service. Accessed 27 April, 2012. Available from http://deswal.org/wpcontent/uploads/2012/04/hooters_30192ec6fe.jpg.

Bottom Right:

123RF. n.d. Stock Photo - Group of friends having dinner in an elegant restaurant toasting with wine. Accessed 27 April, 2012. Available from http://www.123rf.com/photo_7687211_group-of-friends-having-dinner-in-an-elegantrestaurant-toasting-with-wine.html. 
APPENDIX C

SURVEY QUESTIONNAIRE 


\section{PARTICIPANT \#:}

AGE:

GENDER:

FIELD OF STUDY:

YEAR OF STUDY:

$1^{\text {st }}$

$3^{r d}$

$4^{\text {th }}$

Graduate

Working

$\square \square$

$\square$

$\square$

$\square$

1. On a scale from 1 to 7 , rate the overall quality of your ideas for the "Modern-Day Slavery and Human-Trafficking" topic.

Very Low

$\square$

1

$\frac{\square}{2}$

口

Very High

$\square$
5 $\square$

6 $\square$

2. On a scale from 1 to 7 , rate the overall quality of your ideas for the "Restaurant Experience" topic.

Very Low

1

2

3

Very High

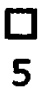

$\square$

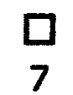

3. In general, which method of idea-generation do you believe allows for more creativity and results in better quality ideas? Briefly explain why.

Individual Idea-Generation

Speedstorming

$\square$ 
4. In general, which do you prefer? Briefly explain why.

Working Alone

$\square$
Working in Groups

$\square$
No Preference

5. On a scale from 1 to 7 , how effective did you find speedstorming for collaborating with people from other disciplines?

Very Low

$\square$

1 $\square$

2 $\square$

3 $\square$

4 $\square$

5
Very High

$\square$

6 $\square$

6. Comments: 
APPENDIX D

INTERVIEW QUESTIONS 


\section{PARTICIPANT \#:}

1. What was your expectation of speedstorming before actually trying it?

2. Explain your experience using speedstorming in the workshop. Did the experience match your expectation?

3. How would you compare your experience using speedstorming with your experience generating ideas alone?

4. Were there any challenges in using speedstorming to collaborate and generate ideas?

5. What is your opinion about the time constraints and the number of rounds?

6. How many team members do you think there should be to get the most out of the speedstorming process?

7. Do you think speedstorming is or can be an effective technique for generating creative ideas? Why?

8. How do you feel about collaborating with other disciplines to generate ideas for design problems?

9. Do you think speedstorming is an effective technique for collaborating with other disciplines and crossing disciplinary boundaries? Why? 
APPENDIX E

CONSENT FORM 
Project Title: Creative Synergy in Interdisciplinary Design Collaboration - Using Speedstorming to Generate Ideas

Date of Ethics Clearance: January 4, 2012

Ethics Clearance for the Collection of Data Expires: May 31, 2012

\section{PROJECT DESCRIPTION}

This research project is concerned with the ability of interdisciplinary design teams (teams made up of members from various disciplines with different backgrounds and expertise who share knowledge amongst each other in pursuit of designing a solution for a particular problem) to collaborate effectively and to generate creative ideas for design solutions. The goal of this research is to test a new idea-generation technique called speedstorming to see if it can help increase the creativity of an interacting team compared to that achieved by a team with members who do not interact with each other.

\section{PROJECT PROCEDURES}

A workshop will be hosted whereby participants will be asked to generate as many good ideas as possible for two different topics in two sessions. The first session will have participants working alone to generate ideas, without interacting with anyone else, and the second session will have them working together, using speedstorming to facilitate the interaction. Participants will be asked to write or draw their ideas on paper and the researcher will collect these sheets at the end of the workshop. There will also be a quick survey questionnaire at the end. The workshop will take approximately one hour and select participants will be asked to take part in an interview which will be approximately 30 minutes of additional time. Refreshments will be served as a thank-you for participation.

During the workshop, the researcher will be making observations and taking notes and photographs. The audio during the select interviews will be recorded using a laptop microphone. All physical notes and the collected sheets will be stored in a key-locked cabinet and will be shredded upon completion of the thesis work in May 2012. All digital files, such as the photographs and the audio recordings, will be stored on a secure USB flashdrive and will also be destroyed upon completion of the thesis work in May 2012. However, the photos that are used in the final thesis document will not be destroyed and they will be moved to a secure external hard-drive for future use in other publication materials (e.g., conference papers, presentations, journal publications, etc.). They will not be used for any other purposes but to support the dissemination of the research findings.

\section{PARTICIPATION}

There are no more risks involved in the participation of this study than that possible in everyday life. The participant has the right to withdraw from the study at any point up until February 6, 2012; if they withdraw, all of their data will be destroyed. All participants will be anonymous unless they agree to the use of their photos in presentations of the research findings. Only the researcher and his supervisors will have access to the collected data. 
By participating in this study, participants can gain first-hand experience using speedstorming and may wish to adopt it for future projects of their own. The ideas that are generated during these workshops may also provide benefit to those involved in the "I Crave Freedom" campaign because they may help in the development of the campaign. If desired, all research findings will be made available upon request.

This project was reviewed and received ethics clearance by the Carleton University Research Ethics Board. Participants can direct questions and concerns about their involvement in the study to the ethics committee chair.

Professor Antonio Gualtierl, Chair

Research Ethics Board

Carleton University Research Office

Carleton University

1125 Colonel By Drive

Ottawa, Ontario K1S $5 B 6$

Tel: 613-520-2517 E-mail: ethics@carieton.ca

General questions and concerns about the research study itself and the workshops can be directed to the researcher.

Tim Haats, Researcher

School of Industrial Design

Tel: $\quad$ E-mail: thaats@connect.carleton.ca

I, effectiveness of using speedstorming to generate creative ideas during interdisciplinary design collaborations.

\section{Photo Release}

I grant permission to the researcher to use photographs of me taken during the workshops. I understand that these photos will be used only for presentation of the research findings and that this will diminish my anonymity.

YES $\square \quad$ NO $\square$

I grant permission to the researcher to store photographs of me taken during the workshops for the purposes of future research and presentations on this topic. YES $\square$ NO $\square$

\section{AUDIO RELEASE}

I grant permission to the researcher to record my voice during the interview, if I do participate in one. I understand that these audio files will be used only for the purposes of this research.

YES $\square \quad$ NO $\square$

By signing below, I acknowledge that the study and consent protocol have been explained, that I understand them, and that I give my consent for participating in this study.

Signature of participant

Signature of researcher
Date

\section{Date}


APPENDIX F

\section{IDEA EVALUATION GUIDELINES}




\section{IDEA QUANTITY}

When it comes to evaluating the quantity of ideas, you must count only the ideas that are non-redundant. In other words, if two or more ideas are very similar and can be considered essentially the same, the ideas would only count as one idea. Please indicate (e.g., number, circle, connect with lines, use arrows, etc.) each non-redundant idea on the idea sheets so that it is clear to the researcher how you counted the total number of nonredundant ideas.

\section{IDEA QUALITY}

The creativity and the quality of ideas can be measured against three factors: (1) novelty and originality, (2) utility and effectiveness, and (3) feasibility. Please refer to the following descriptors of each factor when giving your ratings for the ideas:

\section{Novelty 8 Originality}

Is the idea novel, new or unique? Is the idea original and fresh? Does the idea differ from the common, expected solutions?

\section{Utility \& Effectiveness}

Is the idea something that is useful? Does the idea effectively solve the problem or answer the question?

\section{Feasibility}

Is the idea something that can be achieved or accomplished? Can the idea be reasonably implemented?

Each of these factors above are to be rated on a scale from 1 (very low) to 7 (very high). Please fill out the Scoring Sheet accordingly.

\section{FINAL NOTES}

When evaluating the ideas, please avoid any bias of any kind. Treat each idea the same no matter if it is written or sketched, messy or clear, organized or disorganized, etc. The goal is to give an honest rating for the ideas and not for the delivery or presentation of those ideas. 


\section{APPENDIX G}

\section{SPEEDSTORMING PROTOCOL}

(adapted from Hey et al. 2009) 


\section{LET'S SPEED DATE DESIGN!}

\section{Things to Consider}

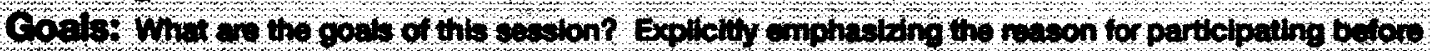

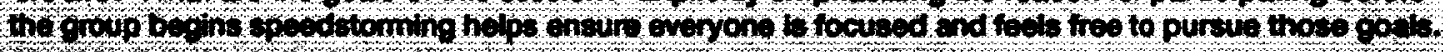

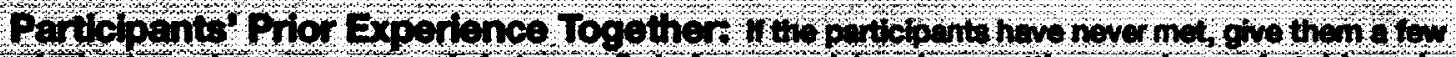

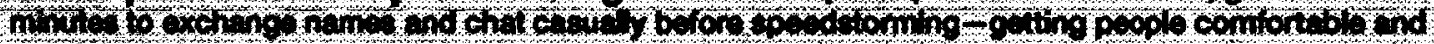

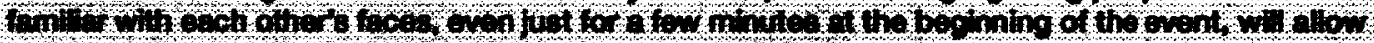

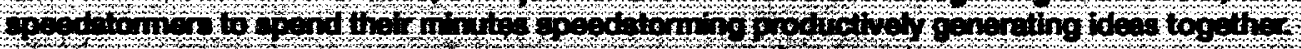

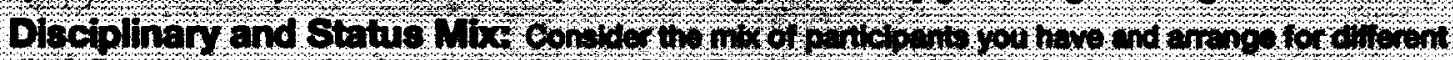

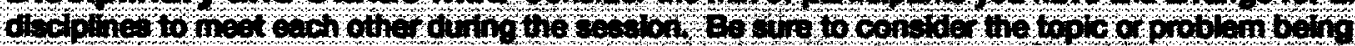

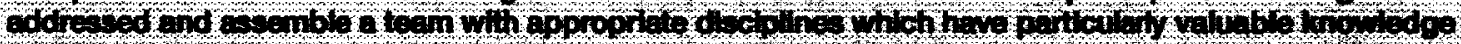

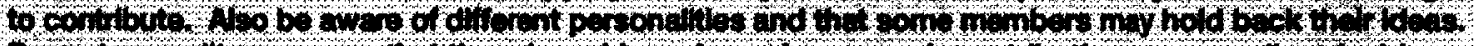

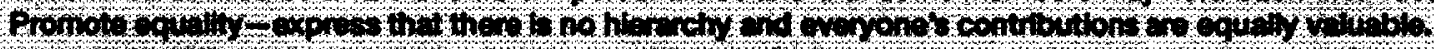

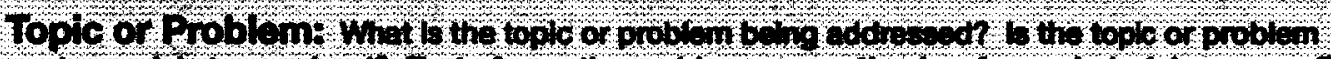

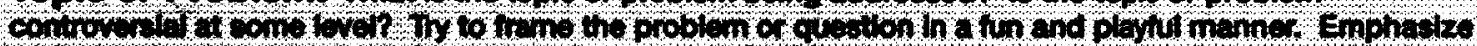
playinoss and avold tocusing on real-word implementation.

\section{Materials}

- A bell to signal time above the talking of participants

- Pencils or pens

- Sheets of paper for documenting ideas

\section{Length}

A maximum of 1.5 hours for the entire session is a good rule-of-thumb to avoid wearing participants out-beyond that, fatigue can hurt participant motivation, satisfaction, and the quality of the interactions and ideas.

When it comes to each pairing, allow between 6-7 minutes before signalling a switch. It may also be useful to allow for an additional minute in later rounds to allow for the sharing of ideas from previous rounds. With smaller groups -6 to 8 participants-run the speedstorming session twice around; with larger groups $-10_{+}$ participants - you may only want to run the speedstorming session once around.

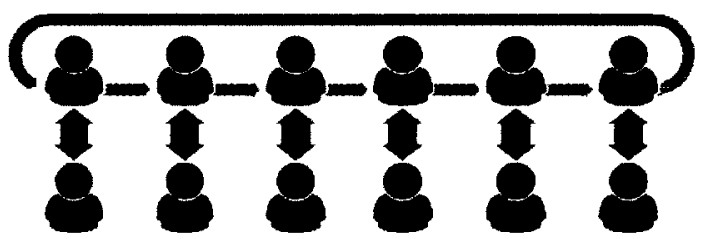

\section{The Process}

1. Set up seats in pairs at least a few feet apart, enough for all participants. Provide enough paper and pencils/pens at each pairing station.

2. Introduce the exercise and explain the procedure. Stress the importance of moving on at the final bell-one slow pair affects the changeover of everyone.

3. Announce the start of each encounter with the bell. Provide a one or two minute warning and a final bell when it is time to change over.

4. Have one set of participants stay still and the other half move around orderly to the stations.

5. Repeat. 